\title{
ESSAYS ON THE INTERACTION BETWEEN MULTILATERAL TARIFF BINDINGS AND THE FORMATION OF PREFERENTIAL TRADE AGREEMENTS
}

\author{
by
}

\author{
Nken Moïse \\ Master of Science, Economics, Sherbrooke University, 2012 \\ Bachelor of Science, Economics, Sherbrooke University, 2008
}

\author{
A dissertation \\ presented to Ryerson University \\ in partial fulfilment of the \\ requirements for the degree of \\ Doctor of Philosophy \\ in the Program of \\ Economics
}

Toronto, Ontario, Canada, 2018

(c) Nken Moïse 2018 


\section{AUTHOR'S DECLARATION FOR ELECTRONIC SUBMISSION OF A DISSERTATION}

I hereby declare that I am the sole author of this dissertation. This is a true copy of the dissertation, including any required final revisions, as accepted by my examiners.

I authorize Ryerson University to lend this dissertation to other institutions or individuals for the purpose of scholarly research.

I further authorize Ryerson University to reproduce this dissertation by photocopying or by other means, in total or in part, at the request of other institutions or individuals for the purpose of scholarly research.

I understand that my dissertation may be made electronically available to the public. 
ESSAYS ON THE INTERACTION BETWEEN MULTILATERAL TARIFF BINDINGS

AND THE FORMATION OF PREFERENTIAL TRADE AGREEMENT

Doctor of Philosophy, 2018

Nken Moïse

Economics

Ryerson University

\begin{abstract}
This dissertation studies the effect of continual reduction in the tariff bindings and its implications on the static and dynamic formation of preferential trade agreements (PTAs). Underlying trade model is a three country "competing exporters" model. First, utilizing a static game of endogenous trade agreement formation between three countries, we examine the effects of continual reduction in tariff bindings on the role of PTA formation in attaining global free trade. We show that, in the free trade agreement (FTA) formation game, when countries are completely symmetric, free trade always obtains as the coalition-proof Nash equilibrium (CPNE) of the FTA game. Under the customs union (CU) game, CU members exercise an exclusion incentive and free trade fails to be a CPNE. When countries are asymmetric with respect to their comparative advantage, the country with a weaker comparative advantage has an incentive to free ride on trade liberalization of the two others and continual reduction in tariff bindings facilitates FTA formation in attaining global free trade.

Next, we employ a three country dynamic model of PTA formation where countries form PTAs over time and investigate the impact of multilateral tariff binding liberalization on the equilibrium extent of FTA and CU formation in isolation. When forming FTAs under relatively high tariff bindings, a myopic free riding incentive of FTA non-members constrains FTA formation. Thus, tariff binding liberalization can facilitate FTA expansion to global free trade. However, when forward looking countries do not value this myopic free riding incentive, tariff binding liberalization can impede FTA expansion to global free trade. In our CU game, CU formation proceeds to global free trade only for relatively high tariff bindings.

Finally, we examine the PTA game where countries endogenously choose between CU and FTA formation. Under such a game, we show that the equilibrium emergence of CUs can prevent global free trade that would otherwise occur through FTAs. In contrast, the equilibrium emergence of FTAs can facilitate global free trade that would otherwise not occur through CUs.
\end{abstract}




\section{Acknowledgements}

I am extremely grateful to all the people whose advice and encouragement have been instrumental to bringing this work to fruition. First and foremost, I would like to express my deepest gratitude to my dissertation supervisor, Professor Halis Murat Yildiz who has been a steady flow of inspiration and insight through his active participation to my research. Murat has given me unwavering support and encouragement throughout my graduate studies, and always motivated and challenged me to shoot for the stars. I have been extremely lucky to encounter him and to have him follow my development. Murat never expressed an ounce of doubt about my ability to complete my dissertation. This sole aspect of him was sufficient enough for me to remove the limits I had. To me, Murat is more than a dissertation supervisor; he is an exceedingly respectable person and researcher, and our relationship is more like a one I would have with a childhood friend of mine who would have been my supervisor. Together, his friendship and selfless contribution to my professional development have been invaluable and will forever be appreciated.

I want to express immense gratitude to my dissertation supervisory committee members for their time, support and feedback on my work. I want to thank Professor Germán Pupato for being available to discuss my dissertation and providing me with valuable suggestions. His excitement for my project and his encouragement on all stages of this project have been a great blessing. I also owe enormous gratitude to Professor Paul Missios for his insightful

feedback and criticism on my work. Professor Missios has guided me since the early stages of my work. I thank him for providing me with many constructive comments and comforting words. I would like to thank deeply my co-author Professor James Lake from Southern Methodist University. His guidance and co-authorship were very valuable for me and helped tremendously finish my dissertation. I also received tutelage and encouragement from Professor Andrey Stoyanov from York University. His input and patient guidance was vital to the development of my skills as an economist.

I am grateful to all my professors at the Economics Department of Ryerson University for imparting me with a broad understanding of Economics. The department offered generous resources and provided an environment of critical thinking that is difficult to find anywhere else. People here are genuinely nice and want to help me out, and I am glad to have been able to interact with many of them. My special mention would go to Professor Maurice Roche for building up my knowledge in the field of International Economics and encouraging me to challenge the boundaries of my imagination.

Moreover, I would like to acknowledge the assistance of Cherie Siy. I am incredibly fortunate for a constant optimism and push from Cherie who has not only given invaluable administrative support, but who has been a sounding board and source of encouragement since the first day I visited the Economics department and throughout the entirety of my graduate career.

Additionally, I would like to thank the fellow students of my cohort: Nazanin Behzadan, Natalia Bezmaternykh, Ugochi Emenogu and Doriane Intungane. They are generous friends and talented economists; and their unique ability to make me laugh has been an invaluable part of my graduate school experience. I have also had the luxury to benefit, 
both intellectually and personally, from working alongside them. My comrades as well showed me the value of investing in one's intellectual community.

This study owes a debt to many people I met and who helped me in a certain way to achieve the completion of this dissertation. For this purpose I would like to thank coach Goulouzelle and president Gilbert Marcy from Entente Family Stade de Reims Athlétisme, coach Stéphane Cuvillier from Team France, coach Richard Crevier from Sherbrooke University, Julie Casista and Jocelyn Touchette from the provincal Ministry of Culture and Communications. I also owe a great debt to Professor Dorothée Boccanfuso and Professor Luc Savard from Sherbrooke University who approved my choice and shoved me to pursue my studies at the doctoral level.

I also want to acknowledge the support that I received during the course of this dissertation from family and friends. Two of my childhood friends were really important for me in the achievement of my doctoral degree. Mehdi BenAhmed and Malik Mellouka are incredible people whose infallible friendship has been immeasurable to me and will remain so forever. I cannot find words to express my gratitude to our other friends, who were sources of laughter, joy, and inspiration. I would like to acknowledge and thank these comradeswho are too numerous to name all of them here: Abdo, Jalil, "Grotos", "Minitos", Alão, Nourrine, Azôte, Hakim, Teqa, Kader, Eddy, Renaud, Sébastien, Frank, Kleber, Daouda, Mamadou, Loïc, Annaig, Hamida, Mounir, Karfa, SidAhmed, Yacouba.

Last but most important, my mother who raised me, supported me, devotedly helped me and always wanted me to be successful. To her I wish to dedicate this dissertation. Without her, I would be a very different person in a different place now, and it must have been impossible to finish a Ph.D.. I am particularly indebted to her for expecting from me only high outcomes, respecting my choices, and instilling in me a strong work ethic and righteousness in my life. Because of her, my work has meaning.

I have received a great deal of assistance in writing this dissertation, though I bear full responsibility for any errors. 


\section{Dedication}

This dissertation is dedicated to my Mother. 


\section{Table of Contents}

List of Tables $\quad$ viii

List of Figures $\quad$ ix

List of Appendices $\quad x$

1 Introduction 1

2 Underlying Trade Model $\quad 10$

2.1 Trade Model . . . . . . . . . . . . . . . . . . . . . . . . . . 10

2.2 Optimal Tariffs (sufficiently high bound tariffs) $\ldots \ldots \ldots \ldots$

2.2 .1 MFN tariffs . . . . . . . . . . . . . . . . . 13

2.2.2 Free Trade Agreement member's Nash tariff . . . . . . . . . . . . 13

2.2.3 Custom Unions member's Nash tariff . . . . . . . . . . . . . . 14

3 Static Implications of Multilateral Tariff Bindings on the Extent of $\begin{array}{lr}\text { Preferential Trade Agreement Formation } & 16\end{array}$

3.1 Introduction . . . . . . . . . . . . . . . . . . . . . . . . 16

3.2 Endogenous Trade Agreements . . . . . . . . . . . . . . . . . . . . 19

3.3 Symmetric Comparative Advantage . . . . . . . . . . . . . . . . 20

3.3.1 Different Tariff Binding Scenarios - Symmetry . . . . . . . . . . . 21

3.3.2 Nash Equilibrium Trade Agreements - Symmetry . . . . . . . . . 22

3.3.3 Coalition Proof Nash Equilibria - Symmetry . . . . . . . . . . . 25

3.4 Asymmetric Comparative Advantage . . . . . . . . . . . . . . . 27

3.4.1 Two larger one smaller exporters . . . . . . . . . . . . 27

3.4.1.1 Different Tariff Binding Scenarios - Asymmetry I . . . . 28

3.4.1.2 Preferences for FTAs under Asymmetry I . . . . . . . . 30

3.4 .2 Two smaller one larger exporters . . . . . . . . . . . . . . . 34

3.4.2.1 Different Tariff Binding Scenarios - Asymmetry II . . . . . 34

3.4.2.2 Preferences for FTAs under Asymmetry II . . . . . . . . . 36

3.5 Customs Union . . . . . . . . . . . . . . . . . . . . . 37

3.5.1 Different Tariff Binding Scenarios - Customs Union . . . . . . . . . 39

3.5.2 Coalition Proof Nash Equilibria - Customs Union . . . . . . . . . . 40

3.6 Conclusion . . . . . . . . . . . . . . . . . . . . . . . 42 
4 Tariff Bindings and Dynamic Formation of Preferential Trade Agreements

4.1 Model . . . . . . . . . . . . . . . . . . . . . . . . . . 46 46

4.1.1 Implications of tariff bindings . . . . . . . . . . . . . . 46

4.1 .2 Strategies and equilibrium concept . . . . . . . . . . . 47

4.2 Equilibrium path of networks: FTA game . . . . . . . . . . . . . . . 49

4.2 .1 FTA formation incentives . . . . . . . . . . . . 50

4.2.1.1 Myopic incentives . . . . . . . . . . . . . . . . 50

4.2.1.2 Farsighted incentives . . . . . . . . . . . . . 51

4.2 .2 Subgames at hub-spoke networks . . . . . . . . . . . . 52

4.2.3 Subgames at FTA insider-outsider networks . . . . . . . . . . . 52

4.2.3.1 Dynamic free riding incentive . . . . . . . . . . 52

4.2.3.2 Dynamic exclusion incentive . . . . . . . . . . . . 54

4.2.4 Subgame at empty network . . . . . . . . . . . . . 56

4.3 Equilibrium path of networks: CU game . . . . . . . . . . . . . 59

4.3 .1 CU formation incentives . . . . . . . . . . . . . . . . . . . 59

4.4 Conclusion . . . . . . . . . . . . . . . . . . . . . 62

5 Dynamic equilibrium with the endogenous choice between Free Trade Agreements and Customs Union $\quad 63$

5.1 FTA Flexibility benefit . . . . . . . . . . . . . . . . . . . 64

5.2 Myopic and farsighted CU coordination benefits . . . . . . . . . . . 65

5.3 Trade-off between FTA flexibility benefit and CU coordination benefits . . 65

5.4 Conclusion . . . . . . . . . . . . . . . . . . . . . . 70

6 Summary and Conclusions $\quad 71$

$\begin{array}{ll}\text { Appendices } & 75\end{array}$

$\begin{array}{lr}\text { Bibliography } & 88\end{array}$ 


\section{List of Tables}

4.1 Feasible network transitions . . . . . . . . . . . . . . . . . 48

4.2 Proposer country's action space for each subgame in FTA game . . . . . . 50

4.3 Proposer country's action space for each subgame in CU game . . . . . . . 59 


\section{List of Figures}

3.1 FTA tariff schedule - Symmetry . . . . . . . . . . . . . . . . . . . . . 22

3.2 FTA tariff schedule - Asymmetry I . . . . . . . . . . . . . . . . . . . . . . 29

3.3 Free Trade is CPNE - Asymmetry I . . . . . . . . . . . . . . . . . . . 32

3.4 Bilateral FTAs are CPNE - Asymmetry I . . . . . . . . . . . . . . . 34

3.5 FTA tariff schedule - Asymmetry II . . . . . . . . . . . . . . . . . . 35

3.6 Free Trade is CPNE - Asymmetry II . . . . . . . . . . . . . . . . . 37

3.7 CU tariff schedule - Symmetry . . . . . . . . . . . . . . . . . . . . 40

3.8 Stable equilibrium under CU - (CU game) Symmetry . . . . . . . . . . 42

4.1 Tariff binding regions . . . . . . . . . . . . . . . . . 47

4.2 Dynamic free riding incentive . . . . . . . . . . . . . . 53

4.3 Dynamic exclusion incentive . . . . . . . . . . . . . . . 55

4.4 Equilibrium path of networks: FTA game . . . . . . . . . . . . 58

4.5 Equilibrium path of networks: CU game . . . . . . . . . . . . 61

5.1 Flexibility benefit of FTAs versus coordination benefits of CUs . . . . . . 67

5.2 Equilibrium path of networks: PTA game . . . . . . . . . . . . . 69 


\section{List of Appendices}

$\begin{array}{ll}\text { A Appendix of Chapter 2 } & 76\end{array}$

$\begin{array}{ll}\text { B Appendix of Chapter } 3 & 78\end{array}$

C Appendix of Chapter $4 \quad 83$

$\begin{array}{lr}\text { D Appendix of Chapter } 5 & 87\end{array}$ 


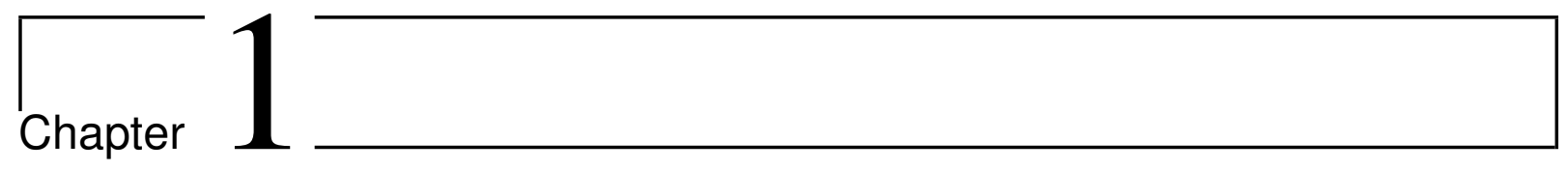

\section{Introduction}

Trade liberalization at the World Trade Organization ${ }^{1}$ (WTO), has proceeded, since its creation in 1948, essentially along two major fronts: periodic rounds of multilateral negotiations that are open to all WTO member countries and the formation of preferential trade agreements (PTAs) among a subset of members. Our objective in this dissertation is to investigate the effects of continual reduction in tariff bindings (resulting from multilateral negotiations) on the endogenous formation of PTAs both statically and dynamically.

Membership in the WTO requires that countries take on commitments with respect to their tariffs and other trade barriers. The first such commitment is the application of symmetric tariff rates on imports from all other WTO members via the MFN principle of nondiscrimination. As the very first Article of the GATT, MFN principle lies at the heart of the WTO system, requiring members to accord the most favourable tariff given to the product of any one member to all other members. In other words, if a member country extends tariff concession to a WTO member country, it has to extend the same concession to all other member countries. Second, a WTO member agrees to take on legally binding commitment on chosen set of products that is a cap above which it promises not to raise its applied tariff. For each of those products with some legally binding commitment, the member chooses an exact value for this upper limit that is referred to as the "tariff binding" or "tariff cap". A WTO member country's MFN applied rate must therefore be less than or equal to the bound tariff rate (tariff binding) in order to be legal under the WTO. ${ }^{2}$ Two things need to be noted about multilateral tariff negotiations. First, they do not aim at the complete elimination of all tariffs (free trade), but to the "substantial reduction" of the general level of tariffs (freer trade). Second, it refers to the reduction of the "binding of duties at then existing levels" resulting from negotiations.

\footnotetext{
${ }^{1}$ The WTO is in some ways a successor to General Agreement on Tariffs and Trade (GATT), and the original GATT text (GATT 1947) is still in effect under the WTO framework.

${ }^{2}$ If a country raises its tariff beyond its bound rate, the countries adversely affected are able to seek remedy via the dispute settlement process through which they may obtain the right to retaliate against an equivalent value of the offending country's exports or the right to receive compensation, usually in the form of reduced tariffs on other products they export to the offending country.
} 
One of the most important achievements of the GATT/WTO to date has been a substantial reduction in the level of bindings in international trade. At the creation of the GATT, the average tariff bindings among trading countries was between 20 and 30 per cent. Since then, eight rounds of multilateral trade negotiations have significantly reduced the bound tariff rates of all WTO members. Following the conclusion of the last successful multilateral round, Uruguay Round (UR) in 1994, the average bindings across all products and countries fell to less than five percent. By contrast, the Doha Round, which is the latest round of trade negotiations, started in 2001 but have stalled and failed to reach a consensus that is acceptable for all the negotiating parties. Note that tariff reductions also take place within the negotiations for accession to the GATT/WTO of new members, as well as in the context of plurilateral negotiations aimed at eliminating tariffs on specific sectors. The most successful plurilateral negotiations, at least as far as the number of participants is concerned, were those carried out pursuant to the Information Technology Agreement (ITA). The ITA's participants ${ }^{3}$ are committed to completely eliminating tariffs on IT products covered by the Agreement. The commitments undertaken under the ITA accrue to all WTO members on an MFN basis. Ultimately, MFN tariff concessions have been and continue to be a cornerstone of multilateral trade liberalization.

Nevertheless, in direct contrast to the central pillar of GATT being the non-discriminatory MFN principle, GATT also allows discriminatory liberalization through PTAs. In particular, Article XXIV of the GATT provides an important exception to the notion of nondiscrimination as specified by the MFN clause by allowing a subset of member countries to form PTAs. A group of WTO member countries can extend tariff concessions to each other via PTAs but not to other WTO member countries. Article XXIV requires PTA members to eliminate their internal tariffs on each other and not to raise their external tariffs on the non-members. Countries can either form Free Trade Agreements (FTAs) and maintain sovereign discretion over their "external tariffs" on non-members; or Customs Unions (CUs) and set a common external tariff on non-members. Although relatively rare in the pre-Uruguay Round world, the implementation of the UR's results coincided with a period of growing formation of PTAs and an expansion of the multilateral system's membership from an initial 23 to 164 economies. ${ }^{4}$ According to the WTO, the number of PTAs in force was 445 as of June, 2017 and all WTO members now have a PTA in force. 90\% of PTAs are in the form of FTAs with CUs comprising the rest (Freund and Ornelas, 2010). Despite the sheer number of FTAs vastly outnumber CUs with the WTO, the existing CUs do involve major trading areas of the world: the EU and much of Latin America (where MERCOSUR resides).

Economists and policy-makers have long suspected that the contrasting fortunes of these two types of trade liberalization (discriminatory and non-discriminatory) may be inter-related. The tension between these discriminatory and non-discriminatory modes of liberalization spawned and, through failure of the current Doha Round, has sustained

\footnotetext{
${ }^{3}$ The ITA was concluded by 29 participants in December 1996. Since then, the number of participants has grown to 82 (counting the EU members as one), representing about 97 per cent of world trade in IT products.

${ }^{4}$ For a discussion of the negotiating history leading up to the GATT, see Irwin, Mavroidis, and Sykes (2008).
} 
a large literature. ${ }^{5}$ There exists an extensive literature dealing with the widespread concern that the formation of PTAs may undermine the prospect of global free trade and serve as an alternative, rather than a complement, to multilateral trade liberalization. ${ }^{6}$ In particular, this literature focuses on understanding how the discriminatory nature of PTAs impacts the degree of global trade liberalization that would otherwise arise in terms of non-discriminatory MFN tariffs set by countries either individually or through global negotiation rounds. However, the reverse analysis on how continual reduction in tariff bindings affects the formation of PTAs and alters the role of Article XXIV of the GATT in attaining global free trade is relatively scarce. In a detailed survey, Freund and Ornelas (2010) documents the scarcity of analyses on how multilateral trade liberalization affects preferential trade agreements and regionalism. This dissertation aims at filling this gap in the literature using an endogenous PTA formation models statically and dynamically in examining the extent of PTA formation as the tariff bindings fall.

Very few examples of studies that examine the implications of multilateral trade liberalization on PTA formation include Ethier (1998), Freund (2000), and Lake and Roy (2017). Ethier (1998) argues that regionalism is a benign consequence of the success of multilateralism since it allows small countries to benefit from formation of FTAs with large countries to gain a marginal advantage over other small countries in attracting foreign direct investment. Freund (2000) examine whether bilateral agreements are enforceable in a standard repeated game framework to explore the criteria for self-enforcing bilateral tariff reductions. Unlike us, Freund (2000) takes bilateral PTAs and multilateral free trade as exogenously given, ignoring the hub and spoke regime in a symmetric oligopoly model of trade. The results we find in Chapter 3 results extend support to Freund (2000) in that, as bound tariffs fall, the forces pulling countries away from free trade into bilateral agreements strengthen implying that the exclusion incentive rises with the multilateral tariff reduction. Unlike Freund (2000), we show that the exclusion incentive goes unexercised and free riding incentive becomes pivotal in a model where FTA formation is endogenous. Because tariff binding liberalization weakens the free riding incentive of FTA non-members, like Freund (2000), we find that multilateral tariff liberalization facilitates FTA expansion in Chapter 4 . In contrast to these positive views regarding multilateral tariff liberalization, Lake and Roy (2017) use an innovative approach where multilateral trade negotiation precedes sequential FTAs and show that global free trade never emerges when global tariff negotiations precede FTA formation. Specifically, Lake and Roy (2017) show how endogenous determination of multilateral tariff bindings generates an FTA exclusion that otherwise would not exist. Like our paper, relatively tight multilateral tariff bindings deliver tariff concessions from FTA non-members to FTA members without FTA members needing to form FTAs with non-members. Ultimately, multilateralism acts as a stumbling bloc to

\footnotetext{
${ }^{5}$ Bagwell et al. (2016) made an excellent survey of economic literature addressing various trade agreements (including WTO and PTAs) and their relative role in trade liberalization from the "terms-of-trade" theory perspective.

${ }^{6}$ Prominent examples in this strand of literature include papers by Krugman (1991), Bhagwati (1991), Yi (1996), Bagwell and Staiger (1997a, 1997b, 1998, 2005a, 2005b), Krishna (1998), Riezamn (1999), Bond et al. (2004), Goyal and Joshi (2006), Furusawa and Konishi (2007), Aghion et al. (2007), Missios et al. (2016), Ornelas (2005, 2007), Saggi (2006), Saggi and Yildiz (2010, 2011), Saggi et al. (2013, 2018), Stoyanov and Yildiz (2015) and Lake (2017).
} 
global free trade.

While the literature has long understood that PTAs can impact the extent of MFN tariff liberalization and hence the ultimate degree of global liberalization, the literature has largely ignored that the extent of MFN tariff liberalization via continual reduction in tariff bindings can impact the extent of PTA formation. This is despite the fact that real world MFN tariff liberalization often takes the form of tariff binding reductions which directly impact the incentives for PTA formation through changing the MFN tariffs that countries face in the absence and presence of a PTA. This observation raises the following key question that we address in this dissertation: how does a continual reduction in tariff bindings across the world impact the role of FTAs and CUs in attaining global free trade? In this dissertation, this question is examined in both static and dynamic PTA formation models.

Underlying trade model in this dissertation, developed in Chapter 2, is a three country competing exporters model which is an adapted version of the two country comparative advantage based framework of Horn et al. (2010). Each country imports one good from the other two countries who are competing exporters in the importing country. We find that in our trade model the formation of a bilateral PTA (both FTA and CU) induces each member to lower its tariff on the non-member country relative to the status quo, i.e. the model exhibits tariff complementarity. To focus on the impact of continual reductions in tariff bindings, our model features exogenous symmetric tariff binding. As a result, exogenously given tariff bindings lead to three distinct scenarios: (i) no tariff binding scenario where the bound tariff rate exceeds the optimal Nash tariffs and countries are free to impose their optimal tariffs under all trade regimes; (ii) partial tariff binding scenario where the bound tariff rate exceeds the optimal tariff of a member country under a PTA but falls below the optimal Nash tariffs and thus the member countries under a PTA are free to impose their optimal external tariffs while the non-member country under a PTA is required to apply the bound tariff rate and (iii) full tariff binding scenario where the bound tariff rate falls below the optimal tariffs of member countries under a PTA and thus countries lose their freedom to impose optimal external tariffs under all possible trade regimes and are required to apply their tariff bindings. Note that while the tariff binding overhang can arise in the first two scenarios, it disappears in the final scenario since tariff bindings bind all countries. Consistent with the legally binding commitments on bound tariff rates, our point of departure is a world in which all countries are the WTO members that face exogenously given tariff bindings and thus their applied rates under any trade regime must therefore be less than or equal to the tariff bindings.

In Chapter 3, we employ a static endogenous PTA formation model in which our analysis on how the continual reduction in tariff bindings affects countries' preferences for PTA formation delivers several interesting insights. We first examine the coalition proof Nash equilibrium agreements (CPNE) of the FTA and CU formation games between symmetric countries under exogenously given tariff bindings. We show that, when countries are completely symmetric, no country has an incentive to unilaterally deviate from global free trade and free ride on trade liberalization by the other two countries regardless of the (i) level of tariff bindings and (ii) the type of PTAs (FTA or CU). However, we show that two countries have incentives to jointly exclude the third one via a bilateral FTA or bilateral 
CU from free trade network when tariff bindings are sufficiently tight. The intuition behind these results can be explained as follows. First consider that tariff bindings are sufficiently lax and countries are able to impose their optimal external tariffs. Under such a case, although the PTA outsider benefits from the lower external tariffs faced when exporting to the PTA members (due to tariff complementarity), it faces discrimination in the export markets of member countries. Through eliminating the discrimination faced in both PTA members' markets, an FTA outsider always benefits from moving from a bilateral FTA to global free trade. When the tariff binding falls below the optimal Nash tariffs, the non-member country under a bilateral PTA loses its ability to set its optimal tariff and is required to impose its tariff binding. On the other hand, the PTA member countries fully enjoy free access in each others market and are either (i) fully able to impose their optimal external tariffs (as under the partial tariff binding scenario) or (ii) impose the same external tariff as the non-member country (as under the full tariff binding scenario). This makes the discrimination faced by the PTA outsider more prominent and weakens any free riding incentive.

When the tariff binding is sufficiently lax, the PTA non-member imposes relatively high tariffs on the PTA members. To eliminate these barriers, the PTA members have a strong incentive for forming an additional PTA with the non-member. However, the strength of this incentive weakens as the PTA outsider becomes more constrained by a tighter tariff binding. Indeed, once the tariff binding is sufficiently tight, PTA members have already extracted substantial tariff concessions from the FTA non-members and this generates an exclusion incentive for PTA members. It is important to note here that the flexibility of FTA formation implies that hub and spoke type of regime is an option under FTA formation only and thus FTAs are more susceptible to opportunistic unilateral deviations by member countries than CUs. As stated above, when countries are symmetric, countries have no incentives to free ride while exclusion incentives arise under both FTA and CU games when tariff bindings are sufficiently tight. We find that free trade always obtains as the CPNE of the FTA game since exclusion incentives go unexercised in the equilibrium due to the flexibility in FTA formation. However, unlike the FTA formation game, countries are able to exercise the exclusion incentive under the CU game and free trade fails to be a CPNE when the tariff bindings are sufficiently tight and thus the pursuit of CUs undermines global free trade.

Given that free trade always arises as a CPNE under the FTA game when countries are completely symmetric, we next examine under what circumstances, if any, free trade fails to be a CPNE. We show that such a possibility arises only when countries are asymmetric with respect to their comparative advantage. It turns out that, due to smaller export and larger import volumes, the country with a weaker comparative advantage in the exporting goods has an incentive to free ride on trade liberalization between the other countries. Lower bound tariff rates disciplines this incentive via limiting the ability of setting optimal tariffs. As before, due to the lure of a hub and spoke arrangement and the relatively flexible nature of FTA formation, exclusion incentives go unexercised and free riding incentive becomes pivotal for multilateral free trade to be a CPNE. As a result, multilateral free trade is more likely to be a CPNE as the multilateral negotiated bound tariff rates decline. This result provides support for the idea that continual decline in tariff bindings acts as a complement 
to the FTA formation in achieving global free trade: FTA formation is more likely to act as a building bloc when it is accompanied by lower tariff bindings.

Here, it is important to note from the existing literature that exclusion incentives for PTA members and free riding incentives for PTA non-members have long been important for theoretical analyses of PTA formation and their role in the attainment of global free trade. $^{7}$ However, a given analysis typically only relies on an exclusion incentive of PTA members or only relies on a free riding incentive of PTA non-members. Relying on free riding incentives in endogenous FTA formation setting, Saggi and Yildiz (2010) show the incentive to free ride on FTA formation is weaker than the incentive to free ride on MFN liberalization of other countries and, hence, FTAs can be a "building bloc" to global free trade. In contrast, Saggi et al. (2013) rely on an exclusion incentive and show the incentive of $\mathrm{CU}$ members to exclude the non-member can be stronger than the MFN free riding incentive and, hence, CUs can be a "stumbling bloc" to global free trade. We extend this literature by examining the degree of exclusion incentives and free riding incentives as tariff bindings fall and determining whether these incentives are exercised in the equilibrium.

Chapters 4 and 5 further study how continual reductions in the tariff binding impact the role of PTAs in the attainment of global free trade dynamically. To this end, We build a three country dynamic model of PTA formation where countries form PTAs over time. While FTA and CU games are examined in isolation in chapter 4, chapter 5 extends our analysis into a "PTA game" where countries can endogenously choose between FTA and $\mathrm{CU}$ formation. In both of these chapters, we examine the Markov perfect equilibrium (MPE).

In the FTA game, with relatively high tariff binding, the key intuition revolves around free riding by the FTA outsider who holds a myopic free riding incentive. Intuitively, despite facing discrimination, the FTA outsider benefits from the well known tariff complementarity phenomena whereby FTA members lower their MFN tariff upon FTA formation. Indeed, the FTA outsider actually becomes worse off upon a subsequent FTA with an FTA insider. In this sense, the FTA outsider holds a myopic free riding incentive. However, by eliminating the discrimination faced in both FTA insider markets, the FTA outsider benefits from global free trade. The tension between this farsighted benefit of global free trade and the myopic free riding incentive generates a dynamic trade-off. A sufficiently patient FTA outsider willingly becomes the spoke because of the farsighted benefit of global free trade. But, a sufficiently myopic FTA outsider holds a dynamic free riding incentive in that it refuses any subsequent FTA formation because the myopic free riding incentive dominates the farsighted benefit of global free trade.

However, continual reductions in the global tariff binding eventually eliminate the myopic free riding incentive by constraining the FTA outsider's ability to levy its optimal tariffs on the FTA insiders. With a relatively low tariff binding, the key intuition revolves around the FTA insiders holding an exclusion incentive. Intuitively, the FTA insiders have

\footnotetext{
${ }^{7}$ Indeed, the seminal contributions of Levy (1997) and Krishna (1998) relied on exclusion incentives. Ornelas (2005) represents an early analysis relying on a free riding incentive. In a recent survey chapter, Lake and Krishna (2018) emphasizes the role played by exclusion incentives and free riding incentives in the theoretical PTA literature.
} 
already extracted tariff concessions from the FTA outsider through the relatively low tariff binding and benefit from excluding the FTA outsider from global free trade to protect their preferential access as FTA insiders. Nevertheless, an FTA insider benefits myopically from forming its own FTA with the FTA outsider and thus becoming the "hub" with preferential access to both of the other "spoke" countries. The tension between this myopic benefit of becoming the hub and the farsighted nature of the exclusion incentive generates a dynamic trade off. A sufficiently myopic FTA insider becomes the hub because of the benefits associated with preferential access to both spoke markets. But, a sufficiently patient FTA insider holds a dynamic exclusion incentive in that it refuses any subsequent FTA formation because of the farsighted benefit of not precipitating expansion to global free trade.

Two main insights emerge when analysing how continual tariff binding reductions change how FTA formation helps or hinders the attainment of global free trade. First, when high tariff bindings prevent FTA expansion to global free trade, continual reductions in the tariff binding facilitate FTA formation that attains global free trade. Specifically, suppose the dynamic free riding incentive prevents global free trade under a sufficiently high tariff binding noting that this requires sufficient myopia. Then, continual reductions in the tariff binding eventually eliminate the dynamic free riding incentive and, despite generating an exclusion incentive, FTA insiders do not hold a dynamic exclusion incentive because the dynamic exclusion incentive requires sufficient patience. In turn, FTA formation yields global free trade.

The second insight is that when high tariffs bindings facilitate FTA expansion to global free trade, continual reductions in tariff bindings change the nature of FTA formation so that FTA expansion no longer facilitates but can rather impede FTA expansion to global free trade. This insight may be especially relevant given the literature documents FTA formation typically takes many years. As such, tariff binding reductions may occur before FTA expansion has time to reach global free trade. In this case, the FTA outsider does not hold a dynamic free riding incentive under the initially high tariff binding because of sufficient patience. However, continual tariff binding reductions create an exclusion incentive and FTA insiders may hold a dynamic exclusion incentive since this also requires sufficient patience. In this case, FTA formation would eventually yield global free trade under the initial and relatively high tariff binding, but continual reductions in the tariff binding generate a dynamic exclusion incentive for FTA insiders who refuse any subsequent FTA formation with the FTA outsider.

Chapter 5 extends our analysis into a "PTA game" where countries can endogenously choose between FTA and CU formation and we introduce the terminology of a "PTA stumbling bloc" and a "PTA building bloc". The key question in this chapter is whether a given type of PTA (i.e. FTAs or CUs) improves or hurts the prospects of global free trade relative to the outcome if this type of PTA was banned? The classic building blocstumbling bloc issue in the PTA literature is typically viewed as a comparison between PTA formation and multilateral liberalization in terms of whether PTA formation improves or hurts the prospects of global free trade relative to the outcome under multilateral liberalization. However, in practice, multilateral liberalization happens in the short bursts in the background whether it be through various global rounds of negotiations or plurilateral 
agreements such as the ITA. In contrast, countries are continuously forming PTAs on the surface of the global trade policy landscape and, in doing so, choosing whether to form FTAs or CUs. Primarily based on Saggi and Yildiz (2010) and Saggi et al. (2013), Maggi (2014) hypothesizes that CU formation constrains the prospects of global free trade but argues such a conclusion requires a model where countries endogenously choose between $\mathrm{CU}$ and FTA formation. Chapter 5 indeed address Maggi's hypothesis by developing a model where countries endogenously choose between FTA and CU formation and asking the following question: does a given type of PTA improve or hurt the prospects of global free trade relative to the outcome if this type of PTA was banned?

In our dynamic PTA formation model, PTA members can hold exclusion incentives and PTA non-members can hold free riding incentives. Rather than tie the existence of these incentives to country asymmetries, which are somewhat nebulous in terms of real world application of theoretical PTA models, we tie them to tariff binding liberalization which has concrete real world interpretations as we discussed above. Whether FTAs or CUs emerge in equilibrium revolves around a dynamic trade off. On one hand, CU formation confers coordination benefits on CU members. From a myopic perspective, CU members benefit from coordination of their external tariffs internalizing the negative intra-PTA externality of tariff complementarity. From a farsighted perspective, CU members benefit from the implication that coordination of their external tariffs confers veto power on each $\mathrm{CU}$ member regarding subsequent $\mathrm{CU}$ expansion to global free trade. This veto power is valuable in the presence of a CU exclusion incentive because, in contrast, each FTA member can form their own subsequent FTA with the FTA non-member and thus precipitate FTA expansion to global free trade. On the other hand, the ability of each FTA member to form their own subsequent FTA with the non-member confers an FTA flexibility benefit on FTA members. This FTA flexibility benefit is valuable because it allows a member of an initial FTA to then become the "hub" and have sole preferential access with the other two "spoke" countries.

We say that CUs (FTAs) are a "PTA stumbling bloc" if CU (FTA) formation emerges in equilibrium and does not lead to global free trade yet FTA (CU) formation would lead to global free trade in the absence of CUs (FTAs). Similarly, we say that CUs (FTAs) are a "PTA building bloc" if CU (FTA) formation emerges in equilibrium and leads to global free trade yet FTA (CU) formation would not lead to global free trade in the absence of CUs (FTAs). Under such model, we determine whether FTAs or CUs emerge in equilibrium.

Ultimately, combining our results in chapters 4 and 5, we confirm Maggi's hypothesis by arguing that FTAs and CUs play very different roles in helping or hurting the prospects for global free trade. On one hand, FTAs can be PTA building blocs but never PTA stumbling blocs. That is, when FTA formation emerges in equilibrium then (i) it can lead to global free trade when $\mathrm{CU}$ formation would not but (ii) if it does not lead to global free trade then neither does CU formation. On the other hand, CUs can be PTA stumbling blocs but never PTA building blocs. That is, when $\mathrm{CU}$ formation emerges in equilibrium then (i) there are conditions where CU expansion will not, but FTA expansion will, lead to global free trade and (ii) when $\mathrm{CU}$ formation leads to global free trade then so does FTA formation. In particular, this PTA building bloc role of FTAs and PTA stumbling bloc role of CUs emerges for an intermediate degree of tariff bindings. This suggests that 
the asymmetric impact of FTAs versus CUs may have become more prevalent with the phase in of Uruguay Round multilateral tariff binding liberalization and plurilateral tariff binding agreements like the Information Technology Agreement.

The dissertation proceeds as follows. Chapter 2 describes our underlying trade model. Chapter 3 examines the coalition proof Nash equilibrium agreements of the FTA formation game for all possible levels of tariff bindings. Then, we extend our analysis in a setting where countries the PTA under consideration is a customs union. Chapters 4-5 analyse the dynamic equilibrium outcome of PTA formation. Chapter 4 analyses FTA game and $\mathrm{Cu}$ game in isolation. Chapter 5 analyses the "PTA game" where countries endogenously choose between FTAs and CUs. Finally, Chapter 6 concludes. All proofs are relegated to Appendices 6, 6, 6 and 6 . 
${ }_{\text {Chapter }}$

\section{Underlying Trade Model}

\subsection{Trade Model}

Our underlying economic framework is an adapted three country version of the two country comparative advantage model of Horn et al. (2010). This model is utilized with different comparative advantage structure assumptions in order to derive results presented in Chapters 3-5.

We consider a perfectly competitive world with three large countries: $z=i, j$, and $k$ and three (non-numéraire) goods: $g=I, J$, and $K$ and a numéraire good $v_{0}$. On the demand side, the representative citizen's utility function is assumed to be quasi-linear:

$$
U\left(\mathbf{v}, v_{0}\right)=u(\mathbf{v})+v_{0}
$$

where $\mathbf{v}=\left[v_{I}, v_{J}, v_{K}\right]$ is the consumption vector for the three non-numéraire goods, $v_{0}$ denotes the consumption of the numéraire good, and $u(\mathbf{v})$ is quadratic and additively separable in the three non-numéraire goods. The demand for good $g$ in country $z$ is then given by

$$
d_{z}^{g}\left(p_{z}^{g}\right)=\alpha-p_{z}^{g}
$$

where $p_{z}^{g}$ denotes the consumer price of good $g$ in country $z$. Assuming that the population in each country is a continuum of measure one, we can write the consumer surplus associated with good $g$ in country $z$ as:

$$
C S_{z}^{g}\left(p_{z}^{g}\right)=u_{z}^{g}\left[d_{z}^{g}\left(p_{z}^{g}\right)\right]-p_{z}^{g} d_{z}^{g}\left(p_{z}^{g}\right)
$$

On the supply side, as in Horn et al. (2010), labour $(\ell)$ is the only factor of production which is employed in the production of the numéraire good that is produced one-for-one from labour. The supply of labour is assumed to be large enough that the numéraire good is always produced in a positive amount; therefore the equilibrium wage is equal to one. Each non-numéraire good is produced from labour with diminishing returns. In particular, we assume the following production function for non-numéraire good $g$ in country $z: Q_{z}^{g}=$ 
$\sqrt{2 \lambda_{z}^{g} \ell_{g}}$, where $Q_{z}^{g}$ is the production of good $g$ in country $z$ and $\ell_{g}$ is the labour employed in the production of good $g$. The supply function of good $g$ in country $z$ is as follows:

$$
s_{z}^{g}\left(q_{z}^{g}\right)=\lambda_{z}^{g} q_{z}^{g}
$$

where $q_{z}^{q}$ denotes the producer price for good $g$ in country $z$.

We assume the following comparative advantage structure across countries: $\lambda_{i}^{I}=\lambda_{j}^{J}=$ $\lambda_{k}^{K}=1$ while $\lambda_{i}^{J}=\lambda_{i}^{K}=1+\lambda_{i} ; \lambda_{j}^{I}=\lambda_{j}^{K}=1+\lambda_{j}$ and $\lambda_{k}^{I}=\lambda_{k}^{J}=1+\lambda_{k}$. In other words, each country has a comparative advantage in two goods while having a comparative disadvantage in the other good: each country imports the good that is indexed by the same upper-case letter as the identity of the country. For example, country $i$ imports good $I$ while exporting good $J$ to country $j$ and good $K$ to country $k$. Thus, there are two competing exporters competing over an imported non-numéraire good in the importing country. Country $z$ 's producer surplus in good $g$ as follows:

$$
P S_{z}^{g}\left(q_{z}^{g}\right)=\int s_{z}^{g}\left(q_{z}^{g}\right) d q_{z}^{g}=\frac{1}{2} \lambda_{z}^{g}\left(q_{z}^{g}\right)^{2}
$$

Due to the absence of any tariff in country $i$ on goods $J$ and $K$, the consumer and producer prices of goods $J$ and $K$ in country $i$ are equal: $q_{i}^{J}=p_{i}^{J}$ and $q_{i}^{K}=p_{i}^{K}$. As there is no domestic taxation for the import competing sector, producer and consumer prices are also equal in this sector: $q_{i}^{I}=p_{i}^{I}$.

As a representative scenario for all goods and countries, consider good $I$ (i.e. the good in which country $i$ is has a comparative disadvantage). Let $t_{i j}$ be the tariff imposed by country $i$ on its imports of good $I$ from country $j$. Ruling out prohibitive tariffs yields the following no-arbitrage conditions for good $I$ :

$$
p_{i}^{I}=p_{j}^{I}+t_{i j}=p_{k}^{I}+t_{i k}
$$

Let $m_{i}^{I}$ be country $i$ 's imports of good $I$ :

$$
m_{i}^{I}=d\left(p_{i}^{I}\right)-s_{i}^{I}\left(p_{i}^{I}\right)=\alpha-2 p_{i}^{I}
$$

Each country's exports of a good must equal its domestic supply of that good minus its local consumption:

$$
x_{j}^{I}=\left(1+\lambda_{j}\right) p_{j}^{I}-\left[\alpha-p_{j}^{I}\right] \text { and } x_{k}^{I}=\left(1+\lambda_{k}\right) p_{k}^{I}-\left[\alpha-p_{k}^{I}\right]
$$

Market clearing for good $I$ requires that country $i$ 's imports equal the total exports of the other two countries:

$$
m_{i}^{I}=\sum_{z \neq i} x_{z}^{I}
$$

Equations (2.6) through (2.9) imply that the equilibrium prices of good $I$ in the im- 
porting country $i$ and an exporting country (say $J$ ) equal:

$$
p_{i}^{I}=\frac{3 \alpha+\sum_{z \neq i} t_{i z}\left(2+\lambda_{z}\right)}{\left(\lambda_{j}+\lambda_{k}+6\right)} \text { and } p_{j}^{I}=\frac{3 \alpha+t_{i k}\left(\lambda_{k}+2\right)-t_{i j}\left(\lambda_{k}+4\right)}{\left(\lambda_{j}+\lambda_{k}+6\right)}
$$

As it is clear from equation (2.10), the price of good $I$ in country $i$ increases in its tariffs (pass through effect) and decreases in the degree of comparative advantage of the other two countries (supply effect). The effect of a country's tariff on its terms of trade (say $t_{i j}$ on country $j$ ) is evident from equation (2.10): only $\frac{2+\lambda_{j}}{\left(\lambda_{j}+\lambda_{k}+6\right)}<1$ of a given increase in either of its tariffs is passed on to domestic consumers with exactly $\frac{\left(\lambda_{k}+4\right)}{\left(\lambda_{j}+\lambda_{k}+6\right)}<1$ of the increase falling on the shoulders of country $j$ 's exporters (terms of trade benefit).

Using the above prices, finding the export of each country is straightforward:

$$
x_{j}^{I}=\frac{\left(2+\lambda_{j}\right)\left[3 \alpha+t_{i k}\left(\lambda_{k}+2\right)-t_{i j}\left(\lambda_{k}+4\right)\right]}{\left(\lambda_{j}+\lambda_{k}+6\right)}-\alpha
$$

Note that the export of country $j$ to country $i\left(x_{j}^{I}\right)$ rises with the degree of comparative advantage country $j\left(\lambda_{j}\right)$ and the tariff the rival exporter faces $\left(t_{i k}\right)$ while it falls with the degree of comparative advantage of the rival exporter $\left(\lambda_{k}\right)$ and the tariff it itself faces in country $i\left(t_{i j}\right)$.

From a welfare perspective, given the partial equilibrium nature of the model, it suffices to consider only protected goods. A country's welfare is defined as the sum of consumer surplus, producer surplus, and tariff revenue over all such goods:

$$
w_{z}=\sum_{g} C S_{z}^{g}+\sum_{g} P S_{z}^{g}+\sum_{z \neq h} t_{z h} x_{h}^{Z}
$$

Using equations (2.6) through (2.10) one can easily obtain welfare of country $i$ as a function of the degrees of comparative advantage and tariffs. ${ }^{1}$

\subsection{Optimal Tariffs (sufficiently high bound tariffs)}

Given a trade regime $r$, country $i$ 's static payoff is denoted by $w_{i}(r)$. Let $\Delta w_{i}(r-v)$ denote the difference between country $i$ 's welfare under trade regimes $r$ and $v: \Delta w_{i}(r-v) \equiv$ $w_{i}(r)-w_{i}(v)$. First, we assume that bound tariffs are sufficiently high and countries are not constrained in imposing their optimal tariffs under all possible trade regimes (i.e. there exists a tariff binding overhang under all trade regimes).

To examine the interaction between the external tariffs of a country, for now, we allow countries to be able to discriminate and later impose the MFN constraint. At the empty

\footnotetext{
${ }^{1}$ Calculations supporting the results reported in this section as well as the rest of the paper are contained in Appendix 6.
} 
network, denoted by $\varnothing$, we find that tariffs are strategic complements:

$$
\frac{\partial^{2} w_{i}(\varnothing)}{\partial t_{i j} \partial t_{i k}}=\frac{2\left(\lambda_{j}+2\right)\left(\lambda_{k}+2\right)\left(\lambda_{j}+\lambda_{k}+7\right)}{\left(\lambda_{j}+\lambda_{k}+6\right)^{2}}>0
$$

In other words, an increase (decrease) in external tariff on one exporter raises the incentive to impose higher (lower) external tariff on the other exporter. The intuition is as follows. As country $i$ imposes higher tariff on country $j$, export supply of country $k$ into country $i$ becomes less elastic and thus the tariff on country $k$ also rises.

\subsubsection{MFN tariffs}

When countries are not constrained by the multilaterally negotiated tariff bindings, each country $i$ chooses a non-discriminatory tariff (in accordance with GATT Article I) $t_{i}=$ $t_{i j}=t_{i k}$ to maximize its welfare:

$$
t_{i}(\varnothing)=\operatorname{Arg} \max w_{i}(\varnothing)=\frac{\alpha\left(\lambda_{j}+\lambda_{k}\right)}{\left(\lambda_{j}+\lambda_{k}+4\right)\left(\lambda_{j}+\lambda_{k}+8\right)}
$$

Note that $t_{i}(\varnothing)$ rises with the degrees of comparative advantage of the exporters $\left(\lambda_{j}\right.$ and $\left.\lambda_{k}\right)$. Next, we examine how an FTA and a CU formation affects members' external tariffs.

\subsubsection{Free Trade Agreement member's Nash tariff}

When countries are not constrained by the tariff bindings, upon FTA formation, member countries remove their internal tariffs on each other and impose their individually optimal external tariff on the non-member. Under a single FTA between $i$ and $j$, denoted by $i j$, we have $t_{i j}=t_{j i}=0$ and the optimal external tariff of country $i$ on the non-member country $k$ is given by: ${ }^{2}$

$$
t_{i k}(i j) \equiv \operatorname{Arg} \max w_{i}(i j)=\frac{\left(\lambda_{j}+\lambda_{k}+8\right) \alpha\left(\lambda_{k}-\lambda_{j}\right)+\alpha \lambda_{k}}{\left(\lambda_{k}+2\right)\left[\left(\lambda_{j}+3\right)\left(\lambda_{j}+\lambda_{k}+7\right)+1\right]}
$$

As indicated above, the model exhibits tariff complementarity so that the formation of a bilateral FTA induces each member to lower its tariff on the non-member country relative to the status quo: $\Delta t_{i k}(\varnothing-i j)=t_{i}(\varnothing)-t_{i k}(i j)>0$. This tariff complementarity becomes deeper as the degree of comparative advantage of the FTA partner rises and the one of the non-member country falls: $\frac{\partial \Delta t_{i k}(\varnothing-i j)}{\partial \lambda_{j}}>0$ while $\frac{\partial \Delta t_{i k}(\varnothing-i j)}{\partial \lambda_{k}}<0 .^{3}$

\footnotetext{
${ }^{2}$ Since the non-member country is the sole importer of the good exported by the member countries, we have $t_{k}(\varnothing)=t_{k}(i j)$. In a hub-spoke network, denoted by $i h$, where $i$ is the hub with $j$ and $k$ being spokes, we have $t_{j k}(i h)=t_{j k}(i j)$ and $t_{k j}(i h)=t_{k j}(i k)$. In contrast, since the hub has an FTA with both spokes, it practices free trade.

${ }^{3}$ See Bagwell and Staiger (1997a, 1997b, 1999) and Saggi and Yildiz (2009) for a detailed discussion of the tariff complementarity effect and Estevadeordal et al. (2008) for empirical evidence in its support.
} 


\subsubsection{Custom Unions member's Nash tariff}

Upon CU formation, members remove tariffs on each other and impose their jointly optimal external tariffs when they are not restricted by the multilaterally negotiated bound tariff rates. ${ }^{4} \mathrm{CU}$ members benefit from tariff coordination because they internalize the negative externality caused by tariff complementarity reducing each other's export surplus. ${ }^{5}$ If two countries, say $i$ and $j$, form a CU denoted by $i j^{u}$, they remove tariffs on each other and impose jointly optimal external tariffs (denoted by $t_{i k}^{u}\left(i j^{u}\right)=t_{i}^{u}$ and $\left.t_{j k}^{u}\left(g_{i j}^{C U}\right)=t_{j}^{u}\right)$ on the non-member country. ${ }^{6}$ The tariff pair $\left(t_{i}^{u}, t_{j}^{u}\right)$ is chosen to solve: ${ }^{7}$

$$
\max _{t_{i}^{u}, t_{j}^{u}} w_{i}\left(i j^{u}\right)+w_{j}\left(i j^{u}\right) \text { subject to } t_{i j}=t_{j i}=0
$$

Given the common external tariff of a $\mathrm{CU}$, we have $t_{i}^{u}=t_{j}^{u}=t^{u}$ and the optimal external tariff of each $\mathrm{CU}$ member is given by

$$
t_{i k}\left(i j^{u}\right)=\frac{\alpha\left(2 \lambda_{k}-\lambda_{j}\right)}{\left(\lambda_{k}+2\right)\left(\lambda_{k}+2 \lambda_{j}+10\right)}
$$

Because of the segmented nature of markets, a non-member does not adjust its MFN tariff when other countries form PTAs. Thus, as a non-CU member, country $k$ 's optimal MFN tariff is $t_{i}(\varnothing)$. Note that, under symmetry, the formation of a CU induces each member country to lower its tariff on the non-member relative to the status quo (i.e. the model exhibits tariff complementarity): $t_{i}(\varnothing)>t_{i k}\left(i j^{u}\right)$. Moreover, like an FTA, this tariff complementarity becomes deeper as the degree of comparative advantage of the FTA partner rises and the one of the non-member country falls: $\frac{\partial \Delta t_{i k}\left(\varnothing-i j^{u}\right)}{\partial \lambda_{j}}>0$ whereas

It is worth noting that tariff complementarity also arises in simple general equilibrium models of trade agreements such as Bond et al. (2004).

${ }^{4}$ Our simple formulation of a CU's tariff choice is intuitively appealing and consistent with much of existing literature, even with asymmetric countries and transfers excluded (e.g. Saggi et al. (2013)). Moreover, our results merely rely on the one period CU payoff possibly exceeding the one period FTA payoff. For issues regarding delegation of tariff-setting authority, the choice of weights in the social welfare function, and tariff sharing rules, see Gatsios and Karp (1991), Melatos and Woodland (2007) and Syropoulos (2003). Importantly, Syropoulos shows CU members have an incentive to influence their common tariffs for external terms-of-trade reasons and for internal distributional purposes. However, given the focus of our paper, we abstract from such considerations.

${ }^{5}$ In Bagwell and Staiger (1997), CU members compete for imports rather than compete for exports. There, a CU is only beneficial because of a "market power" effect: CU members pool their market power and extract a larger terms of trade gain from non-members.

${ }^{6}$ Our simple formulation of a CU's tariff choice problem is intuitively appealing and in line with much of existing literature. However, Syropoulos (2003) has shown that the nature of the sharing rule of a CU with respect to tariff revenue can affect tariff preferences as well as the trade patterns of CU members in ways that can prevent the implementation of jointly optimal tariffs. An important insight of his analysis is that CU members have an incentive to influence their common tariffs not just for external terms-of-trade reasons but also for internal distributional purposes. Given the focus of our paper, we abstract from such considerations.

${ }^{7}$ The assumption that the CU maximizes the sum of national utilities is commonly employed in the literature. Issues of the delegation of tariff-setting authority and the choice of weights in the social welfare function are discussed by Gatsios and Karp (1991) and Melatos and Woodland (2007). 
$\frac{\partial \Delta t_{i k}\left(\varnothing-i j^{u}\right)}{\partial \lambda_{k}}<0$. However, unlike an FTA, member countries under a CU internalize each other's export surplus under the joint welfare maximization and thus higher external tariff (weaker tariff complementarity) arises: $t_{i}(\varnothing)>t_{i k}\left(i j^{u}\right)>t_{i k}(i j)$. 


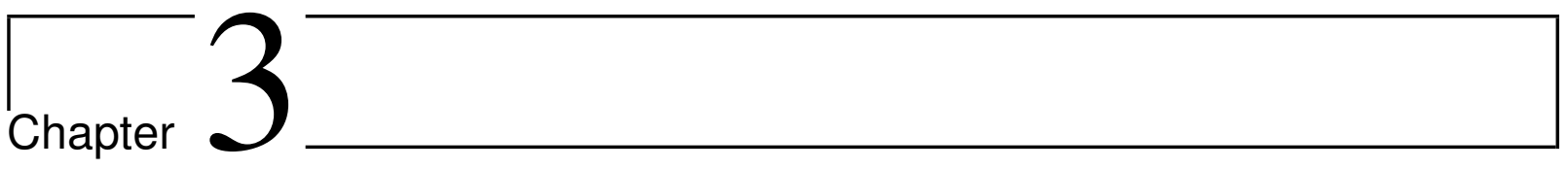

\section{Static Implications of Multilateral Tariff Bindings on the Extent of Preferential Trade Agreement Formation}

\subsection{Introduction}

In this chapter, we first examine the coalition proof Nash equilibrium agreements of the PTA formation game between symmetric countries under exogenously given tariff bindings. ${ }^{1}$ This exercise allows to investigate how equilibrium PTA formation, and specifically the attainment of global free trade, changes with continual reductions in the symmetric tariff binding. Then, we extend our analysis into a setting where countries are asymmetric with respect to their degree of comparative advantage.

We first find that the formation of a bilateral PTA (both FTA and CU) induces each member to lower its tariff on the non-member country relative to the status quo, i.e. the model exhibits tariff complementarity. As a result, exogenously given tariff bindings lead to three distinct scenarios: (i) no tariff binding scenario where the bound tariff rate exceeds the optimal Nash tariffs and countries are free to impose their optimal tariffs under all trade regimes; (ii) partial tariff binding scenario where the bound tariff rate exceeds the optimal tariff of a member country under a PTA but falls below the optimal Nash tariffs and thus the member countries under a PTA are free to impose their optimal external tariffs while the non-member country under a PTA is required to apply the bound tariff rate and (iii) full tariff binding scenario where the bound tariff rate falls below the optimal tariffs of member countries under a PTA and thus countries lose their freedom to impose optimal external tariffs under all possible trade regimes and are required to apply their tariff bindings. Note that while the tariff binding overhang can arise in the first two scenarios, it disappears in the final scenario since tariff bindings bind all countries. ${ }^{2}$ The existing literature on trade agreements ignores the tariff bindings and thus focus only on

\footnotetext{
${ }^{1}$ The methodology and the results contained in this chapter are documented in Nken and Yildiz (2018).

${ }^{2}$ The tariff binding overhang literature includes Bagwell and Staiger (2005a), Amador and Bagwell
} 
the very first scenario where countries impose their optimal tariffs. In this paper, we go one step further and examine more realistic cases where countries are not able to impose their optimal tariffs due to sufficiently tight tariff bindings.

Our analysis on how the continual reduction in tariff bindings affects countries' preferences for PTA formation delivers several interesting insights. We first show that, when countries are completely symmetric, no country has an incentive to unilaterally deviate from global free trade and free ride on trade liberalization by the other two countries regardless of the (i) level of tariff bindings and (ii) the type of PTAs (FTA or CU). However, we show that two countries have incentives to jointly exclude the third one via a bilateral FTA or bilateral CU from free trade network when tariff bindings are sufficiently tight.

The intuition behind these results can be explained as follows. First consider that tariff bindings are sufficiently lax and countries are able to impose their optimal external tariffs. Under such a case, although the PTA outsider benefits from the lower external tariffs faced when exporting to the PTA members (due to tariff complementarity), it faces discrimination in the export markets of member countries. Through eliminating the discrimination faced in both PTA members' markets, an FTA outsider always benefits from moving from a bilateral FTA to global free trade. When the tariff binding falls below the optimal Nash tariffs, the non-member country under a bilateral PTA loses its ability to set its optimal tariff and is required to impose its tariff binding. On the other hand, the PTA member countries fully enjoy free access in each others market and are either (i) fully able to impose their optimal external tariffs (as under the partial tariff binding scenario) or (ii) impose the same external tariff as the non-member country (as under the full tariff binding scenario). This makes the discrimination faced by the PTA outsider more prominent and weakens any free riding incentive.

When the tariff binding is sufficiently lax, the PTA non-member imposes relatively high tariffs on the PTA members. To eliminate these barriers, the PTA members have a strong incentive for forming an additional PTA with the non-member. However, the strength of this incentive weakens as the PTA outsider becomes more constrained by a tighter tariff binding. Indeed, once the tariff binding is sufficiently tight, PTA members have already extracted substantial tariff concessions from the FTA non-members and this generates an exclusion incentive for PTA members. Here, it is important to note that Saggi and Yildiz (2010) show that there exists no exclusion incentive under symmetry in a competing exporters model. Our result suggests that this result fails to hold when countries are constrained in imposing their optimal tariffs due to sufficiently tight tariff bindings.

As is well known, the central difference between a bilateral FTA and a bilateral CU is that FTA members impose individually optimum external tariffs while members of a CU impose common external tariffs, internalizing the negative externality of tariff complementarity on each other's export. This difference in tariff setting behaviour between the two types of PTAs has important consequences. The requirement that $\mathrm{CU}$ members set a common external tariff implies that individual CU members do not have the ability

(2013) and Beshkar et al. (2015) who argue that uncertianty over governments' future political economy motivations during trade negotiations can justify the demand for the flexibility over future applied tariffs. 
to form an additional PTA without the consent of other CU members while FTA members are free to enter into additional FTAs with non-member countries without requiring consent from its existing FTA partners. As a result, CU expansion must move directly from a bilateral $\mathrm{CU}$ to global free trade and $\mathrm{CU}$ members have veto power over such $\mathrm{CU}$ expansion. In other words, FTA members enjoy more flexibility than CU members while CU members enjoy coordination benefits both in setting external tariffs and in excluding the non-member country. We show that this crucial difference between a CU and an FTA has important consequences for the prospect of global free trade.

First, it is immediate to note under the no tariff binding and partial tariff binding scenarios that, the joint external tariff determination under a CU leads to higher external tariffs relative to the ones under an FTA. Therefore, under such a case, the free riding incentive of a country is weaker when facing a CU relative to an FTA while the exclusion incentive of CU members is stronger than the one of FTA members. Under the full tariff binding scenario, since all countries impose the exogenously given bound tariff rates, a bilateral CU is identical to a bilateral FTA from both member and non-member countries' perspectives. It is important to note here that the flexibility of FTA formation implies that hub and spoke type of regime is an option under FTA formation only and thus FTAs are more susceptible to opportunistic unilateral deviations by member countries than CUs. As stated above, when countries are symmetric, countries have no incentives to free ride while exclusion incentives arise under both FTA and CU games when tariff bindings are sufficiently tight. We find that free trade always obtains as the CPNE of the FTA game since exclusion incentives go unexercised in the equilibrium due to the flexibility in FTA formation. However, unlike the FTA formation game, countries are able to exercise the exclusion incentive under the CU game and free trade fails to be a CPNE when the tariff bindings are sufficiently tight and thus the pursuit of CUs undermines global free trade.

To understand the intuition behind this key result, suppose we start with announcements leading to free trade. Due to the existence of an exclusion incentive in our model, two countries benefit if they jointly deviate to announcements wherein they call for an FTA with only each other when tariff bindings are low. We find that the initial deviation is never self-enforcing since the welfare of a hub country under a hub and spoke regime exceeds that of the member of a single FTA and thus free trade is always a CPNE under the FTA game when countries are symmetric. By contrast, two independent CUs (a hub and spoke type arrangement) are not feasible due to common external tariff requirement and thus the initial joint deviation of two countries that converts free trade to a bilateral $\mathrm{CU}$ is self-enforcing and free trade fails to be a CPNE in the CU game when bound tariffs are sufficiently low. As a result, whereas the exclusion incentive is reflected in the equilibrium of the CU game, it goes unexpressed in the FTA game due to the lure of a hub and spoke arrangement and the flexibility that FTA members have in pursuing such an arrangement.

Given that free trade always arises as a CPNE under the FTA game when countries are completely symmetric, we next examine under what circumstances, if any, free trade fails to be a CPNE. We show that such a possibility arises only when countries are asymmetric with respect to their comparative advantage. ${ }^{3}$ It turns out that, due to smaller export and larger

\footnotetext{
${ }^{3}$ Our results extend support to Krugman (1991) and Grossman and Helpman (1995) who argue that
} 
import volumes, the country with a weaker comparative advantage in the exporting goods has an incentive to free ride on trade liberalization between the other countries. Lower bound tariff rates disciplines this incentive via limiting the ability of setting optimal tariffs. As before, due to the lure of a hub and spoke arrangement and the relatively flexible nature of FTA formation, exclusion incentives go unexercised and free riding incentive becomes pivotal for multilateral free trade to be a CPNE. As a result, multilateral free trade is more likely to be a CPNE as the multilateral negotiated bound tariff rates decline. This result provides support for the idea that continual decline in tariff bindings acts as a complement to the FTA formation in achieving global free trade: FTA formation is more likely to act as a building bloc when it is accompanied by lower tariff bindings.

First, we focus on the scenario where countries are completely symmetric with respect to their degrees of comparative advantage. Within this scenario, we employ an endogenous FTA formation game in which each country is free to pursue either no trade liberalization or bilateral trade liberalization or multilateral free trade. ${ }^{4}$ Our objective is to isolate the consequences of the interaction of the multilateral reduction in bound tariff rates and FTA formation in achieving global free trade. To this end, we assume that the tariff bindings are exogenously given and countries are constrained by these tariff bindings in setting their optimum external tariffs. Under such an environment, we examine the coalition proof Nash equilibrium agreements of the FTA formation game for all possible by the tariff bindings. Then, we extend our analysis to two different settings: (i) where countries are asymmetric with respect to their degree of comparative advantage and (ii) where countries are symmetric while PTA under consideration is a customs union.

\subsection{Endogenous Trade Agreements}

We now describe our game of preferential trade liberalization. In the first stage, each country simultaneously announces the names of countries with whom it wants to sign an FTA. Let $\Omega^{r}$ denote the announcement profile that leads to regime $r$. Country $i$ 's announcement is denoted by $\sigma_{i}$ and its strategy set $S_{i}$ consists of four possible announcements:

$$
S_{i}=\{\{\phi, \phi\},\{j, \phi\},\{\phi, k\},\{j, k\}\}
$$

where $\{\phi, \phi\}$ denotes an announcement in favor of no FTA with either trading partners, $\{j, \phi\}$ in favor of an FTA with only country $j ;\{\phi, k\}$ in favor of an FTA with only country $k$; and $\{j, k\}$ in favor of FTAs with both of them.

It is important to note that we employ a game of announcements or proposals. In our game, a country does not announce in favour of a specific trade agreement but rather names partners with whom it wants to form such agreements. Since a trade agreement requires

asymmetries across countries can play a crucial role in determining incentives for preferential and multilateral trade liberalization.

${ }^{4}$ Since all countries have market power in our model, allowing for unilateral liberalization is not necessary: no country will choose to pursue such liberalization in our model. 
consent from both sides, the mapping between various announcements profiles that occurs and the types of trade agreements that countries can form are as follows:

(i) No two announcements match or the only matching announcements are $\{\phi, \phi\}$. Such announcement profiles $\Omega^{\varnothing}$ yield No agreement $\varnothing$ under which all countries impose their optimal Nash tariffs on one another as tariff bindings do not bind. If they are constrained, they are required to apply the tariff bindings.

(ii) Two countries announce each others' name and there is no other matching announcement: i.e., $j \in \sigma_{i}$ and $i \in \sigma_{j}$ while $i \notin \sigma_{k}$ and/or $k \notin \sigma_{i}$ and $j \notin \sigma_{k}$ and/or $k \notin \sigma_{j}$. All of these announcement profiles $\Omega^{i j}$ yield an FTA between countries $i$ and $j$ denoted by $\langle i j\rangle$ under which members impose zero tariffs on each other and the optimal external tariff $t_{i k}(i j)$ and $t_{j k}(i j)$ on the non-member if these tariffs fall below the tariff bindings. Otherwise, they apply the exogenously given tariff bindings.

(iii) Country $i$ announces in favour of signing an FTA with countries $j$ and $k$ while countries $j$ and/or $k$ announce only in favor of signing an FTA with country $i$ : i.e. $j \in \sigma_{i}$ and $i \in \sigma_{j}$ and $k \in \sigma_{i}$ and $i \in \sigma_{k}$ while $k \notin \sigma_{j}$ and/or $j \notin \sigma_{k}$. This set of announcement profiles $\Omega^{i h}$ yields a pair of independent FTAs (i.e. a hub and spoke trading regime) with $i$ is the common member denoted by $\langle i j, i k\rangle$ (or simply $\langle i h\rangle$ ) under which countries $j$ and $k$ impose the tariff $t_{j k}(i h)$ and $t_{k j}(i h)$ on each other if these tariffs fall below the tariff bindings while practising free trade with the hub country $i$.

(iv) All countries announce each others' names. The corresponding announcement profile $\Omega^{F}$ yields global free trade, denoted by $\langle F\rangle$, under which all countries eliminate their tariffs on each other.

Note that since an FTA between two countries can arise only if it is mutually acceptable to both sides, multiple announcement profiles can map into the same agreement. For example, the FTA $\langle i j\rangle$ obtains when $(i)$ countries $i$ and $j$ call only each other, regardless of the nature of country $k$ 's announcement: if $\sigma_{i}=\{j, \phi\}$ and $\sigma_{j}=\{i, \phi\}$, then $\langle i j\rangle$ obtains for all four possible announcements on the part of country $k$, i.e., for $\sigma_{k} \epsilon\{\{\phi, \phi\},\{i, \phi\}$, $\{\phi, j\},\{i, j\}\}$ so that country $k$ 's announcement has no bearing upon the outcome when neither of the other two countries' announce its name; $(i i)$ countries $i$ and $j$ announce each other's name and either one or both of them also announce country $k$ but country $k$ does not reciprocate: $\sigma_{i}=\{j, k\}$ and $\sigma_{j}=\{i, \phi\}$ but $i \notin \sigma_{k}$ or $\sigma_{i}=\{j, \phi\}$ and $\sigma_{j}=\{i, k\}$ but $j \notin \sigma_{k}$ or $\sigma_{i}=\{j, k\}$ and $\sigma_{j}=\{i, k\}$ but $i, j \notin \sigma_{k}$.

\subsection{Symmetric Comparative Advantage}

Using the equilibrium prices derived in equation (2.10), we maintain, throughout the remainder of this section, the following complete symmetry assumption: ${ }^{5}$

\footnotetext{
${ }^{5}$ Calculations supporting the results reported in this section as well as the rest of the paper are contained in the appendix.
} 
Assumption 3.1

$$
\lambda_{z}=\lambda \text { for all } z=i, j, k \text {. }
$$

(Symmetry)

Under symmetry, when countries are not constrained by tariff bindings, each country imposes a non-discriminatory tariff on its trading partners: $t_{z}(\varnothing)=t^{\varnothing}$, for all $z=i, j, k$ and due to market segmentation the non-member country under a bilateral FTA (say $\langle i j\rangle$ ) imposes the same external tariff on the member countries as the one under No agreement: $t_{k i}(i j)=t_{k j}(i j)=t^{\varnothing}$ where

$$
t^{\varnothing}=\frac{\alpha \lambda}{2(\lambda+2)(\lambda+4)}
$$

Similarly, when member countries under a bilateral FTA (say $\langle i j\rangle$ ) and spoke countries under a hub and spoke regime (say $\langle i h\rangle$ ) are not bound, their optimal external tariffs are as follows: $t_{i k}(i j)=t_{j k}(i j)=t_{j k}(i h)=t_{k j}(i h)=t^{f}$ where

$$
t^{f}=\frac{\alpha \lambda}{(\lambda+2)\left(2 \lambda^{2}+13 \lambda+22\right)}
$$

\subsubsection{Different Tariff Binding Scenarios - Symmetry}

Let $\tau$ denote the bound tariff rate resulting from multilateral negotiations and countries are not allowed to raise their tariffs to a higher level than their bound rates. Thus, given the above optimal tariffs and feasible bound rates, we have three possible scenarios (illustrated in Figure 3.1):

(i) no tariff binding scenario where the tariff binding exceeds the optimal tariff under No agreement: $\tau>t_{z}(\varnothing)$ so that countries are free to impose their optimal tariffs under all trade regimes;

(ii) partial tariff binding scenario where the tariff binding exceeds the optimal tariff under an FTA but falls below the optimal tariff under No agreement: $t^{f}<\tau<t^{\varnothing}$. Under such a case, countries under $\varnothing$ and the non-member country under an FTA impose $\tau$ while the member countries under an FTA and spoke countries under a hub and spoke regime are free to impose their optimal external tariffs and

(iii) full tariff binding scenario where the tariff binding is below the optimal tariff under an FTA: $\tau<t^{f}$. Under this scenario, countries lose their freedom to impose optimal tariffs under all trade regimes and apply $\tau$ (no tariff binding overhang). 


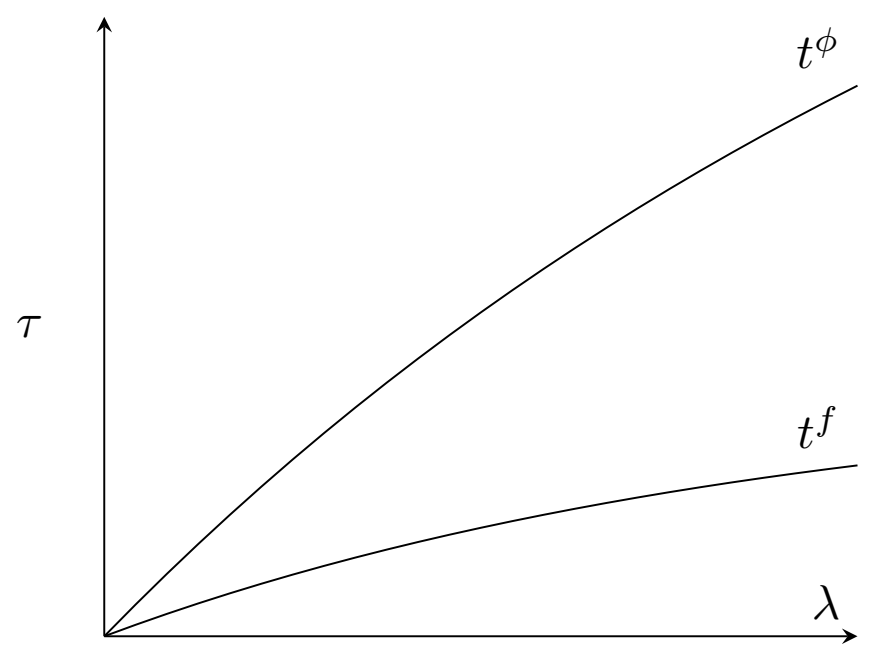

Figure 3.1: FTA tariff schedule - Symmetry

\subsubsection{Nash Equilibrium Trade Agreements - Symmetry}

Before deriving equilibrium agreements, we report a useful lemma that is easy to establish:

Lemma 3.1 Under symmetry, we have:

(i) $\Delta w_{i}(i j-\varnothing)=\Delta w_{j}(i j-\varnothing)>0$ for all $\tau$ and $\lambda$ while $\Delta w_{k}(i j-\varnothing)>0$ only when $\tau>\bar{\tau}(\lambda)$ where $t^{f}<\bar{\tau}(\lambda)<t^{\varnothing}$

(ii) $\Delta w_{k}(F-i j)>0$ for all $\tau$ and $\lambda$;

(iii) $w_{i}(i h)>\max \left\{w_{i}(F), w_{i}(i j), w_{i}(\varnothing)\right\}$ and $\Delta w_{j}(F-i h)=\Delta w_{k}(F-i h)>0$ for all $\tau$ and $\lambda$;

(iv) $\Delta w_{j}(i h-i k)=\Delta w_{k}(i h-i j)>0$ only when $\tau<\underline{\tau}(\lambda)$ where $t^{f}<\underline{\tau}(\lambda)<t^{\varnothing}$ and

(v) $\bar{\tau}(\lambda)>\underline{\tau}(\lambda)$ for all $\lambda$.

The first part of the above lemma implies that, a pair of symmetric countries under $\varnothing$ always have an incentive to form a bilateral FTA and thus neither member country $(i$ or $j$ ) has an incentive to unilaterally break its FTA link. Part (i) also informs us that the formation of a bilateral FTA makes the non-member country better-off only when the tariff binding is sufficiently lax: $\tau>\bar{\tau}(\lambda)$. Thus, when $\tau>\bar{\tau}(\lambda)$ holds, we argue that the formation of a bilateral FTA is Pareto improving. Here it is important to note that, relative to no agreement $\varnothing$, the benefit from staying outsider under a bilateral FTA gets weaker with the reduction in tariff bindings since it restricts the ability of the non-member country to impose its optimal tariff and it completely disappears when $\tau<\bar{\tau}(\lambda)$ holds. Therefore, when $\tau<\bar{\tau}(\lambda)$ holds, the formation of an FTA makes member countries better off at the expense of the non-member. 
Similar discussion applies to the second part of the above Lemma. We first note that no symmetric country has incentive to unilaterally break its link with both partners that leads to a deviation from multilateral free trade to an FTA in which it itself is not a member provided that countries are free to impose their optimal tariffs as under the no tariff binding scenario. As the bound tariff rates fall, this unilateral incentive gets even weaker since it restricts the ability of the non-member country to impose its optimal tariff. Part (iii) says that the hub country $i$ under $\langle i h\rangle$ is better off relative to free trade $\langle F\rangle$ while each spoke country is worse off. Note that the hub country $i$ enjoys sole privileged access in both spoke countries under $\langle i h\rangle$ - neither spoke country imposes a tariff on the hub country whereas both impose external tariffs on each other. As a result of this favourable treatment, country $i$ is strictly better off under $\langle i h\rangle$ relative to $\langle F\rangle$. To see why the spokes are worse off under $\langle i h\rangle$ relative to $\langle F\rangle$, first note that aggregate global welfare is strictly higher under $\langle F\rangle$ relative to $\langle i h\rangle$. Since the hub is strictly better off under $\langle i h\rangle$ relative to $\langle F\rangle$ and welfare of the two spoke countries is equal due to symmetry, both spokes must be worse off under $\langle i h\rangle$ relative to $\langle F\rangle$.

Furthermore, part (iii) also informs us that the welfare of a hub country is higher than that of the member of a single bilateral FTA (and thus the under no agreement due to part $(i)$ ). Starting from a single FTA, the hub country's second FTA lowers the domestic welfare and raises the export surplus due to the privileged access in another country and the latter effect dominates the former regardless of the tariff binding. Part $(i v)$ of the above Lemma implies that a spoke country has an incentive to revoke its FTA with the hub and become an outsider facing an FTA between the other two countries unless the tariff binding is sufficiently tight. When the tariff binding is sufficiently tight $(\tau<\underline{\tau}(\lambda))$, the non-member country's ability to impose optimal MFN tariff is restricted and staying outside an FTA becomes less attractive.

The above discussion in parts (ii) and (iii) argues that free riding incentives do not play any role for the equilibrium condition for free trade. One question remains to be answered: do countries have incentives to jointly exclude a country from free trade network?

Proposition 3.1a (exclusion incentive - Symmetry) : Suppose Assumption 3.1 holds. Even though there exist no free riding incentives, exclusion incentive arises when bound tariff rates are sufficiently low: $\Delta w_{i}(F-i j)=\Delta w_{j}(F-i j)<0$ when $0<\tau<\widehat{\tau}(\lambda)$ where $t^{f}<\widehat{\tau}(\lambda)<t^{\phi}$.

The above proposition establishes the existence of an exclusion incentive when the tariff binding is sufficiently tight. The forces that give rise to the exclusion incentive can be understood as follows. First note that when countries are free to set their optimal tariffs as under the no tariff binding scenario $\left(\tau>t_{z}(\varnothing)\right)$, the non-member country imposes relatively high tariff on the members. To eliminate this high tariff, the FTA members have a strong incentive for FTA expansion and thus exclusion incentive does not exist: $\Delta w_{i}(F-i j)>0$ holds. However, the strength of this incentive weakens as the nonmember becomes more constrained by a tighter tariff binding: $\Delta w_{i}(F-i j)$ declines as $\tau$ falls and $\Delta w_{i}(F-i j)=0$ obtains when $\tau=\widehat{\tau}(\lambda)$. As $\tau$ falls below $\widehat{\tau}(\lambda)$, we find that a pair of countries benefit if they can successfully exclude the third country from free 
trade network. Note from part (ii) of Lemma 3.1 that the exclusion incentive exists at the expense of the excluded country.

Using Lemma 3.1, we can show that the Nash equilibria of the FTA game are as follows:

Proposition 3.2 (Symmetry - Nash) : Suppose Assumption 3.1 holds. Then, the following announcement profiles are Nash equilibrium of the FTA game:

(i) $\Omega^{\varnothing} \equiv\left\{\sigma_{i}=\{\phi, \phi\}, \sigma_{j}=\{\phi, \phi\}, \sigma_{k}=\{\phi, \phi\}\right\}$ leading to $\varnothing$ for all $\tau$ and $\lambda$;

(ii) $\Omega^{i j} \equiv\left\{\sigma_{i}=\{j, \phi\}, \sigma_{j}=\{i, \phi\}, \sigma_{k}=\{\phi, \phi\}\right\}$ leading to $\langle i j\rangle$ for all $\tau$ and $\lambda$;

(iii) $\Omega^{F} \equiv\left\{\sigma_{i}=\{j, k\}, \sigma_{j}=\{i, k\}, \sigma_{k}=\{i, j\}\right\}$ leading to $\langle F\rangle$ for all $\tau$ and $\lambda$ while

(iv) $\Omega^{i h} \equiv\left\{\sigma_{i}=\{j, k\}, \sigma_{j}=\{i, \phi\}, \sigma_{k}=\{i, \phi\}\right\}$ leading to $\langle i h\rangle$ is a Nash equilibrium only when $\tau<\underline{\tau}(\lambda)$.

The logic behind Proposition 3.2 is as follows. It is straightforward that the announcement profile $\Omega^{\varnothing}$ is a Nash equilibrium since no country has an incentive to announce another's name if the latter does not announce its name in return. Next consider $\Omega^{i j}$. Note from part $(i)$ of Lemma 3.1 that neither member country ( $i$ or $j$ ) has an incentive to unilaterally change its announcement from that which it makes under $\Omega^{i j}$ since doing so only leads to no agreement $\varnothing$, under which its welfare is lower. Similarly, given that neither country $i$ nor country $k$ announces its name, country $k$ has no incentive to alter its announcement from $\sigma_{k}=\{\phi, \phi\}$ since doing so has no bearing on the resulting trade agreement. Thus, the announcement profile $\Omega^{i j}$ yielding a bilateral FTA is a Nash equilibrium.

Now consider the announcement profile $\Omega^{F}$ that yields global free trade $\langle F\rangle$. Parts $(i i)$ and (iii) of Lemma 3.1 together imply that a country (say $k$ ) has no incentive to unilaterally deviate from its announcement $\{i, j\}$ since doing so alters the trade regime from from $\langle F\rangle$ to $\langle i j\rangle$ or $\langle i h\rangle$ or $\langle j h\rangle$ under which it is worse off. Therefore, the announcement profile $\Omega^{F}$ that yields global free trade $\langle F\rangle$ is always a Nash equilibrium.

Finally, consider the announcement profile $\Omega^{i h}$ associated with the hub and spoke regime $\langle i h\rangle$. First note from part (iii) of Lemma 3.1 that, the hub country $i$ has no incentive to unilaterally change its announcement from $\{j, k\}$ to $\{j, \phi\}$ or $\{\phi, k\}$ or $\{\phi, \phi\}$ since doing so translates into a deviation from the hub and spoke regime $\langle i h\rangle$ where $i$ is the hub country to $\langle i j\rangle$ or $\langle i k\rangle$ or $\varnothing$ respectively. Now consider the unilateral incentive of a spoke country to deviate from $\Omega^{i h}$. Part $(i v)$ of Lemma 3.1 states that, only when $\tau>\underline{\tau}(\lambda)$ holds, either spoke country (say $j$ ) has an incentive to unilaterally deviate from its announcement $\{i, \phi\}$ to $\{\phi, \phi\}$ since this deviation translates into a deviation from $\langle i h\rangle$ where $j$ is a spoke country to $\langle i k\rangle$ where $j$ is a non-member country. As a result, when $\tau \leq \underline{\tau}(\lambda)$ holds, neither the hub nor the spokes have an incentive to unilaterally alter their announcements from $\Omega^{i h}$ so that hub and spoke regime $\langle i h\rangle$ is indeed supported by a announcement profile that constitutes a Nash equilibrium of the FTA game.

It is immediate to note from Proposition 3.2 that there is a unique announcement profile that supports each agreement as a Nash equilibrium and that the profile itself is the most 
parsimonious one. For example, even though $\left\{\sigma_{i}=\{\phi, j\}, \sigma_{j}=\{\phi, \phi\}, \sigma_{k}=\{\phi, \phi\}\right\}$ also maps to $\varnothing$, such an announcement profile does not constitute a Nash equilibrium. To see why, simply note that given these announcements, country $j$ has an incentive to alter its announcement from $\sigma_{j}=\{\phi, \phi\}$ to $\sigma_{j}=\{i, \phi\}$ in order to form the bilateral FTA $\langle i j\rangle$. Similarly, it is worth considering briefly as to why $\left\{\sigma_{i}=\{j, \phi\}, \sigma_{j}=\{i, \phi\}, \sigma_{k}=\{i, \phi\}\right\}$ is not a Nash equilibrium profile even though, just as the announcement profile $\Omega^{i j}$, its maps into the FTA $\langle i j\rangle$. Under this announcement profile, given the announcements of countries $j$ and $k$, as per part ( $i i i$ ) of Lemma 3.1, country $i$ has an incentive to alter its announcement to $\sigma_{i}=\{j, k\}$ so as to obtain the trade agreement $\langle i h\rangle$ under which it is the hub. Using analogous reasoning, we can rule out all other non-parsimonious announcements as candidates for Nash equilibria.

\subsubsection{Coalition Proof Nash Equilibria - Symmetry}

To deal with the multiplicity problem and to capture the process of FTA formation in a more realistic fashion, we refine the set of Nash equilibria by isolating those Nash equilibria that are coalition-proof. Following Bernheim et al. (1987): “... an agreement is coalitionproof if and only if it is Pareto efficient within the class of self-enforcing agreements. In turn, an agreement is self-enforcing if and only if no proper subset (coalition) of players, taking the actions of its complement as fixed, can agree to deviate in a way that makes all of its members better off." Therefore, a coalition proof Nash equilibrium (CPNE) is immune to all self-enforcing coalitional deviations.

Which, if any, of the Nash equilibrium announcement profiles described in Proposition 3.2 are CPNE? We begin by considering whether the announcement profile $\Omega^{F}$ that leads to global free trade $\langle F\rangle$ is a CPNE. Since world welfare is the highest under $\langle F\rangle$, each country prefers $\langle F\rangle$ to $\varnothing$ and thus we can immediately rule out any coalitional announcement deviations that would lead to a deviation from $\langle F\rangle$ to $\varnothing$. Similarly, we know from part (iii) of Lemma 3.1 that no two countries (say $j$ and $k$ ) have incentives to jointly alter their announcements from $\{i, k\}$ to $\{i, \phi\}$ and $\{i, j\}$ to $\{i, \phi\}$, respectively since doing so would lead to a deviation from $\langle F\rangle$ to $\langle i h\rangle$ where both are spokes (and spokes are worse of relative to free trade).

Finally, taking the announcement of their complement (country $k$ ) fixed, consider the joint deviation of two countries (say $i$ and $j$ ) from their announcements $\{j, k\}$ and $\{i, k\}$ to $\{j, \phi\}$ and $\{i, \phi\}$ respectively. This joint deviation implies a coalitional deviation from free trade $\langle F\rangle$ to a bilateral FTA $\langle i j\rangle$. From Proposition 3.2 we know that, taking the announcement of their complement (country $k$ ) fixed at $\sigma_{k}=\{i, j\}$, the above coalitional deviation in announcements would occur when $\tau<\bar{\tau}(\lambda)$ holds. The question then becomes whether this joint deviation is self-enforcing. The next proposition argues that it is not:

Proposition 3.1b (unexercised exclusion incentive) : Suppose Assumption 3.1 holds and $\tau<\widehat{\tau}(\lambda)$ holds. Then, even though a pair of countries benefit from excluding the third country from their own free trade network, the lure of becoming hub under a hub and spoke regime and the flexibility that FTA members have to pursue such an arrangement yield that such incentive goes unexercised in the equilibrium. 
The intuition behind the above proposition is as follows. When $\tau<\widehat{\tau}(\lambda)$ holds, two countries (say $i$ and $j$ ) have incentives to jointly deviate from their free trade announcements $\{j, k\}$ and $\{i, k\}$ to $\{j, \phi\}$ and $\{i, \phi\}$ respectively. Note that taking the announcement of the excluded country as given $\sigma_{k}=\{i, j\}$, we know from Lemma 3.1 part (iii) that country $i$ has an incentive to alter its announcement $\{j, \phi\}$ to $\{j, k\}$ further in order to create the trading regime $\langle i h\rangle$ where it becomes the hub. Similarly, country $j$ has an incentive to alter its announcement $\{i, \phi\}$ to $\{i, k\}$ so as to itself become the hub. Thus, the initial coalitional announcement deviations that can cause free trade $\langle F\rangle$ to be replaced by the bilateral FTA $\langle i j\rangle$ is not self-enforcing. The key message of this result is that even though a pair of countries benefit from excluding the third country from their trade agreement, they are unable to exercise this exclusion incentive in equilibrium.

The above discussion and propositions together imply that there exists no unilateral and self enforcing coalitional incentives to deviate from the announcement profile $\Omega^{F}$ and thus the following result obtains:

Proposition 3.3 (Symmetry-CPNE) : Suppose Assumption 3.1 holds. Then, the announcement profile leading to $\langle F\rangle$ is $C P N E$ for all $\tau$ and $\lambda$.

As in Saggi and Yildiz (2010), the above result implies that if global trade liberalization were to confer equal gains upon all countries (which is what happens when countries are completely symmetric), the pursuit of FTAs is compatible with the goal of achieving global free trade. Unlike Saggi and Yildiz (2010), we go one step further and obtain this result for all possible tariff bindings. The flexible nature of FTAs plays a crucial role in ensuring that the exclusion incentive goes unexercised in the FTA game: the lure of a hub and spoke trading arrangement ends up delivering free trade as a CPNE of the FTA game.

Next, we consider whether the announcement profiles that lead to the other agreements are CPNE. First, consider no agreement $\varnothing$. Note from Lemma 3.1 part $(i)$ that any two countries (say $i$ and $j$ ) have an incentive to coalitionally change their announcements from $\{\phi, \phi\}$ and $\{\phi, \phi\}$ to $\{j, \phi\}$ and $\{i, \phi\}$ respectively, taking country $k$ 's announcement fixed: $\sigma_{k}=\{\phi, \phi\}$. This initial deviation is self-enforcing since no proper subset of the initially deviating countries (neither $i$ nor $j$ ) has an incentive to alter its announcement unilaterally (i.e. announcement profile that leads to $\langle i j\rangle$ is a Nash equilibrium). Therefore, the announcement profile that leads to $\varnothing$ is not a CPNE.

Is the announcement profile that leads to a hub and spoke regime (say $\langle i h\rangle$ ) a CPNE? Note from part (iii) of Lemma 3.1 that countries $j$ and $k$ have an incentive to coalitionally change their announcements from $\{i, \phi\}$ and $\{i, \phi\}$ to $\{i, k\}$ and $\{i, j\}$ respectively, taking country $i$ 's announcement fixed at $\sigma_{i}=\{j, k\}$. This coalitional deviation would convert the hub and spoke regime $\langle i h\rangle$ to free trade $\langle F\rangle$. Furthermore, this initial coalitional deviation is self-enforcing since no proper subset of the initially deviating countries (neither $j$ nor $k$ ) has an incentive to further unilaterally deviate since $\langle F\rangle$ is a Nash equilibrium. Therefore, the announcement profile that leads to a hub and spoke regime is not a CPNE.

Finally, we examine whether the announcement profile that leads to a bilateral FTA $\langle i j\rangle$ is a CPNE. From parts $(i i i)$ and $(i v)$ of Lemma 3.1 we know that, taking country 
$j$ 's announcement fixed at $\sigma_{j}=\{i, \phi\}$, countries $i$ and $k$ have an incentive to coalitionally change their announcements from $\{j, \phi\}$ and $\{\phi, \phi\}$ to $\{j, k\}$ and $\{i, \phi\}$ respectively when $\tau<\underline{\tau}(\lambda)$ holds. This initial coalitional deviation would convert FTA $\langle i j\rangle$ to the hub and spoke regime $\langle i h\rangle$ where $i$ is the hub and $j$ and $k$ are spokes. Furthermore, when $\tau<\underline{\tau}(\lambda)$ holds, this initial coalitional deviation is self-enforcing since no proper subset of the initially deviating countries (neither $i$ nor $k$ ) has an incentive to unilaterally alter its announcement since the announcement profile that leads to $\langle i h\rangle$ is a Nash equilibrium. Moreover, all three countries have incentives to jointly deviate from their announcements $\Omega^{i j}$ to $\Omega^{F}$ when $\tau>\widehat{\tau}(\lambda)$ holds and this coalitional deviation is self enforcing since no proper subset of the initially deviating countries has an incentive to deviate further. Combining these two self enforcing deviations with part (iv) of Lemma 3.1, it is immediate that the announcement profile that leads to a bilateral FTA is a CPNE only when $\underline{\tau}(\lambda) \leq \tau \leq \widehat{\tau}(\lambda)$ holds and under such a case we have multiple CPNE and theory offers no guidance which of these equilibria would arise.

Given Proposition 3.3, it is natural to ask: under what circumstances, if any, free trade fails to be a CPNE? We show next that such a possibility arises (only) when countries are asymmetric with respect to their comparative advantage.

\subsection{Asymmetric Comparative Advantage}

From hereon, we drop the assumption that the degrees of comparative advantages are symmetric across countries. In what follows, the size of a country is measured by the degree of comparative advantage in the exporting sectors, translating directly into asymmetries of volume of exports. In other words, since the model is partial equilibrium in nature and lacks any income effects, an increase in a country's degree of comparative advantage in this model increases its exports of non-numéraire/protected goods. Since import demand functions are symmetric, the larger the comparative advantage of the other countries in their exporting goods, the larger the import volume of a country. Thus, the smaller exporting countries are also the larger importing countries. It is worth emphasizing that in our model no country is a price taker on world markets - in fact each country is the unique importer of a single good and therefore has market power that it can exploit via an external tariff.

How does the asymmetry affect the preferences of countries for trade agreement formation?

\subsubsection{Two larger one smaller exporters}

To highlight the role played by asymmetric comparative advantage, it proves instructive to consider a scenario where two countries ('larger' exporting countries denoted by $l$ and $\left.l^{\prime}\right)$ have higher degrees of comparative advantages in their exporting sectors than the third 
(denoted by $s$; refereed to as the 'smaller' exporting country). ${ }^{6}$ Accordingly, let the pattern of asymmetry be given by: ${ }^{7}$

\section{Assumption 3.2}

$$
\underline{\lambda} \leq \lambda_{s}<\lambda_{l}=\lambda_{l^{\prime}}=\lambda
$$

(Asymmetry I)

Here it is important to note from (2.13) that, in order to guarantee non-negative tariffs, we assume that the degree of asymmetry is not very large: $\lambda_{s} \geq \underline{\lambda}=\sqrt{\lambda^{2}+8 \lambda+25}-5$.

The following lemma informs us how the incentive of a larger exporting country to form an FTA depends on the degree of comparative advantage of the smaller trading partner:

Lemma 3.2 Let country $s$ be an FTA partner of country $l$ under regime $r$ but not under regime $v$. Then, the following holds: $\frac{\partial \Delta w_{l}(r-v)}{\partial \lambda_{s}}<0$.

The intuition underlying the inequality $\frac{\partial \Delta w_{l}(r-v)}{\partial \lambda_{s}}<0$ is as follows. The weaker the comparative advantage of a smaller exporting country, the larger the increase in the export surplus of larger importing country as an FTA partner from the elimination of its smaller partner's optimal tariff and the smaller the loss due to its own trade liberalization since the tariff reduction applies to a smaller volume of imports (due to the smaller export capacity of its partner). This immediately implies that a larger exporting country prefers to form a bilateral FTA with the smaller of its two trading partners:

$$
w_{l}(s l) \geq w_{l}\left(l l^{\prime}\right)
$$

From hereon, let $\lambda_{i}(r-v)$ denotes the critical degree of comparative advantage of country $s$ at which country $i$ is indifferent between regimes $r$ and $v$.

\subsubsection{Different Tariff Binding Scenarios - Asymmetry I}

The optimal tariffs reported in Chapter 2 (Section 2.2) combined with Assumption 3.2 leads to the following ranking of the optimal tariffs under all feasible trade regimes, assuming that bound tariff rates do not bind: ${ }^{8}$

$$
t_{s}(\varnothing)>t_{l}(\varnothing)>t_{l l^{\prime}}(s l)>t_{s l^{\prime}}(s l)>t_{l s}\left(l l^{\prime}\right)>0
$$

As before, let $\tau$ denote the bound tariff rate. Given the above ranking, "no tariff binding" and "full tariff binding" scenarios are similar to the one under complete symmetry while the partial tariff binding scenario has four distinct sub-scenarios as illustrated in Figure 3.2:

\footnotetext{
${ }^{6}$ As noted earlier, in our model no country is 'small' in the traditional sense since all three can influence their terms of trade. Hence we use the word 'smaller' as opposed to 'small'.

${ }^{7}$ In the next section, we show that our results extend to the case where there are two smaller and one larger exporters.

${ }^{8}$ Note that, due to market segmentation, the following holds: $t_{s}(\varnothing)=t_{s l}\left(l l^{\prime}\right) ; t_{l}(\varnothing)=t_{l s}\left(s l^{\prime}\right) ; t_{l l^{\prime}}(s l)=$ $t_{l l^{\prime}}(s h) ; t_{s l^{\prime}}(s l)=t_{s l^{\prime}}(l h)$ and $t_{l s}\left(l l^{\prime}\right)=t_{l s}\left(l^{\prime} h\right)$.
} 
(i) no tariff binding scenario arises when $\tau>t_{s}(\varnothing)$ holds. Under such a case, all countries are free to impose their optimal tariffs under all feasible trade regimes (tariff binding overhang under all regimes).

(ii) partial tariff binding scenario

- $t_{l}(\varnothing)<\tau<t_{s}(\varnothing)$ : except for country $s$ under $\varnothing$ and as a non-member under the bilateral FTA $\left\langle l l^{\prime}\right\rangle$, countries are free to impose their optimal tariffs under all feasible trade regimes. Country $s$ under $\varnothing$ and $\left\langle l l^{\prime}\right\rangle$ is constrained to impose $\tau$.

- $t_{l l^{\prime}}(s l)<\tau<t_{l}(\varnothing)$ : countries under $\varnothing$ (and non-member countries under a bilateral FTA) are constrained to impose the tariff bindings while FTA member countries are free to impose their optimal tariffs.

- $t_{s l^{\prime}}(s l)<\tau<t_{l l^{\prime}}(s l)$ : countries under $\varnothing$ (and non-member countries under a bilateral FTA) and larger member country under $\langle s l\rangle$ or $\left\langle s l^{\prime}\right\rangle$ (and as a spoke under $\langle s h\rangle)$ are constrained to impose their tariff bindings while the other FTA member countries are free to impose their optimal tariffs.

- $t_{l s}\left(l l^{\prime}\right)<\tau<t_{s l^{\prime}}(s l)$ : except for the member countries under $\left\langle l l^{\prime}\right\rangle$ (and larger spoke country under $\langle l h\rangle)$, countries are constrained to impose their tariff bindings.

(iii) full tariff binding scenario arises when $\tau<t_{l s}\left(l l^{\prime}\right)$ holds. Under this scenario, all countries lose their freedom to impose optimal tariffs under the entire set of trade regimes and they are required to apply their tariff bindings.

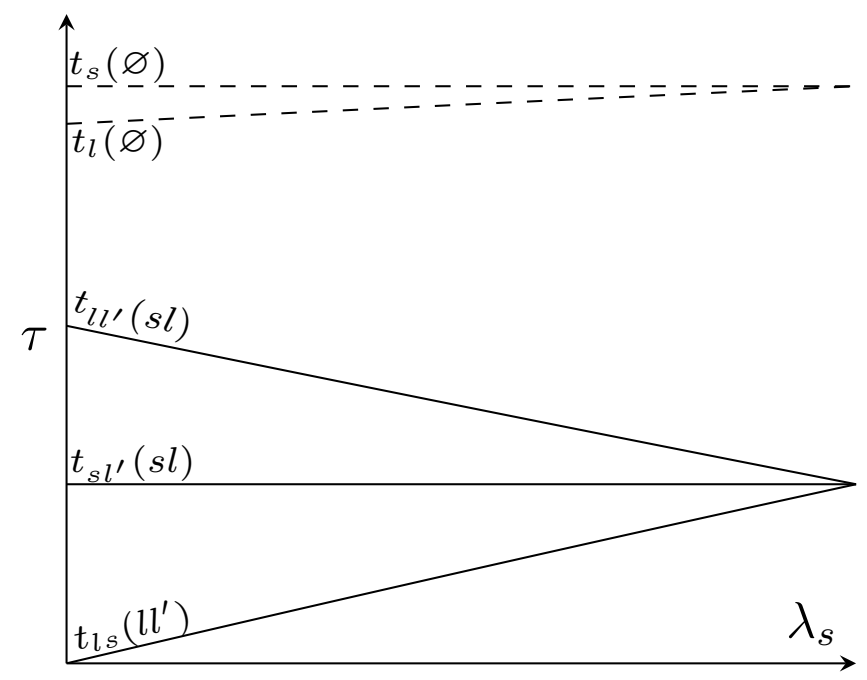

Figure 3.2: FTA tariff schedule - Asymmetry I 


\subsubsection{Preferences for FTAs under Asymmetry I}

To avoid redundancy, we focus directly on free trade and examine when free trade is a CPNE under the scenario with asymmetric comparative advantage. To this end, we first state the following lemma that is useful in deriving the CPNE condition for free trade:

Lemma 3.3 Suppose that Assumption 3.2 holds. Then, we have

(i) $\Delta w_{l}(s l-\varnothing)>0 ; \Delta w_{l}(F-\varnothing)>0 ; \Delta w_{l}\left(F-s l^{\prime}\right)>0 ; \Delta w_{l}(F-s h)>0$ and $\Delta w_{l}\left(F-l^{\prime} h\right)>0$ for all $\tau, \lambda$ and $\lambda_{s}$ and

(ii) $\Delta w_{l}\left(l h-l l^{\prime}\right)>0$ and $\Delta w_{s}(s h-s l)>0$ for all $\tau, \lambda$ and $\lambda_{s}$.

The first part of the above lemma is an extension Lemma 3.1 into an asymmetric setting for large countries. Note that since $\Delta w_{l}\left(F-s l^{\prime}\right)>0 ; \Delta w_{l}(F-s h)>0$ and $\Delta w_{l}\left(F-l^{\prime} h\right)>0$ for all $\tau, \lambda$ and $\lambda_{s}$, a larger exporting country has no incentive to unilaterally deviate from its announcement that leads to free trade.

Lemma 3.3 implies that the only announcement deviation a larger exporting country (say $l$ ) would participate is the joint deviation with the other larger exporting country (country $l^{\prime}$ ) or with the smaller exporting country (country $s$ ) from their announcements that lead to free trade to announcements that lead to a bilateral FTA between each other.

However, even when such incentives exist, it is immediate from part (ii) of the above Lemma that they are not self-enforcing since $\Delta w_{l}\left(l h-l l^{\prime}\right)>0$ and $\Delta w_{s}(s h-s l)>0$ always hold. To see it more clearly, taking the announcement of country $s$ as given, consider the joint deviation of two larger exporting countries from their respective announcements $\sigma_{l}=\left\{s, l^{\prime}\right\}$ and $\sigma_{l^{\prime}}=\{s, l\}$ to $\sigma_{l}=\left\{\phi, l^{\prime}\right\}$ and $\sigma_{l^{\prime}}=\{\phi, l\}$ leading to deviation from $\langle F\rangle$ to $\left\langle l l^{\prime}\right\rangle$. Such deviation happens only when $\lambda_{s}>\lambda_{l}\left(F-l l^{\prime}\right)$. In other words, two larger exporting countries have incentives to jointly exclude the small exporting country only when the degree of comparative advantage asymmetry is sufficiently small. However, since $\Delta w_{l}\left(l h-l l^{\prime}\right)>0$ always holds, taking the announcement of country $s$ as given: $\sigma_{s}=\left\{l, l^{\prime}\right\}$, either of the initially deviating larger exporting countries (say country $l$ ) has incentive to further deviate from $\sigma_{l}=\left\{\phi, l^{\prime}\right\}$ to $\sigma_{l}=\left\{s, l^{\prime}\right\}$ to become the hub country under $\langle l h\rangle$. As a result, the initial announcement deviation is not self enforcing. Similarly, since $\Delta w_{s}(s h-s l)>0$ always holds as well, the same logic applies for the coalitional announcement deviations of country $s$ and one of the larger exporting countries to exclude the other larger exporting country. Even when such deviation occurs, it is not a selfenforcing one since country $s$ has an incentive to further deviate to become a hub country. Then, the following result is an immediate extension of Propositions 3.1a and 3.1b into the asymmetric setting:

Proposition 3.4 (exclusion incentive - asymmetry) : Suppose Assumption 3.2 holds. While exclusion incentives arise, the flexibility that FTA members have in forming an additional FTA yields that such incentive goes unexercised in the equilibrium. 
Lemma 3.3 and Proposition 3.4 together imply that there exists no self-enforcing coalitional deviation in which a larger exporting country is involved. As a result, the unilateral announcement deviation of the smaller country from $\Omega^{F}$ is pivotal for $\Omega^{F}$ for being a CPNE. Thus, we have to consider the following two unilateral deviations of country $s$ :

(i) unilateral announcement deviation of country $s$ from $\sigma_{s}=\left\{l, l^{\prime}\right\}$ to $\sigma_{s}=\{l, \phi\}$ (or $\left.\sigma_{s}=\left\{\phi, l^{\prime}\right\}\right)$ leading to deviation from $\langle F\rangle$ to $\langle l h\rangle$ (or $\left.\left\langle l^{\prime} h\right\rangle\right)$.

(ii) unilateral announcement deviation of country $s$ from $\sigma_{s}=\left\{l, l^{\prime}\right\}$ to $\sigma_{s}=\{\phi, \phi\}$ leading to deviation from $\langle F\rangle$ to $\left\langle l l^{\prime}\right\rangle$.

Consider the unilateral deviation (i) first. We know from our previous discussion that, when countries are completely symmetric, no country has an incentive to unilaterally deviate irrespective of the bound tariff rates. However, the asymmetry in comparative advantages leads to asymmetric preferences for trade liberalization. We can easily show that, due to the smaller volume of its exports, country $s$ benefits less from tariff reductions granted by a larger exporting country and it loses relatively more from eliminating its own optimal tariff since it applies to relatively larger import volumes and thus we can show that $\frac{\partial \Delta w_{s}(F-l h)}{\partial \lambda_{s}}>0$ always holds. We find that there exists a critical threshold degree of asymmetry beyond which country $s$ has an incentive to unilaterally deviate from its free trade announcement $\sigma_{s}=\left\{l, l^{\prime}\right\}$ to $\sigma_{s}=\{l, \phi\}$ (or $\sigma_{s}=\left\{\phi, l^{\prime}\right\}$ ) leading to deviation from $\langle F\rangle$ to $\langle l h\rangle\left(\right.$ or $\left.\left\langle l^{\prime} h\right\rangle\right)$ :

$$
\Delta w_{s}(F-l h)<0 \text { when } \lambda_{s}<\lambda_{s}(F-l h) \text { where } \frac{\partial \lambda_{s}(F-l h)}{\partial \tau}>0
$$

The above result argues that the incentive of country $s$ to unilaterally deviate from $\sigma_{s}=\left\{l, l^{\prime}\right\}$ to $\sigma_{s}=\{l, \phi\}$ (or $\sigma_{s}=\left\{\phi, l^{\prime}\right\}$ ) gets weaker with the reduction in tariff binding.

Now, consider the unilateral deviation (ii). First, we should note that a similar intuitive discussion applies as above and we find that, when country $s$ is sufficiently smaller exporter, the benefit from being able to impose import tariffs dominates the benefit from free market access and thus it has an incentive to unilaterally deviate from its free trade announcement $\sigma_{s}=\left\{l, l^{\prime}\right\}$ to $\sigma_{s}=\{\phi, \phi\}$ leading to deviation from $\langle F\rangle$ to $\left\langle l l^{\prime}\right\rangle$ :

$$
\Delta w_{s}\left(F-l l^{\prime}\right)<0 \text { when } \lambda_{s}<\lambda_{s}\left(F-l l^{\prime}\right) \text { where } \frac{\partial \lambda_{s}\left(F-l l^{\prime}\right)}{\partial \tau}>0
$$

Two observations leads to our main result: (i) $\lambda_{s}\left(F-l l^{\prime}\right)>\lambda_{s}(F-l h)$ and thus the incentive of country $s$ to unilaterally deviate from $\sigma_{s}=\left\{l, l^{\prime}\right\}$ to $\sigma_{s}=\{\phi, \phi\}$ leading to deviation from $\langle F\rangle$ to $\left\langle l l^{\prime}\right\rangle$ determines the CPNE condition for $\langle F\rangle$ and (ii) since $\frac{\partial \lambda_{s}\left(F-l l^{\prime}\right)}{\partial \tau}>$ 0 , the incentive of country $s$ to unilaterally deviate from free trade announcement and free ride under $\left\langle l l^{\prime}\right\rangle$ gets weaker with the reduction in tariff binding. We can now state our main result that is illustrated in Figure 3.3:

Proposition 3.5 (free riding incentive - asymmetry) : Suppose Assumption 3.2 holds. Then, $\Omega^{F} \equiv\left\{\sigma_{s}=\left\{l, l^{\prime}\right\}, \sigma_{l}=\left\{s, l^{\prime}\right\}, \sigma_{l^{\prime}}=\{s, l\}\right\}$ leading to $\langle F\rangle$ is CPNE only when $\lambda_{s} \geq \lambda_{s}\left(F-l l^{\prime}\right)$ and it is more likely to be a CPNE as the tariff bindings decline. 


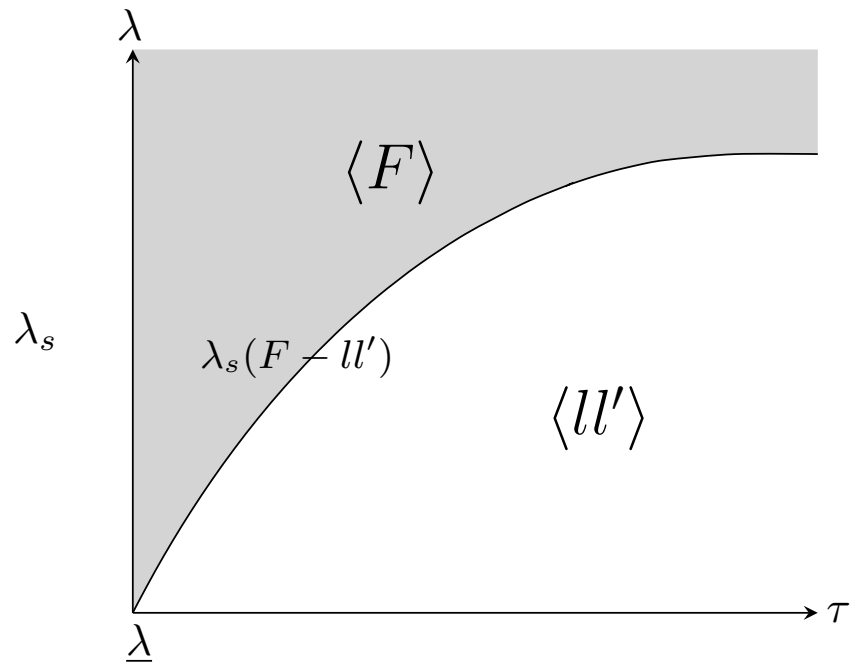

Figure 3.3: Free Trade is CPNE - Asymmetry I

Based on the above discussion, continual reduction in tariff binding disciplines the ability of the smaller exporting (and thus larger importing) country in imposing external tariffs and thus weakens its incentive to free ride on trade liberalization by the larger exporting countries. Since FTA formation is flexible in signing independent FTAs and exclusion incentives go unexercised, it is the free riding incentive that determines the CPNE condition for multilateral free trade. The above finding suggests that multilateral free trade is more likely to be a CPNE as the tariff binding declines. Therefore, this result provides support for the idea that continual reduction in tariff binding facilitates the FTA formation in attaining global free trade.

Next, we examine the following question: what if $\lambda_{s}<\lambda_{s}\left(F-l l^{\prime}\right)$ and global free trade fails to obtain? First, consider no agreement $\varnothing$. Since $\Delta w_{l}\left(l l^{\prime}-\varnothing\right)>0$ for all $\tau, \lambda$ and $\lambda_{s}$, two larger exporting countries $\left(l\right.$ and $\left.l^{\prime}\right)$ have an incentive to coalitionally change their announcements from $\{\phi, \phi\}$ and $\{\phi, \phi\}$ to $\left\{\phi, l^{\prime}\right\}$ and $\{\phi, l\}$ respectively, taking country $s^{\prime} s$ announcement fixed: $\sigma_{s}=\{\phi, \phi\}$. This initial deviation is self-enforcing since no proper subset of the initially deviating countries (neither $l$ nor $l^{\prime}$ ) has an incentive to alter its announcement unilaterally (i.e. announcement profile that leads to $\left\langle l l^{\prime}\right\rangle$ is always a Nash equilibrium). Therefore, the announcement profile that leads to $\varnothing$ is not a CPNE. We next examine whether announcement profile that leads to a $\langle s h\rangle$ is a CPNE. Note from Lemma 3.3 part $(i)$ that $\Delta w_{l}(F-s h)>0$ for all $\tau, \lambda$ and $\lambda_{s}$ and thus countries $l$ and $l^{\prime}$ have an incentive to coalitionally change their announcements from $\{s, \phi\}$ and $\{s, \phi\}$ to $\left\{s, l^{\prime}\right\}$ and $\{s, l\}$ respectively, taking country $s^{\prime}$ s announcement fixed at $\sigma_{s}=\left\{l, l^{\prime}\right\}$. This coalitional deviation would convert the hub and spoke regime $\langle s h\rangle$ to free trade $\langle F\rangle$ and it is a self-enforcing deviation since a larger exporting country has no incentive to unilaterally deviate from its announcement that leads to free trade as established in Lemma 3.3. 
Now consider the announcement profile that leads to a $\langle l h\rangle$. Note first that we already established the following above: $\lambda_{s}\left(F-l l^{\prime}\right)>\lambda_{s}(F-l h)$ for all $\tau$ and $\lambda$, and thus the unilateral deviation incentive of country $s$ under $\Omega^{F}$ from $\sigma_{s}=\left\{l, l^{\prime}\right\}$ to $\sigma_{s}=\{\phi, \phi\}$ leading to deviation from $\langle F\rangle$ to $\left\langle l l^{\prime}\right\rangle$ is stronger than the the unilateral deviation incentive of country $s$ from $\sigma_{s}=\left\{l, l^{\prime}\right\}$ to $\sigma_{s}=\{l, \phi\}$, leading to deviation from $\langle F\rangle$ to $\langle l h\rangle$. This immediately implies that, when $\lambda_{s}<\lambda_{s}\left(F-l l^{\prime}\right)$ holds, country $s$ under $\Omega^{\text {lh }}$ always has an incentive to unilaterally deviate from from $\{l, \phi\}$ to $\{\phi, \phi\}$ converting $\langle l h\rangle$ to $\left\langle l l^{\prime}\right\rangle$ and thus $\langle l h\rangle$ is not even a Nash equilibrium (therefore not a CPNE).

Finally, we examine whether the announcement profiles that lead to a bilateral FTAs are CPNE when $\lambda_{s}<\lambda_{s}\left(F-l l^{\prime}\right)$. First consider the announcement profile $\Omega^{l l^{\prime}}$. We have established above that $\Delta w_{l}\left(l l^{\prime}-\varnothing\right)>0$ for all $\tau, \lambda$ and $\lambda_{s}$ and thus $\Omega^{l l^{\prime}}$ is always a Nash equilibrium. When $\lambda_{s}<\lambda_{s}\left(F-l l^{\prime}\right)$ holds, small country has no incentive to participate in the coalitional announcement deviation converting $\left\langle l l^{\prime}\right\rangle$ into $\langle F\rangle$. Moreover, as we discussed above, country $s$ under $\Omega^{l l^{\prime}}$ has no incentive to jointly deviate with country $l$ from their respective announcements $\{\phi, \phi\}$ and $\left\{\phi, l^{\prime}\right\}$ to $\{l, \phi\}$ and $\left\{s, l^{\prime}\right\}$ leading to a deviation from $\left\langle l l^{\prime}\right\rangle$ to $\langle l h\rangle$. Finally note from Lemma 3 that even when coalitional deviations leading to deviation from $\left\langle l l^{\prime}\right\rangle$ to $\langle s l\rangle$ and $\left\langle l l^{\prime}\right\rangle$ to $\langle s h\rangle$ occur, they are not self-enforcing since a proper subset of initially deviating countries has incentive to further deviate. As a result, when free trade fails to a CPNE (when $\lambda_{s}<\lambda_{s}\left(F-l l^{\prime}\right)$ ), $\Omega^{l l^{\prime}}$ arises as a CPNE. We conclude our discussion with the discussion of whether $\Omega^{s l}$ is a CPNE. It turns out to be that the critical deviation under $\Omega^{s l}$ is the joint announcement deviation of countries $s$ and $l^{\prime}$ from their respective announcements $\{l, \phi\}$ and $\{\phi, \phi\}$ to $\left\{l, l^{\prime}\right\}$ and $\{s, \phi\}$ converting $\langle s l\rangle$ into $\langle s h\rangle$. We know from part (ii) of Lemma 3.3 that country $s$ always has an incentive to participate in such a coalitional deviation while country $l^{\prime}$ does so only when $\lambda_{s}<\lambda_{l^{\prime}}(s h-s l)$. This joint announcement deviation is self-enforcing since neither $s$ nor $l^{\prime}$ has an incentive to further deviate taking the announcement of complements as given. When $\lambda_{l^{\prime}}(s h-s l)<\lambda_{s}<\lambda_{s}\left(F-l l^{\prime}\right)$ holds, there exists no other self-enforcing deviation from $\Omega^{s l}$ and thus it is a CPNE. Based on the above discussion, the following result is immediate:

Proposition 3.6 : Suppose Assumption 3.2 holds and $\lambda_{s}<\lambda_{s}\left(F-l l^{\prime}\right)$. Then, the following result holds:

(i) $\Omega^{l l^{\prime}} \equiv\left\{\sigma_{s}=\{\phi, \phi\}, \sigma_{l}=\left\{\phi, l^{\prime}\right\}, \sigma_{l^{\prime}}=\{\phi, l\}\right\}$ leading to $\left\langle l l^{\prime}\right\rangle$ is always CPNE while

(ii) announcement profiles leading to any bilateral FTA is CPNE when $\lambda_{l^{\prime}}(s h-s l) \leq$ $\lambda_{s} \leq \lambda_{s}\left(F-l l^{\prime}\right)$.

The above proposition and Figure 3.4 imply that when the degree of asymmetry in comparative advantage is sufficiently large and free trade fails to be a CPNE, bilateral FTAs emerge in the equilibrium while hub and spoke regimes never arise. An asymmetric FTA $\langle s l\rangle$ is a CPNE only when the degree of asymmetry is moderate and the bound tariff rates are sufficiently high. When the degree of asymmetry rises and/or the bound tariff rates fall sufficiently, the unique CPNE is the FTA between two larger exporters. Here, it is important to emphasize that exclusion incentive does not play any role in the equilibrium 


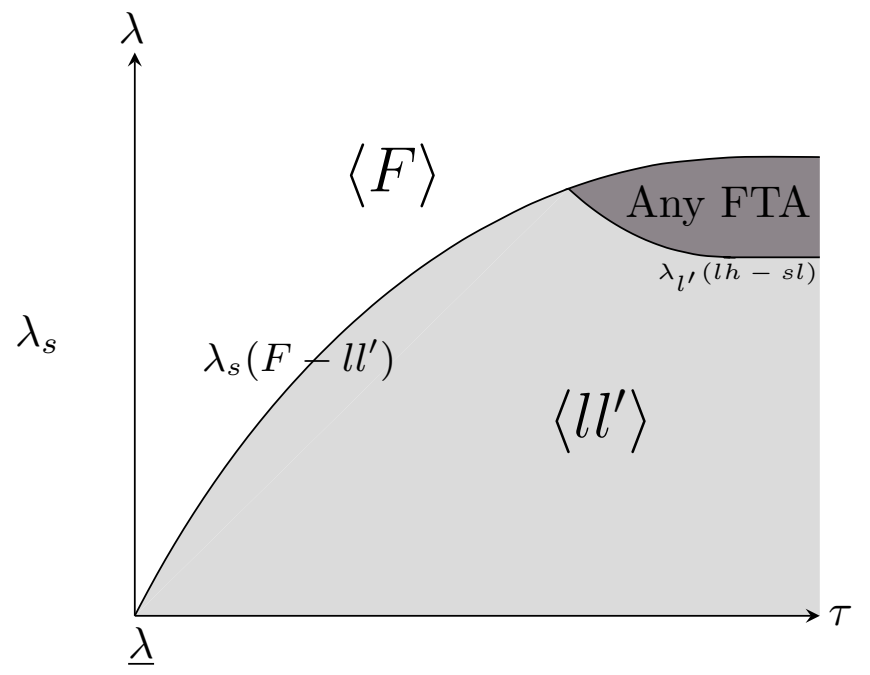

Figure 3.4: Bilateral FTAs are CPNE - Asymmetry I

and thus we can not interpret these trade agreements as "gated globalization" as in Lake and Roy (2017). Another important takeaway from the above result is that, unlike Freund (2000), bilateral FTAs become less likely to be a CPNE as the tariff bindings decline. As explained in detail before, the endogeneity in FTA formation and the flexibility of forming independent FTAs were absent in Freund (2000) and this creates the divergence in the results.

Next, we show that our main result continues to hold under different structure of asymmetry.

\subsubsection{Two smaller one larger exporters}

Consider now the case where two countries ('smaller' exporting countries denoted by $s$ and $s^{\prime}$ ) have lower degrees of comparative advantages in their exporting sectors than the third (denoted by l; refereed to as the 'larger' exporting country). Accordingly, let the pattern of asymmetry be given by:

\section{Assumption 3.3}

$$
\underline{\lambda} \leq \lambda_{s}=\lambda_{s^{\prime}}<\lambda_{l}=\lambda
$$

\subsubsection{Different Tariff Binding Scenarios - Asymmetry II}

Assuming that tariff bindings are sufficiently lax so that they do not bind, the optimal tariff ranking under Assumption 3.3 is as follows

$$
t_{s}(\varnothing)>t_{l}(\varnothing)>t_{s l}\left(s s^{\prime}\right)>t_{l s^{\prime}}(s l)>t_{s s^{\prime}}(s l)>0
$$


Thus, as before, we have four distinct sub-scenarios as illustrated in Figure 3.5:

(i) no tariff binding scenario arises when $\tau>t_{s}(\varnothing)$ holds. Under such a case, all countries are free to impose their optimal tariffs under all feasible trade regimes.

(ii) partial tariff binding scenario:

- $t_{l}(\varnothing)<\tau<t_{s}(\varnothing)$ : except for country $s$ under $\varnothing$ and as a non-member under the bilateral FTA $\left\langle s^{\prime} l\right\rangle$, countries are free to impose their optimal tariffs under all feasible trade regimes. Country $s$ under $\varnothing$ and $\left\langle s^{\prime} l\right\rangle$ is constrained to impose the tariff binding $\tau$.

- $t_{s l}\left(s s^{\prime}\right)<\tau<t_{l}(\varnothing)$ : countries under $\varnothing$ (and non-member countries under a bilateral FTA) are constrained to impose $\tau$ while FTA member countries are free to impose their optimal tariffs.

- $t_{l s^{\prime}}(s l)<\tau<t_{s l}\left(s s^{\prime}\right)$ : countries under $\varnothing$ (and non-member countries under a bilateral FTA) and smaller member countries under $\left\langle s s^{\prime}\right\rangle$ (and as a spoke under $\langle s h\rangle$ or $\left.\left\langle s^{\prime} h\right\rangle\right)$ are constrained to impose $\tau$ while the member countries under the FTA between larger and smaller countries, i.e. $\langle s l\rangle$ and $\left\langle s^{\prime} l\right\rangle$, are free to impose their optimal tariffs.

- $t_{s s^{\prime}}(s l)<\tau<t_{l s^{\prime}}(s l)$ : except for the smaller member country under $\langle s l\rangle$ and $\left\langle s^{\prime} l\right\rangle$ (and smaller spoke country under $\langle l h\rangle$ ), countries are constrained to impose $\tau$.

(iii) full tariff binding scenario arises when $\tau<t_{s}(s l)$ holds. Under this scenario, all countries lose their freedom to impose optimal tariffs under the entire set of trade agreements and they are required to apply $\tau$.

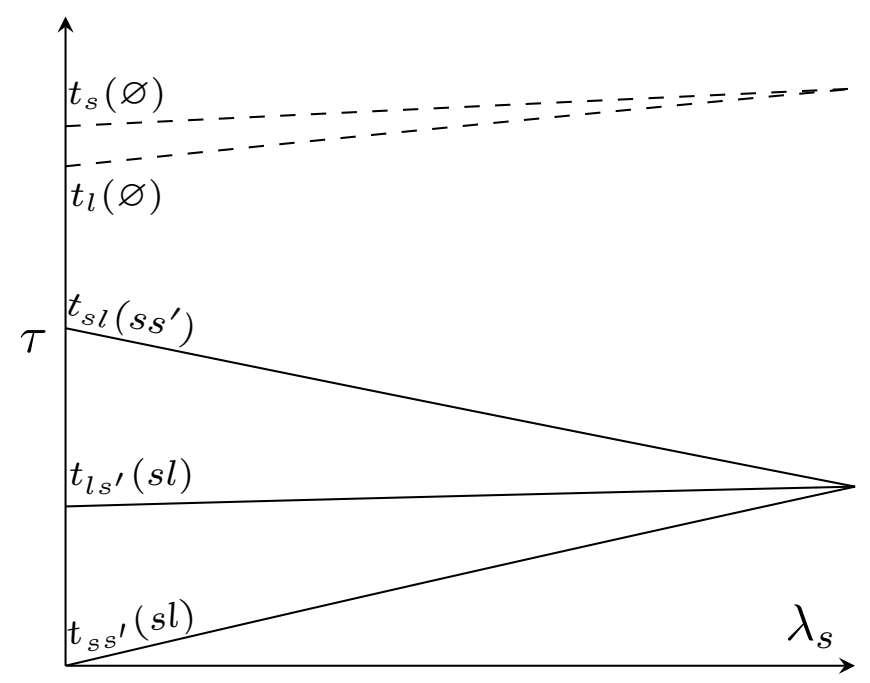

Figure 3.5: FTA tariff schedule - Asymmetry II 


\subsubsection{Preferences for FTAs under Asymmetry II}

To save space, we directly move to the following lemma that proves to be useful in deriving when free trade is a CPNE:

Lemma 3.4 Suppose that Assumption 3.3 holds. Then, we have Suppose that Assumption holds. Then, we have

(i) $\Delta w_{i}(i j-\varnothing)>0, i, j=s, s^{\prime}, l$ for all $\tau, \lambda$ and $\lambda_{s}$;

(ii) $w_{i}(i h)>\max \left\{w_{i}(F), w_{i}(i j), w_{i}(\varnothing)\right\}, i, j=s, s^{\prime}, l$ and $\Delta w_{s}(F-l h)=\Delta w_{s^{\prime}}(F-l h)>$ 0 for all $\tau, \lambda$ and $\lambda_{s}$;

(iii) $\Delta w_{l}(F-s h)=\Delta w_{l}\left(F-s^{\prime} h\right)>0$ for all $\tau, \lambda$ and $\lambda_{s}$ while $\Delta w_{s}\left(F-s^{\prime} h\right)=$ $\Delta w_{s^{\prime}}(F-s h)>0$ only when $\lambda_{s}>\lambda_{s}\left(F-s^{\prime} h\right)$;

(iv) $\Delta w_{l}\left(F-s s^{\prime}\right)>0$ for all $\tau, \lambda$ and $\lambda_{s}$ while $\Delta w_{s}\left(F-s^{\prime} l\right)=\Delta w_{s^{\prime}}(F-s l)>0$ only when $\lambda_{s}>\lambda_{s}\left(F-s^{\prime} l\right)$ and

(v) $\lambda_{s}\left(F-s^{\prime} l\right)>\lambda_{s}\left(F-s^{\prime} h\right)$ for all $\tau$ and $\lambda$.

It is immediate from the parts (iii) and (iv) of the above lemma that the larger exporting country has no incentive to unilaterally deviate from its announcement that leads to free trade. Focusing on the coalitional deviations from the announcement profile leading to global free trade, the first and second part of Lemma 3.4 implies that, even when two countries have incentives to jointly deviate, such coalitional deviation is never self-enforcing. To see it more clearly, taking the announcement of country $l$ as given, consider the joint deviation of two smaller exporting countries from their respective announcements $\sigma_{s}=$ $\left\{s^{\prime}, l\right\}$ and $\sigma_{s^{\prime}}=\{s, l\}$ to $\sigma_{s}=\left\{s^{\prime}, \phi\right\}$ and $\sigma_{s^{\prime}}=\{s, \phi\}$ leading to deviation from $\langle F\rangle$ to $\left\langle s s^{\prime}\right\rangle$. Such deviation happens only when $\lambda_{s}>\lambda_{s}\left(F-s s^{\prime}\right)$.

However, the second part of Lemma 3.4 informs us that, taking the announcement of country $l$ as given: $\sigma_{l}=\left\{s, s^{\prime}\right\}$, either of the initially deviating smaller exporting countries (say $s$ ) has an incentive to further deviate from $\sigma_{s}=\left\{s^{\prime}, \phi\right\}$ to $\sigma_{s}=\left\{s^{\prime}, l\right\}$ to become the hub country under $\langle s h\rangle$. The similar intuition applies for the coalitional deviation of one of the smaller exporting countries and the larger exporting country to exclude the other smaller exporting country. Either of the initially deviating countries has incentive to further deviate, making the initial deviation not self-enforcing. ${ }^{9}$ Therefore, we restate our previous finding: although exclusion incentives exist when tariff bindings are sufficiently tight, the flexibility that FTA members have in forming an additional FTA yields that such incentive goes unexercised in the equilibrium.

The above discussion together with part (v) of Lemma 3.4 informs us that, as before, the unilateral announcement deviation of a smaller exporting country (say $s$ ) from $\sigma_{s}=\left\{s^{\prime}, l\right\}$ to $\sigma_{s}=\{\phi, \phi\}$ leading to deviation from $\langle F\rangle$ to $\left\langle s^{\prime} l\right\rangle$ determines whether $\Omega^{F}$ is a CPNE:

\footnotetext{
${ }^{9}$ Two smaller countries can have incentives to coalitionally deviate from their free trade announcements to announcements leading to no agreement. This coalitional deviation is not self-enforcing as well due to part (i) of Lemma 3.4.
} 
Proposition 3.7 : Suppose Assumption 3.3 holds. Then, $\Omega^{F} \equiv\left\{\sigma_{s}=\left\{l, l^{\prime}\right\}, \sigma_{l}=\left\{s, l^{\prime}\right\}, \sigma_{l^{\prime}}=\{s, l\}\right\}$ leading to $\langle F\rangle$ is CPNE only when $\lambda_{s}>\lambda_{s}\left(F-s^{\prime} l\right)$ and it is more likely to be a CPNE as the tariff bindings decline.

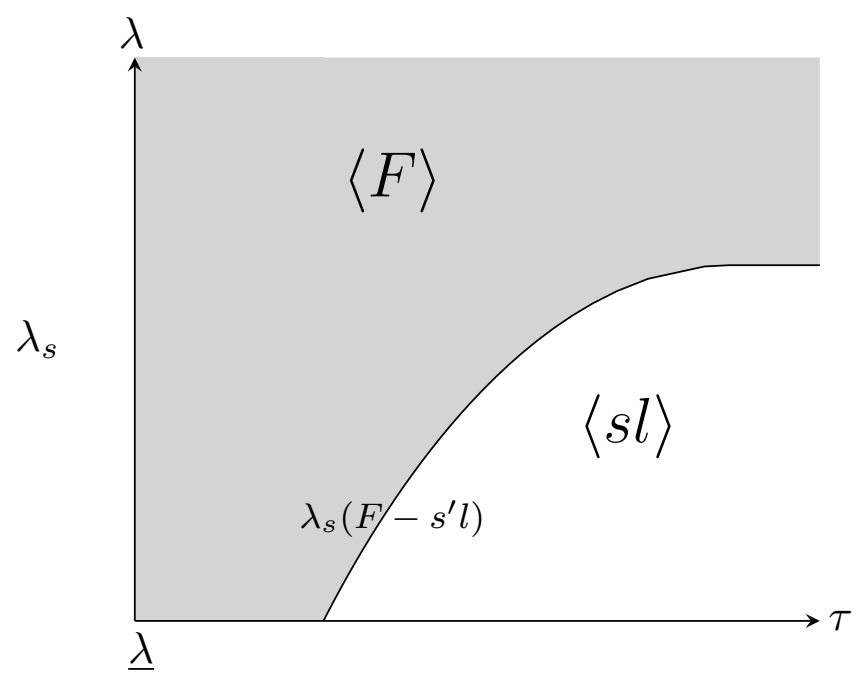

Figure 3.6: Free Trade is CPNE - Asymmetry II

The above result, represented in Figure 3.6, argues that our main finding is robust to the structure of asymmetry: free riding incentive of smaller exporting countries is pivotal for free trade to arise in the equilibrium while exclusion incentives go unexercised. With the continual reduction in tariff bindings, free riding incentives fall and global free trade becomes more likely to be a CPNE. ${ }^{10}$

So far, our findings suggest that, due to the flexibility of FTA formation, exclusion incentives go unexercised in the equilibrium. What if the preferential trade agreement is a customs union rather than an FTA and hub and spoke regimes are not feasible? Next, we examine this question under complete symmetry to shed light on the implications of common external tariff requirement of CU.

\subsection{Customs Union}

Suppose the PTA under consideration is a CU as opposed to an FTA and countries are symmetric with respect to their comparative advantage (Assumption 3.1 holds). To have a comparable result and figure to the ones under the FTA game, we assume that $\lambda \leq \frac{1}{2}{ }^{11}$

\footnotetext{
${ }^{10}$ What if $\lambda_{s}\left(F-s^{\prime} l\right)$ and global free trade fails to obtain? Under such a case, we find that the announcement profile leading to a bilateral FTA between a smaller exporting country and the larger exporting country $\left(\langle s l\rangle\right.$ or $\left.\left\langle s^{\prime} l\right\rangle\right)$ is the CPNE.

${ }^{11}$ Note that when $\lambda$ is sufficiently large, free trade fails to be a CPNE under the CU game regardless of bound tariff rates since exclusion incentives always arise.
} 
As under the FTA game, at the first stage of the CU formation game each country announces the names of countries with whom it wants to form a CU. Country $i$ 's announcement is denoted by $\sigma_{i}$ and its strategy set $S_{i u}$ consists of four possible announcements:

$$
S_{i u}=\left\{\{\phi, \phi\},\left\{j_{u}, \phi\right\},\left\{\phi, k_{u}\right\},\left\{j_{u}, k_{u}\right\}\right\}
$$

where $\{\phi, \phi\}$ denotes an announcement in favor of no CU with either trading partners, $\left\{j_{u}, \phi\right\}$ in favor of a CU with only country $j ;\left\{\phi, k_{u}\right\}$ in favour of a CU with only country $k$; and $\left\{j_{u}, k_{u}\right\}$ in favour of a $\mathrm{CU}$ that includes both its trading partners (announcement in favour of free trade). The mapping between various announcements profiles and the CUs that can arise is as follows: $(i)$ when no two announcements match or the only matching announcements are $\{\phi, \phi\}$ we obtain no agreement $\varnothing ;(i i)$ a CU between countries $i$ and $j$ denoted by $\left\langle i j_{u}\right\rangle$ is formed if they announce each others' names and there is no other matching announcement: i.e. $\left\langle i j_{u}\right\rangle$ is formed if $j_{u} \in \sigma_{i}, i_{u} \in \sigma_{j}$ and both (a) $k_{u} \notin \sigma_{i}$ and/or $i_{u} \notin \sigma_{k}$ and (b) $k_{u} \notin \sigma_{j}$ and/or $j_{u} \notin \sigma_{k}$ hold; ( $\left.i v\right)$ free trade $\langle F\rangle$ obtains iff all countries announce each other's names. Recall that the equivalent of a hub and spoke trading regime cannot arise under the CU game due to the fact that CU members coordinate their external tariffs.

As is well known, the central difference between an FTA and a CU is that members of a CU impose common external tariffs on non-members whereas FTA members adopt individually optimal tariffs. This difference in tariff setting behaviour between the two types of PTAs has an important consequence affecting the role of exclusion incentive in the equilibrium determination. It is crucial to note that, while an FTA member is free to enter into additional trade agreements (such as hub and spoke trading regimes) with nonmember countries without requiring consent from its existing FTA partners, a CU member can only do so if all other members also agree to participate in the new agreements. In other words, FTA members enjoy more flexibility in agreement formation than CU members.

While the optimal tariff analysis under no agreement stays the same as before, optimal tariff determination under a bilateral $\mathrm{CU}$ is different due to the common external tariff requirement. Here, it is worth mentioning that since each country is the unique importer of a good in our competing exporters model, the "market power effect" of a CU emphasized by Bagwell and Staiger (1997a) does not arise since that effect arises only when CU members " compete" for imports. ${ }^{12}$ As a result, the coordination of tariffs is beneficial to CU members only because each members internalizes the effect of its tariff on the export surplus of the other member. If two countries form a CU, they remove tariffs on each other and impose jointly optimal external tariffs (denoted by $t_{i}^{u}$ and $t_{j}^{u}$ ) on the non-member country. ${ }^{13}$ The

\footnotetext{
${ }^{12}$ See Missios et al. (2016) and Saggi et al. (2018) for details of tariff setting behaviour in a competing importers model.

${ }^{13}$ Our simple formulation of a CU's tariff choice problem is intuitively appealing and in line with much of existing literature. However, Syropoulos (2003) has shown that the nature of the sharing rule of a CU with respect to tariff revenue can affect tariff preferences as well as the trade patterns of CU members in ways that can prevent the implementation of jointly optimal tariffs. An important insight of his analysis is that $\mathrm{CU}$ members have an incentive to influence their common tariffs not just for external terms-of-trade reasons but also for internal distributional purposes. Given the focus of our paper, we abstract from such considerations.
} 
tariff pair $\left(t_{i}^{u}, t_{j}^{u}\right)$ is chosen to solve: ${ }^{14}$

$$
\max _{t_{i}^{u}, t_{j}^{u}} w_{i}(i j)+w_{j}(i j) \text { subject to } t_{i j}=t_{j i}=0
$$

Since countries are symmetric, we have $t_{i}^{u}=t_{j}^{u}=t^{u}$ and the optimal external tariff of each $\mathrm{CU}$ member is given by

$$
t^{u}=\frac{\alpha \lambda}{(\lambda+2)(3 \lambda+10)}
$$

Note that, under symmetry, the formation of a $\mathrm{CU}$ induces each member country to lower its tariff on the non-member relative to the status quo (i.e. the model exhibits tariff complementarity): $t^{u}<t^{\phi} .{ }^{15}$ Moreover, unlike an FTA, member countries under a CU internalize each other's export surplus under the joint welfare maximization and thus higher external tariff (weaker tariff complementarity) arises: $t^{f}<t^{u}<t^{\phi}$.

\subsubsection{Different Tariff Binding Scenarios - Customs Union}

Similar to the FTA game under symmetry, we have three tariff binding scenarios (illustrated in Figure 3.7):

(i) no tariff binding scenario where the tariff binding exceeds the optimal tariff under No agreement: $\tau>t_{z}(\varnothing)$ so that countries are free to impose their optimal tariffs under all trade regimes (the above optimal tariffs apply);

(ii) partial tariff binding scenario where the tariff binding exceeds the optimal tariff under a CU but falls below the optimal tariff under No agreement: $t^{u}<\tau<t^{\varnothing}$. Under such a case, countries under $\varnothing$ and the non-member country under a CU impose $\tau$ while the member countries under a CU are free to impose their optimal external tariffs.

(iii) full tariff binding scenario where the tariff binding falls below the optimal tariff under an FTA: $\tau<t^{u}$. Under this scenario, countries lose their freedom to impose optimal tariffs under all trade regimes and apply $\tau$.

It is immediate from the preceding tariff discussion that while no tariff binding scenario stays the same under both FTA and CU formation games, the bound tariff rate ranges shrink under the partial tariff binding scenario and expands under the full tariff binding scenario when the PTA is a CU relative to an FTA since $t^{f}<t^{u}$.

\footnotetext{
${ }^{14}$ The assumption that the CU maximizes the sum of national utilities is commonly employed in the literature. Issues of the delegation of tariff-setting authority and the choice of weights in the social welfare function are discussed by Gatsios and Karp (1991) and Melatos and Woodland (2007).

${ }^{15}$ It is noteworthy that tariff complementarity also arises in the general equilibrium model of Bond et al. (2004). For empirical evidence regarding tariff complementarity in the context of the Latin American CU MERCOSUR, see Estevadeordal et al. (2008).
} 


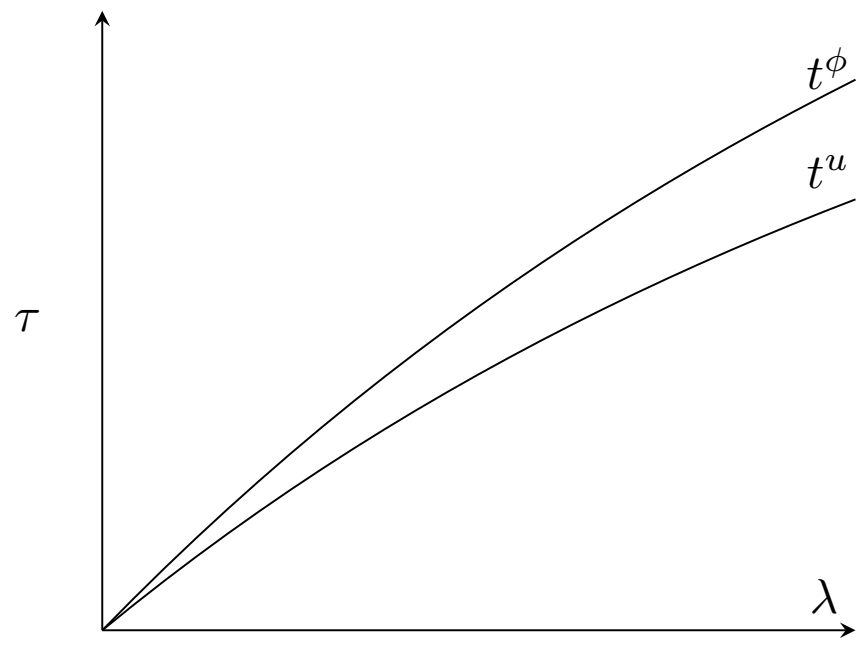

Figure 3.7: CU tariff schedule - Symmetry

\subsubsection{Coalition Proof Nash Equilibria - Customs Union}

Before deriving the equilibrium trade agreements under the $\mathrm{CU}$ formation game, we establish the following lemma:

Lemma 3.5 Suppose that countries have symmetric comparative advantage. Then, we have:

(i) $\Delta w_{i}\left(i j^{u}-\varnothing\right)=\Delta w_{j}\left(i j^{u}-\varnothing\right)>0$ and $\Delta w_{k}\left(i j^{u}-\varnothing\right)<0$ for all $\tau$ and $\lambda$;

(ii) $\Delta w_{i}\left(F-i j^{u}\right)=\Delta w_{j}\left(F-i j^{u}\right)>0$ only when $\tau>\widehat{\tau}^{u}(\lambda)$ where $t^{u}<\widehat{\tau}^{u}(\lambda)<t^{\varnothing}$;

(iii) $\Delta w_{k}\left(F-i j^{u}\right)>0$ for all $\tau$ and $\lambda$;

Note that, relative to an FTA formation game, each member country internalizes the negative externality of each other's external tariff via common external tariff determination under the $\mathrm{CU}$ and thus benefits more from a bilateral $\mathrm{CU}$ formation. Therefore, as under the FTA game, a pair of symmetric countries under $\varnothing$ always have an incentive to form a bilateral CU and thus the announcements leading to a bilateral CU is always a Nash equilibrium and $\Omega^{\varnothing}$ is not a CPNE of the CU game. Unlike the FTA game, the formation of a bilateral $\mathrm{CU}$ always makes the non-member country worse-off irrespective of the bound tariff rates and thus the formation of a $\mathrm{CU}$ is never Pareto-improving since it always makes member countries better off at the expense of the non-member. Consistent with this intuition, part (iii) of the above lemma informs us that there exists no free riding incentive on trade liberalization of the other two member countries via CU. As a result, the announcement profile $\Omega^{F}$ leading to $\langle F\rangle$ is always a Nash equilibrium.

Similar to the FTA game, the second part of the above lemma argues in favor of the idea that two countries have incentives to exclude the third country from free trade network 
when the tariff bindings are sufficiently tight. Note that when the bound tariff rates fall below $t_{z}(\varnothing)$, the non-member country loses its ability to set its optimal MFN tariff under a bilateral $\mathrm{CU}$ while facing a larger tariff under a $\mathrm{CU}$ relative to an FTA. Joint welfare maximization implies that the exclusion incentive is stronger under a $\mathrm{CU}$ relative to an FTA and thus $\widehat{\tau}^{u}(\lambda)>\widehat{\tau}(\lambda)$ for all $\lambda$. Here, it is important to note that Saggi et al. (2013) show under symmetry that there exists no exclusion incentive under a CU formation game in a competing exporters model when tariff bindings are not taken into account. Our result confirms this finding under " no tariff binding scenario" but goes one step further and suggests that this result fails to hold when countries are constrained in imposing their optimal tariffs due to sufficiently tight tariff bindings.

Recall that the key message in the FTA game was that even though a pair of countries benefit from excluding the third country from their trade agreement, they are unable to exercise this exclusion incentive in equilibrium. The flexible nature of FTAs plays a crucial role in ensuring that the exclusion incentive goes unexercised in the FTA game. Since hub and spoke regimes cannot arise under the $\mathrm{CU}$ formation game, are countries able to exercise the exclusion incentive in equilibrium?

It is immediate from Lemma 3.4 that $\Omega^{F}$ is a CPNE of the CU game only when $\tau \geq \widehat{\tau}^{u}(\lambda)$ where $t^{u}<\widehat{\tau}^{u}(\lambda)<t^{\varnothing}$. To see why, taking the complement's announcement as given, simply consider the coalitional deviation of countries $i$ and $j$ from $\Omega^{F}$ to $\Omega^{i j_{u}} \equiv$ $\left\{\sigma_{i}=\left\{j_{u}, \phi\right\}, \sigma_{j}=\left\{i_{u}, \phi\right\} \sigma_{k}=\left\{i_{u}, j_{u}\right\}\right\}$. Observe from Lemma 3.4 that this coalitional deviation happens when $\tau<\widehat{\tau}^{u}(\lambda)$, altering the trade regime from free trade to the $\mathrm{CU}$ $\left\langle i j_{u}\right\rangle$ and since CU members enjoy higher welfare than that under no agreement, neither member country has an incentive to further unilaterally alter its announcements and thus the initial deviation is self-enforcing.

Finally, we argue that the announcement profile leading to a bilateral CU is a CPNE only when $\tau \leq \widehat{\tau}^{u}(\lambda)$. Starting with any Nash equilibrium announcement profile that yields the $\mathrm{CU}\left\langle i j_{u}\right\rangle$, member countries have no incentive to jointly alter their announcements to either obtain $\varnothing$ or $\langle F\rangle$ since they are worse off under either of these outcomes. Thus, we can state the following result, illustrated in Figure 3.8:

Proposition 3.8 : Suppose that countries have symmetric comparative advantage. Then, in a $C U$ formation game

(i) $\Omega^{F}$ leading to global free trade is a CPNE only when $\tau \geq \widehat{\tau}^{u}(\lambda)$ and

(ii) $\Omega^{i j_{u}}$ leading to a bilateral $C U$ is a CPNE only when $\tau \leq \widehat{\tau}^{u}(\lambda)$

The main difference between the results in the FTA game (Proposition 3.3) and the CU game (Proposition 3.8) is driven by the relatively flexible nature of FTAs compared to CUs. In the FTA game, when two countries ( $i$ and $j$ ) have incentives to jointly exclude the third country from free trade by forming a bilateral FTA, each member has an incentive to sign an independent FTA with the excluded country thereby making itself a hub. The ability to act on this incentive acts as a deterrent for the other initially deviating country 
(say $j$ ) since it is worse off as a spoke under $\langle i h\rangle$ relative to free trade and thus the initial joint deviation from the announcement profile $\Omega^{F}$ to $\Omega^{i j}$ does not occur. However, unlike the FTA game, no such deterrent exists under the $\mathrm{CU}$ game since $\mathrm{CU}$ expansion must move directly from a bilateral $\mathrm{CU}$ to global free trade and $\mathrm{CU}$ members have veto power over such CU expansion.

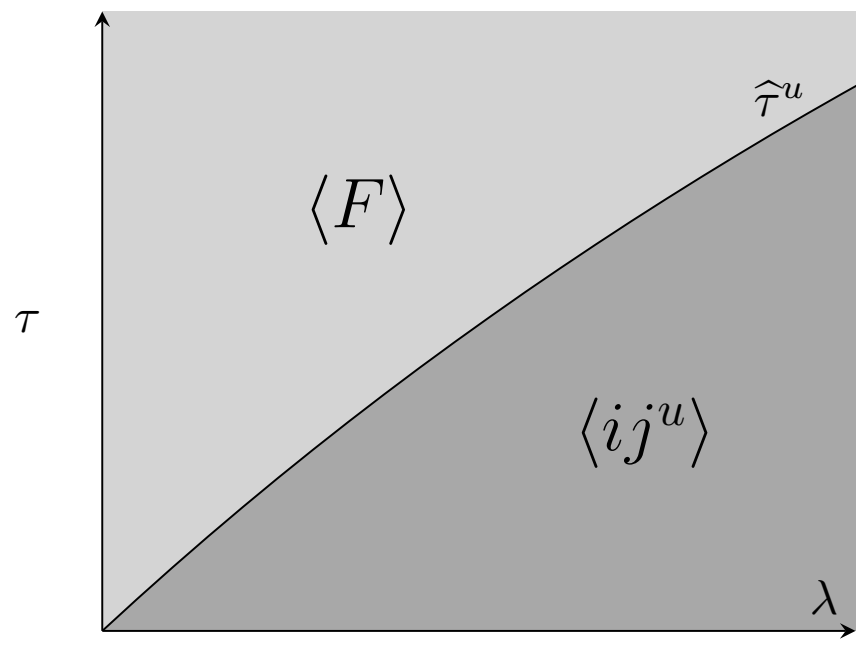

Figure 3.8: Stable equilibrium under CU - (CU game) Symmetry

It is immediate from Figure 3.8 that global free trade is less likely to be a CPNE as the bound tariff rates fall. Here, we should emphasize that while our FTA results diverges from Freund (2000), Proposition 3.8 provides support for Freund (2000) when preferential trade agreement is a customs union rather than an FTA: continual reduction in tariff bindings enhances the incentives to form a bilateral $\mathrm{CU}$ relative to free trade since the set-up in Freund (2000) converges to our CU formation game where hub and spoke regime is not feasible and exclusion incentive plays a crucial role in equilibrium. While the PTA formation and multilateral tariff reduction are modelled differently, another important observation would be that the above result is also consistent with Lake and Roy (2017), arguing that "gated globalization" becomes more likely as the reduction in tariff bindings gets deeper when the PTA under consideration takes the form of a CU rather than an FTA.

\subsection{Conclusion}

We show that the flexible nature of FTA formation due to the independent external tariff setting plays a major role in identifying whether free riding or exclusion incentives play pivotal role in equilibrium. When countries are completely symmetric, no country has an incentive to free ride on trade liberalization by the other two countries while two countries have incentives to exclude the third one when tariff bindings are sufficiently tight. Due to 
the flexibility in FTA formation, such exclusion incentives go unexercised and free trade always obtains as the coalition proof Nash equilibrium (CPNE) of the FTA game. However, since hub and spoke regimes are not allowed in the $\mathrm{CU}$ game and $\mathrm{CU}$ members have veto power over $\mathrm{CU}$ expansion, countries are able to exercise the exclusion incentive and thus free trade fails to be CPNE when tariff bindings are sufficiently tight. This result suggests that, when countries are symmetric, the pursuit of CUs undermines global free trade when tariff bindings are sufficiently tight while FTA formation always act as building blocs irrespective of the tariff bindings.

We then question when and why, if any, global free trade fails to obtain in FTA formation game. To this end, we consider a scenario where countries are asymmetric with respect to their comparative advantage. Our findings suggest that the country with a weaker comparative advantage in the exporting goods (thus larger importer country) has incentive to free ride on trade liberalization of the other two countries and this incentive is critical for whether multilateral free trade obtains as a CPNE. Since the reduction in bound tariff rates disciplines the ability of the free riding smaller exporting country in setting its external tariffs, multilateral free trade arises more likely as a CPNE (and thus act as a building bloc). This result provides support for the idea that continual reduction in tariff bindings facilitates the FTA formation in attaining global free trade.

It is important to note that FTA formation and $\mathrm{CU}$ formation games are examined in isolation and the choice between these two types of PTAs is not endogenously determined. In the next two Chapters (4-5) we examine this question in a dynamic set-up, similar to the one employed by Lake and Yildiz (2016) and Lake (2018). In this dynamic setting, we examine in Chapter 4 FTA formation and CU formation games separately. In Chapter 5, we endogenize the choice of PTA type and examine a pure farsighted PTA formation under exogenously given tariff bindings. 


$\Gamma_{\text {Chapter }}$

\section{Tariff Bindings and Dynamic Formation of Preferential Trade Agreements}

In this paper, we utilize a dynamic model of PTA formation where countries form PTAs over time in order to address how continual reductions in the tariff bindings impact the role of each type of PTA in helping or hindering the attainment of global free trade. ${ }^{1}$ Our model features symmetric countries. We first analyse an "FTA game" where countries can only form FTAs. With relatively high tariff binding, the key intuition revolves around free riding by the FTA outsider. Intuitively, despite facing discrimination, the FTA outsider benefits from the well known tariff complementarity phenomena whereby FTA members lower their MFN tariff upon FTA formation. Indeed, the FTA outsider actually becomes worse off upon a subsequent FTA with an FTA insider. In this sense, the FTA outsider holds a myopic free riding incentive. However, by eliminating the discrimination faced in both FTA insider markets, the FTA outsider benefits from global free trade. The tension between this farsighted benefit of global free trade and the myopic free riding incentive generates a dynamic trade-off. A sufficiently patient FTA outsider willingly becomes the spoke because of the farsighted benefit of global free trade. But, a sufficiently myopic FTA outsider holds a dynamic free riding incentive in that it refuses any subsequent FTA formation because the myopic free riding incentive dominates the farsighted benefit of global free trade.

However, continual reductions in the global tariff binding eventually eliminate the myopic free riding incentive by constraining the FTA outsider's ability to levy its optimal tariffs on the FTA insiders. With a relatively low tariff binding, the key intuition revolves around the FTA insiders holding an exclusion incentive. Intuitively, the FTA insiders have already extracted tariff concessions from the FTA outsider through the relatively low tariff binding and benefit from excluding the FTA outsider from global free trade to protect their preferential access as FTA insiders. Nevertheless, an FTA insider benefits myopically from forming its own FTA with the FTA outsider and thus becoming the "hub" with preferential access to both of the other "spoke" countries. The tension between this myopic

\footnotetext{
${ }^{1}$ The methodology and the results contained in this and the following chapters are documented in Lake et al. (2018).
} 
benefit of becoming the hub and the farsighted nature of the exclusion incentive generates a dynamic trade off. A sufficiently myopic FTA insider becomes the hub because of the benefits associated with preferential access to both spoke markets. But, a sufficiently patient FTA insider holds a dynamic exclusion incentive in that it refuses any subsequent FTA formation because of the farsighted benefit of not precipitating expansion to global free trade.

Two main insights emerge when analysing how continual tariff binding reductions change how FTA formation helps or hinders the attainment of global free trade. First, when high tariff bindings prevent FTA expansion to global free trade, continual reductions in the tariff binding facilitate FTA formation that attains global free trade. Specifically, suppose the dynamic free riding incentive prevents global free trade under a sufficiently high tariff binding noting that this requires sufficient myopia. Then, continual reductions in the tariff binding eventually eliminate the dynamic free riding incentive and, despite generating an exclusion incentive, FTA insiders do not hold a dynamic exclusion incentive because the dynamic exclusion incentive requires sufficient patience. In turn, FTA formation yields global free trade.

The second insight is that when high tariffs bindings facilitate FTA expansion to global free trade, continual reductions in tariff bindings change the nature of FTA formation so that FTA expansion no longer facilitates but can rather impede FTA expansion to global free trade. This insight may be especially relevant given the literature documents FTA formation typically takes many years. As such, tariff binding reductions may occur before FTA expansion has time to reach global free trade. In this case, the FTA outsider does not hold a dynamic free riding incentive under the initially high tariff binding because of sufficient patience. However, continual tariff binding reductions create an exclusion incentive and FTA insiders may hold a dynamic exclusion incentive since this also requires sufficient patience. In this case, FTA formation would eventually yield global free trade under the initial and relatively high tariff binding, but continual reductions in the tariff binding generate a dynamic exclusion incentive for FTA insiders who refuse any subsequent FTA formation with the FTA outsider.

Unlike our "FTA game" which features tensions between myopic and farsighted incentives, our "CU game" is much simpler. Two observations are important: (i) CU expansion must move directly from the $\mathrm{CU}$ insider-outsider network to global free trade and (ii) $\mathrm{CU}$ insiders have veto power over such CU expansion. While the CU non-member always benefits from $\mathrm{CU}$ expansion to global free trade, $\mathrm{CU}$ insiders want to exclude the $\mathrm{CU}$ non-member from such expansion when the tariff binding is relatively low. As for FTA insiders, a relatively low tariff binding implies the CU members have extracted substantial tariff concessions from the $\mathrm{CU}$ non-member without giving concessions to the $\mathrm{CU}$ nonmember via $\mathrm{CU}$ expansion. Thus, CU formation proceeds to global free trade only for relatively high tariff bindings.

The paper proceeds as follows. Section 4.1 describes succinctly our model both the underlying trade model and the game theoretic model of PTA formation. Section 4.2 analyses the equilibrium outcome of the "FTA game" where countries can only form FTAs. Section 4.3 analyses the equilibrium outcome of the "CU game" where countries can only 
form CUs. Finally, Section 4.4 concludes. The Appendix contains all proofs.

\subsection{Model}

Ultimately, our model allows countries to form PTAs over time. As described in Chapter 2 , our model consists of three countries $a, b$ and $c$; three (non-numéraire) goods $A, B$ and $C$; and, a numéraire good $v_{0}$. Where appropriate, we hereafter use $z=i, j, k$ as generic notation for countries and $Z=I, J, K$ as generic notation for non-numéraire goods. By utilizing the equilibrium prices derived in equation (2.10), we maintain throughout the reminder of this paper the symmetric comparative advantage structure across countries (i.e., $\lambda_{z}=\lambda$ for $z=i, j, k$ ). In each period, countries choose optimal applied tariffs given the network of PTAs and existing tariff bindings. In turn, production, consumption and international trade take place given the network of PTAs and the applied tariffs chosen by countries. Section 4.1.1 describes how countries choose applied tariffs subject to the existing network of PTAs and the existing tariff bindings. Section 4.1.2 details our dynamic game theoretic model of PTA formation.

\subsubsection{Implications of tariff bindings}

Naturally, countries cannot raise their applied tariff above the tariff binding they have agreed during multilateral negotiations. In this paper, we take the tariff bindings from multilateral negotiations as exogenous. Further, given our symmetric countries, we consider a symmetric tariff binding $\tau$.

Given the optimal tariffs derived in Equations (3.1)-(3.2) and (3.5), and an exogenous tariff binding $\tau$, Figure 4.1 illustrates four possible ranges. The last region in Figure 4.1 is the "No binding region" . Here, regardless of PTA formation, the tariff binding $\tau$ exceeds the optimal applied tariff of all countries: $\tau>t^{\phi}>t^{u}>t^{f}$. Thus, the tariff binding never binds. This is the range typically considered by the existing PTA literature that ignores the implications of multilaterally negotiated tariff bindings.

However, the tariff binding binds once $\tau<t^{\phi}$. In the "Non-member binding region," $t^{u}<\tau<t^{\phi}$ which says the tariff binding binds the applied tariffs of the FTA outsider and $\mathrm{CU}$ outsider who thus levy an applied tariff of $\tau$ that lies below their optimal applied tariff $t^{\phi}$. However, this tariff binding $\tau$ does not bind any other countries.

The tariff binding binds the applied tariffs of CU insiders (in addition to FTA and CU outsiders) once $t^{f}<\tau<t^{u}$. That is, CU insiders levy an applied tariff $\tau$ that lies below their optimal applied tariff $t^{u}$. Finally, once in the "FTA binding region" of $\tau<t^{f}$, the tariff binding now binds the applied tariffs of all countries who all levy an applied tariff $\tau$ below their optimal applied tariff. 


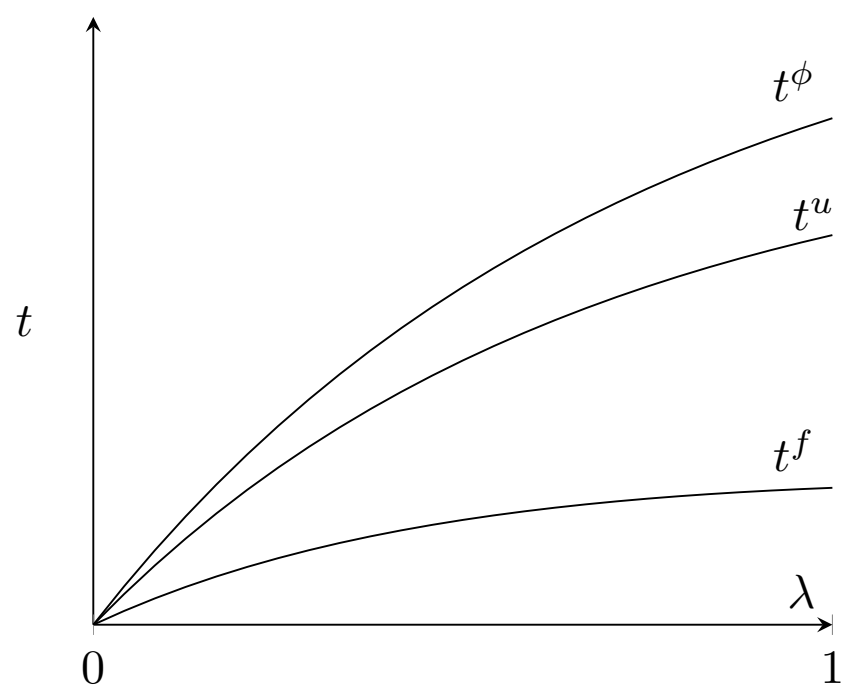

Figure 4.1: Tariff binding regions

\subsubsection{Strategies and equilibrium concept}

Our dynamic model follows Lake and Yildiz (2016) and Lake (2018), and is similar to Seidmann (2009). We assume at most one PTA can form in a period and that PTAs formed in previous periods are binding and hence cannot be severed. ${ }^{23}$ Given a network $g_{t-1}$ at the beginning of the current period $t$, we refer to the current period $t$ as the subgame at $g_{t-1}$. Table 4.1 illustrates the current period feasible transitions $g_{t-1} \rightarrow g_{t}$ where $g_{t}$ denotes the network at the end of the current period.

Note that a network remains permanently when one of two conditions occur, and this happens from no later than the third period. First, when no agreement forms in a given period, the assumption below of Markov strategies implies no agreement will form in any subsequent period. Second, once global free trade emerges, the assumption that previously formed agreements cannot be severed implies global free trade remains forever. Because the network remains unchanged from no later than the third period onwards, we let the last network in a path of networks denote the network that remains forever: for example, $g_{t-1} \rightarrow g_{t} \rightarrow g_{t+1}$ describes the path of networks that begins at $g_{t-1}$ and then passes through $g_{t}$ and then remains at $g_{t+1}$ forever; alternatively, the path of networks $g_{\varnothing} \rightarrow g_{\varnothing}$

\footnotetext{
${ }^{2}$ Ornelas (2008) and Ornelas and Liu (2012), among others, argue the binding nature of trade agreements is pervasive in the literature and, notwithstanding Brexit, realistic in terms of real world observation. They also argue the assumption of binding agreements can represent a reduced form for more structural justifications such as sunk costs (see McLaren (2002) and, for empirical support, Freund and McLaren (1999).

${ }^{3}$ Because, negotiations often take many years to complete (e.g. despite not being signed until 1992, Odell (2006, p. 193) documents NAFTA negotiations dating back to 1986; also see Mölders (2012, 2015) and Freund and McDaniel (2016), we essentially interpret a period as the required time to negotiate an agreement.
} 


\begin{tabular}{c|c}
\hline \hline$g_{\varnothing}$ & $g_{\varnothing}, g_{i j}^{F A}, g_{i k}^{F A}, g_{j k}^{F A}, g_{i j}^{C U}, g_{i k}^{C U}, g_{j k}^{C U}$ \\
$g_{i j}^{F T A}$ & $g_{i j}^{F T A}, g_{i}^{H}, g_{j}^{H}$ \\
$g_{i j}^{C U}$ & $g_{i j}^{C U}, g^{F T}$ \\
$g_{i}^{H}$ & $g_{i}^{H}, g^{F T}$ \\
$g^{F T}$ & $g^{F T}$ \\
\hline
\end{tabular}

Table 4.1: Feasible network transitions

indicates that no PTA ever forms.

Ultimately, countries have preferences over paths of PTA networks with $\beta$ denoting the discount factor. To this end, given a network $g$, we assume country $i$ 's one period payoff is its national welfare $w_{i}(g)$. Continuation payoffs capture country preferences over paths of PTA networks. Given a feasible transition $g_{t-1} \rightarrow g_{t}$ from the network $g_{t-1}$ at the beginning of the current period to the network $g_{t}$ at the end of the current period, the context will often make clear the path of networks $g_{t+1} \rightarrow g_{t+2} \rightarrow \ldots$ that follow this current period transition. Thus, we simply let $V_{i}\left(g_{t}\right)$ represent the continuation payoff from the path of networks $g_{t-1} \rightarrow g_{t} \rightarrow g_{t+1} \rightarrow g_{t+2} \rightarrow \ldots$. For concreteness, suppose the network at the beginning of the current period is the empty network $g_{\varnothing}$. Then, country $i$ 's continuation payoff from the path of networks $g_{\varnothing} \rightarrow g_{i j}^{C U} \rightarrow g^{F T}$ is $V_{i}\left(g_{i j}^{C U}\right)=w_{i}\left(g_{i j}^{C U}\right)+\frac{\beta}{1-\beta} w_{i}\left(g^{F T}\right)$. Alternatively, given the empty network $g_{\varnothing}$ remains forever if no PTA forms in the current period, country $i$ 's continuation payoff from the path of networks $g_{\varnothing} \rightarrow g_{\varnothing}$ is $V_{i}\left(g_{\varnothing}\right)=$ $\frac{1}{1-\beta} w_{i}\left(g_{\varnothing}\right)$.

Like Lake and Yildiz (2016) and Lake (2017), we assume a deterministic protocol where a single "leader" country (country $a$ ) has the first opportunity in each period to propose a PTA that has not yet formed. Naturally, the leader country must be a member of this PTA and the associated transition must be feasible (see Table 4.1). The proposed PTA forms if and only if all "recipient" country (country $b$ and/or $c$ ) accept the proposal. If the leader country does not have a proposal accepted by the follower countries, one of the follower countries has the opportunity to propose a PTA. The proposal ability of the follower countries distinguishes our protocol from Aghion et al. (2007) where only the leader country can make proposals and hence, for example, the two follower countries could not form their own FTA as spokes.

Formally, Stages 1-2 describe the protocol in every period:

Stage 1(a). Country $a$ has the opportunity to propose a PTA. If the PTA forms then the period ends. If the recipient country rejects the proposal then the game moves to Stage 1(b). If country $a$ proposes CU expansion to countries $b$ and $c$ global free trade, or country $a$ makes no proposal, then the game moves to Stage $2 .^{4}$

\footnotetext{
${ }^{4}$ Note that, as specified in Table 4.1, FTA proposals involve a single recipient country. In particular, expansion from $g_{i j}^{F T A}$ to $g^{F T}$ proceeds via a hub-spoke network $g_{i}^{H}$ or $g_{j}^{H}$. However, also as specified in
} 
Stage 1(b). Country $a$ has the opportunity to propose a PTA with the country who did not reject its proposal in Stage 1(a). If the PTA forms then the period ends. Otherwise, the game moves to Stage 2.

Stage 2. Country $b$ has the opportunity to propose a PTA. No matter what happens here, the period ends.

As described earlier, this protocol implies that the network remains unchanged upon the attainment of global free trade or when no agreement forms in a period. Thus, the network remains unchanged from at most the third period onwards.

We consider an "FTA game" where countries can only propose FTAs and a "CU game" where countries can only propose CUs. Having received a proposal $\rho_{i}(g)$ from country $i$, each recipient country $j$ (i.e., a country of the proposed agreement) announces a response $r_{j}\left(g, \rho_{i}(g)\right) \in\{Y, N\}$ where $Y(N)$ denotes the acceptance (rejection) of the proposal by country $j$.

For each subgame at a network $g$, the Markov strategy of each country $i$ must do two things: (i) specify a proposal $\rho_{i}(g) \in P_{i}(g)$ for the stage(s) where it is the proposer and (ii) assign a response $r_{i}\left(g, \rho_{j}(g)\right) \in\{Y, N\}$ to any proposal it may receive from some other country $j$. We solve for a type of pure strategy Markov perfect equilibrium. Specifically, using backward induction, we solve for a pure strategy subgame perfect equilibrium where the proposal by the proposer and the response by the respondent in the current period only depend on history via the network in place at the end of the previous period..$^{5}$

Next, we use backward induction to solve for the equilibrium path of each PTA networks. Section 4.2 analyses the "FTA game" where countries can only form FTAs and Section 4.3 analyses the "CU game" where countries can only form CUs. Finally, Section 4.4 concludes.

\subsection{Equilibrium path of networks: FTA game}

In this section, we analyze the "FTA game" where countries can only form FTAs to help isolate the driving forces behind FTA formation. The "FTA game" set of proposals is specified in Table 4.2 .

Naturally, FTA formation incentives drive the equilibrium network of FTAs. In our model, these incentives include both the myopic incentives that depend on comparisons of one period payoffs across different FTA networks and the farsighted incentives that depend

Table 4.1, by definition, CU expansion from $g_{i j}^{C U}$ proceeds directly to $g^{F T}$ and hence involves two recipient countries.

${ }^{5}$ We make two assumptions that conveniently restrict attention to certain Markov Perfect Equilibria. Given the simultaneity of responses to a proposal for CU expansion to include the CU outsider, we assume recipient country accept such proposals if it prefers global free trade over the status quo: $r_{k}\left(g_{i j}^{C U}, i j k^{C U}\right)=$ $Y$ if and only if $w_{k}\left(g^{F T}\right)>w_{k}\left(g_{i j}^{C U}\right)$. When a response $r_{j}\left(g, \rho_{i}(g)\right)=N$ merely delays formation of the PTA to a later stage of the same period, we assume the recipient country responds with $r_{j}\left(g, \rho_{i}(g)\right)=Y$. An arbitrarily small cost of making a proposal motivates this assumption. 


\begin{tabular}{c|ccc} 
& $P_{i}(g)$ & $P_{j}(g)$ & $P_{k}(g)$ \\
\hline \hline$g_{\varnothing}$ & $\left\{\phi, i j^{F T A}, i k^{F T A}\right\}$ & $\left\{\phi, i j^{F T A}, j k^{F T A}\right\}$ & $\left\{\phi, i k^{F T A}, j k^{F T A}\right\}$ \\
$g_{i j}^{F T A}$ & $\left\{\phi, i k^{F T A}\right\}$ & $\left\{\phi, j k^{F T A}\right\}$ & $\left\{\phi, i k^{F T A}, j k^{F T A}\right\}$ \\
$g_{i}^{H}$ & $\{\phi\}$ & $\left\{\phi, j k^{F T A}\right\}$ & $\left\{\phi, j k^{F T A}\right\}$ \\
$g^{F T}$ & $\{\phi\}$ & $\{\phi\}$ & $\{\phi\}$ \\
\hline
\end{tabular}

Table 4.2: Proposer country's action space for each subgame in FTA game

on comparisons of continuation payoffs across different paths of FTA networks. We now discuss the key myopic and farsighted incentives in turn.

\subsubsection{FTA formation incentives}

\subsubsection{Myopic incentives}

Lemma 4.1 describes the myopic incentives driving the equilibrium path of networks under the FTA formation game. For notational convenience, we let $\Delta w_{i}\left(g^{\prime}-g\right) \equiv w_{i}\left(g^{\prime}\right)-w_{i}(g)$ and also let $g+i j^{F T A}$ denote the network that results when an FTA between countries $i$ and $j$ is added to network $g$.

Lemma 4.1 (i) $\Delta w_{i}\left(g^{\prime}-g\right)>0$ for $g^{\prime}=g+i j^{F T A}$ and $g \neq g_{j k}^{F T A}$.

(ii) $\Delta w_{i}\left(g_{j}^{H}-g_{j k}^{F T A}\right)>0$ if and only if $\tau<\bar{\tau}_{O U T}^{F T A}$ where $\bar{\tau}_{O U T}^{F T A} \in\left(t^{f}, t^{\phi}\right)$

(iii) $\Delta w_{i}\left(g_{i j}^{F T A}-g_{j k}^{F T A}\right)>0$ for $\tau<\tilde{\tau}$ where $\tilde{\tau} \in\left(\bar{\tau}_{O U T}^{F T A}, t^{\phi}\right)$.

Part (i) governs the attractiveness of bilateral FTAs. Intuitively, the exchange of preferential market access makes bilateral FTA formation myopically attractive. Two particularly important instances are that an FTA insider benefits from becoming the hub via an FTA with the FTA outsider, $\Delta w_{i}\left(g_{i}^{H}-g_{i j}^{F T A}\right)>0$, and that spokes benefit from forming the final FTA that yields global free trade, $\Delta w_{i}\left(g_{i}^{H}-g_{i j}^{F T A}\right)>0$. However, part (i) allows an exception. Specifically, despite the discrimination faced as an FTA outsider, the FTA outsider benefits from tariff complementarity which lowers the external tariffs faced when exporting to the FTA insiders. Thus, an FTA outsider might not benefit from a bilateral FTA.

Parts (ii)-(iii) describe the FTA outsider's "free riding" incentives. When the tariff binding does not bind the FTA outsider, i.e. $\tau>t^{\phi}$, the FTA outsider benefits from the tariff complementarity practised by FTA insiders and from imposing its optimal tariff on both FTA insiders. Indeed, these benefits are large enough that a country prefers being an FTA outsider than an FTA insider. However, the tariff binding constrains this ability to impose optimal tariffs on the FTA insiders once $\tau<t^{\phi}$. Once the tariff binding falls below $\tilde{\tau}$, part (iii) says a country prefers being an FTA insider over an FTA outsider. But, as long as the tariff binding does not bind too tightly, i.e. $\tau>\bar{\tau}_{\text {OUT }}^{F T A}$, part (ii) says the FTA outsider still prefers remaining an FTA outsider over becoming a spoke. Here, we say 
the FTA outsider has a myopic free riding incentive. Once the tariff binding is sufficiently tight, $\tau<\bar{\tau}_{O U T}^{F T A}$, this myopic free riding incentive disappears.

We now move on to discuss the farsighted incentives that drive FTA formation.

\subsubsection{Farsighted incentives}

Lemma 4.2 describes the farsighted incentives that drive the equilibrium path of networks.

Lemma 4.2 (i) $\Delta w_{i}\left(g^{F T}-g_{j k}^{F T A}\right)>0$.

(ii) $\Delta w_{i}\left(g_{i}^{F T}-g_{i j}^{F T A}\right)>0$ if and only if $\tau>\bar{\tau}_{I N}^{F T A}$ where $\bar{\tau}_{I N}^{F T A} \in\left(t^{f}, t^{\phi}\right)$.

(iii) $\Delta w_{i}\left(g_{i}^{H}-g^{F T}\right)>0$.

Part (i) addresses the possibility of a farsighted free riding incentive for the FTA outsider. However, it says that an FTA outsider always benefits from global free trade via eliminating the discrimination faced in both FTA insider markets. That is, from a farsighted perspective, an FTA outsider has an incentive to participate in FTA expansion that yields global free trade. Thus, an FTA outsider does not hold a farsighted free riding incentive. Later, the tension between the myopic free riding incentive and the absence of a farsighted free riding incentive determines whether the FTA outsider has a dynamic free riding incentive.

Lemma 4.1 described how an FTA insider myopically benefits from becoming the hub. However, Lemma 4.1 also described how spokes have a myopic incentive to form the final FTA leading to global free trade. Thus, from a farsighted perspective, an FTA insider understands that becoming the hub will precipitate global free trade. To this end, Lemma 4.2(ii) addresses the farsighted incentive of whether FTA insiders benefit from permanently excluding the FTA outsider from susbequent FTA formation that delivers global free trade. Global free trade benefits the FTA insiders by removing the FTA outsider's tariff barriers. This benefit is relatively high with a sufficiently lax tariff binding but relatively low with a sufficiently tight tariff binding. As such, Lemma 4.2(ii) says FTA insiders have an exclusion incentive when the tariff binding is sufficiently tight; intuitively, they have already extract tariff concessions from the FTA outsider without engaging in FTA formation. Later, the tension between the myopic incentive to become the hub and the farsighted nature of the exclusion incentive determines whether FTA insiders hold a dynamic exclusion incentive.

Part (iii) represents the "flexibility benefit" of FTAs relative to CUs. As such, its relevance emerges later when analyzing the PTA game, in Chapter ??, where countries endogenously choose between FTAs and CUs. Because of the sovereign discretion over external tariffs, each FTA insider has the flexibility to form its own future FTA and become the hub. In contrast, CU formation proceeds directly to global free trade. Thus, the flexibility of FTAs poses a farsighted benefit of FTA formation relative to CU formation.

This FTA flexibility benefit is valuable, i.e. $\Delta w_{i}\left(g_{i}^{H}-g^{F T}\right)>0$, because spoke-spoke FTA formation erodes the preferential access enjoyed by the hub country in the spoke markets.

We now solve the equilibrium path of networks in the FTA game by backward induction. 


\subsubsection{Subgames at hub-spoke networks}

To begin the backward induction, consider a subgame at a hub-spoke network $g_{i}^{H}$. The following lemma follows directly from Lemma 4.1(i).

Lemma 4.3 In the subgame at a hub-spoke network $g_{i}^{H}$, spoke countries form the final FTA that leads to global free trade: $g_{i}^{H} \rightarrow g^{F T}$.

\subsubsection{Subgames at FTA insider-outsider networks}

We now roll back to a subgame at an insider-outsider network $g_{i j}^{F T A}$. As discussed above, tensions between myopic and farsighted FTA formation incentives exist for both the FTA outsider and FTA insiders. We first explore this tension facing the FTA outsider.

\subsubsection{Dynamic free riding incentive}

A tension between myopic and farsighted incentives for the FTA outsider creates the possibility of a dynamic free riding incentive. Lemma 4.2(i) said the elimination of discrimination drives the farsighted incentive of an FTA outsider to participate in FTA expansion that yields global free trade: $\Delta w_{k}\left(g^{F T}-g_{i j}^{F T}\right)>0$. However, Lemma 4.1(ii) said an FTA outsider has a myopic free riding incentive, and hence a myopic incentive to refuse subsequent FTA formation, with a sufficiently lax tariff binding: $\Delta w_{k}\left(g_{i}^{H}-g_{i j}^{F A}\right)<0$ if and only if $\tau>\bar{\tau}_{O U T}^{F T A}$. That is, an FTA outsider does not hold a myopic free riding incentive when the tariff binding is sufficiently tight because this severely constrains its ability to impose optimal tariffs on the FTA insiders. In this case, no dynamic free riding incentive exists because an FTA outsider happily participates in subsequent FTA formation from myopic and farsighted perspectives.

However, a sufficiently lax tariff binding $\tau>\bar{\tau}_{\text {OUT }}^{F T A}$ generates a myopic free riding incentive and the possibility of a dynamic free riding incentive. Here, the discount factor mediates the tension between the FTA outsider's farsighted incentive to become a spoke and its myopic free riding incentive. Specifically, the FTA outsider prefers becoming a spoke rather than remaining a permanent FTA outsider when

$$
w_{k}\left(g_{i}^{H}\right)+\frac{\beta}{1-\beta} w_{k}\left(g^{F T}\right)>\frac{1}{1-\beta} w_{k}\left(g_{i j}^{F T A}\right) .
$$

As one would expect from our above discussion, this can only fail if the FTA outsider holds a myopic free riding incentive $\Delta w_{k}\left(g_{i j}^{F T A}-g_{i}^{H}\right)>0$. Further, (4.1) reduces to

$$
\beta>\bar{\beta}_{O U T}(\tau) \equiv\left[1+\frac{\Delta w_{k}\left(g^{F T}-g_{i j}^{F T A}\right)}{\Delta w_{k}\left(g_{i j}^{F T A}-g_{i}^{H}\right)}\right]^{-1}
$$

which says a sufficiently patient FTA outsider becomes a spoke or, alternatively, a sufficiently myopic FTA outsider refuses subsequent FTA formation. In this latter case, i.e. 
$\beta<\bar{\beta}_{\text {OUT }}(\tau)$, we say the FTA outsider has a dynamic free riding incentive. Moreover, the extent that the FTA outsider holds a dynamic free riding incentive rises (i.e. $\bar{\beta}_{O U T}(\tau)$ rises) as the myopic free riding incentive $\Delta w_{k}\left(g_{i j}^{F T A}-g_{i}^{H}\right)$ increases relative to the farsighted incentive of becoming a spoke $\Delta w_{k}\left(g^{F T}-g_{i j}^{F T A}\right)$.

Figure 4.2 illustrates the dynamic free riding incentive and how it varies with the tariff binding. An FTA outsider has a dynamic free riding incentive when $\beta<\bar{\beta}_{O U T}(\tau)$. In this case, the FTA outsider is sufficiently myopic that the myopic free riding incentive dominates the farsighted incentive to become a spoke and, hence, the FTA outsider refuses subsequent FTA formation. In the "no binding region" of $\tau>t^{\phi}$, the FTA outsider's optimal applied tariff remains unbound and, in turn, stays unchanged. Thus, $\bar{\beta}_{O U T}(\tau)$ remains constant. However, the FTA outsider's optimal tariff becomes bound once we move into the "non-member binding region" where $\tau<t^{\phi}$. By reducing the FTA outsider's ability to impose optimal tariffs on FTA insiders, the myopic free riding incentive weakens and the farsighted incentive to become a spoke strengthens. In turn, the dynamic free riding incentive weakens, i.e. $\bar{\beta}_{O U T}(\tau)$ falls, as the tariff binding continues falling below $t^{\phi}$. Indeed, the dynamic free riding incentive disappears once the tariff binding falls below $\bar{\tau}_{\text {OUT }}^{F T A}$ (i.e. $\bar{\beta}_{\text {OUT }}(\tau)$ becomes negative) because the myopic free riding incentive disappears and, hence, regardless of the discount factor, the FTA outsider becomes a spoke.

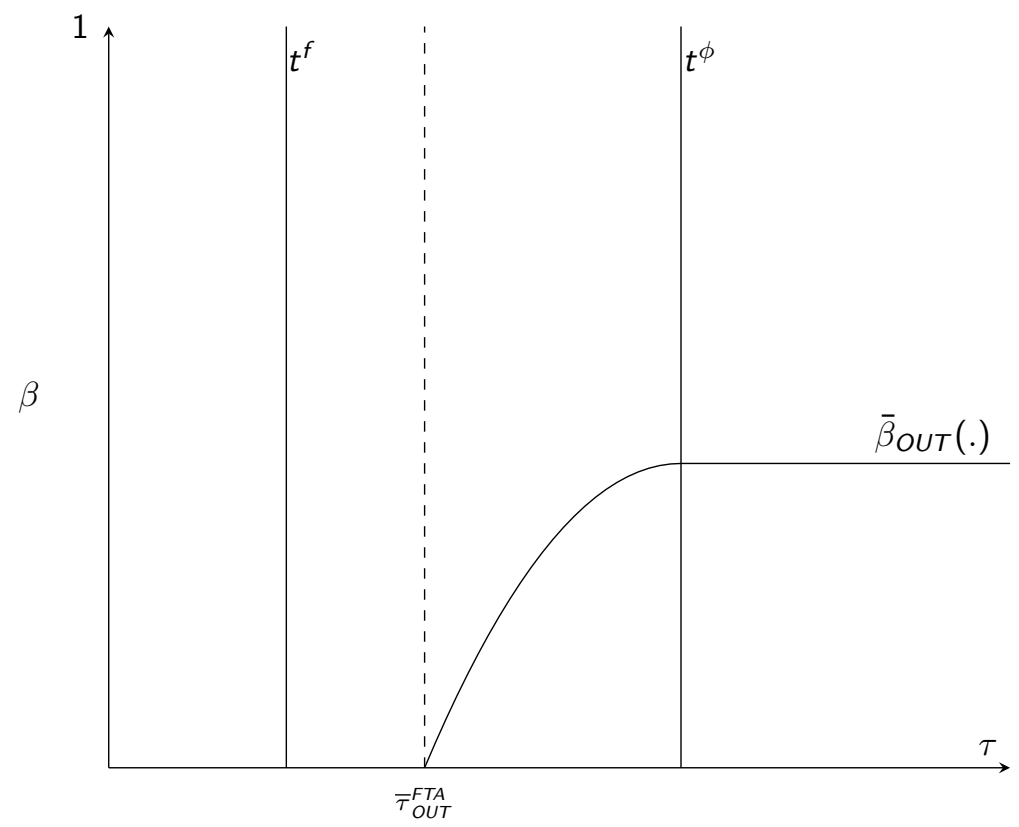

Figure 4.2: Dynamic free riding incentive

Next, we examine the myopic and farsighted incentives of FTA insiders. 


\subsubsection{Dynamic exclusion incentive}

A tension between myopic and farsighted incentives for FTA insiders creates the possibility of a dynamic exclusion incentive. Myopically, having sole preferential access in both spoke markets makes FTA formation with the FTA outsider attractive for an FTA insider: $\Delta w_{i}\left(g_{i}^{H}-g_{i j}^{F T A}\right)>0$. However, from a farsighted view, an FTA insider anticipates the subsequent erosion of this preferential access via the spoke-spoke FTA that precipitates global free trade. Indeed, Lemma 4.2(ii) said an FTA insider holds an exclusion incentive, and thus benefits from permanently excluding the FTA outsider from subsequent FTA formation, with a sufficiently tight tariff binding: $\Delta w_{i}\left(g_{i j}^{F T A}-g^{F T}\right)>0$ if and only if $\tau<\bar{\tau}_{I N}^{F T A}$. That is, an FTA insider does not hold an exclusion incentive when the binding is sufficiently lax because the relatively high FTA outsider tariffs make FTA formation with the FTA outsider attractive. In this case, there is no dynamic exclusion incentive because FTA formation with the FTA outsider is attractive from both myopic and farsighted perspectives.

However, an FTA insider holds an exclusion incentive with a sufficiently tight tariff binding $\left(\tau<\bar{\tau}_{I N}^{F T A}\right)$. Here, by constraining the FTA outsider's applied tariff, the FTA insiders extract substantial tariff concessions from the FTA outsider without any reciprocal concessions to the FTA outsider. In turn, the discount factor mediates the myopic incentive to become the hub and the farsighted incentive to exclude the FTA outsider. Specifically, an FTA insider prefers to become the hub rather than remain a permanent FTA insider when

$$
w_{i}\left(g_{i}^{H}\right)+\frac{\beta}{1-\beta} w_{i}\left(g^{F T}\right)>\frac{1}{1-\beta} w_{i}\left(g_{i j}^{F T A}\right) .
$$

As one would expect from our above discussion, this can only fail if the FTA insider holds an exclusion incentive $\Delta w_{i}\left(g_{i j}^{F T A}-g^{F T}\right)>0$. Further, (4.3) reduces to

$$
\beta<\bar{\beta}_{I N}(\tau) \equiv\left[1+\frac{\Delta w_{i}\left(g_{i j}^{F T A}-g^{F T}\right)}{\Delta w_{i}\left(g_{i}^{H}-g_{i j}^{F T}\right)}\right]^{-1} .
$$

which says a sufficiently myopic FTA insider becomes the hub or, alternatively, a sufficiently patient FTA insider refuses subsequent FTA formation with the FTA outsider. In this latter case, i.e. $\beta>\bar{\beta}_{I N}(\tau)$, we say the FTA insider has a dynamic exclusion incentive. Moreover, the extent that the FTA insider holds a dynamic exclusion incentive rises (i.e. $\bar{\beta}_{I N}(\tau)$ falls $)$ as the exclusion incentive $\Delta w_{i}\left(g_{i j}^{F T A}-g_{i}^{F T}\right)$ increases relative to the myopic incentive of becoming the hub $\Delta w_{i}\left(g_{i}^{H}-g_{i j}^{F T A}\right)$.

Figure 4.3 illustrates the dynamic exclusion incentive and how it varies with the tariff binding $\tau$. An FTA insider has a dynamic exclusion incentive when $\beta>\bar{\beta}_{I N}(\tau)$. In this case, an FTA insider is sufficiently patient that the farsighted nature of the exclusion incentive dominates the myopic incentive to become the hub and, hence, the FTA insider refuses subsequent FTA formation with the FTA outsider. Naturally, a pre-requisite for the dynamic exclusion incentive, i.e. $\bar{\beta}_{I N}(\tau)<1$, is that the FTA insider actually holds an exclusion incentive. As discussed above, this requires sufficiently tight tariff bindings, $\Delta w_{i}\left(g_{i j}^{F T A}-g^{F T}\right)>0$ if and only if $\tau<\bar{\tau}_{I N}^{F T A}$, so that the FTA insider extracts substantial 
tariff concessions from the FTA outsider without engaging in FTA formation with the FTA outsider. As Figure 4.3 shows, the dynamic exclusion continues strengthening, i.e. $\bar{\beta}_{I N}(\tau)$ falls, as the tariff binding falls through FTA binding region $\tau<\bar{\tau}_{I N}^{F T A}$.

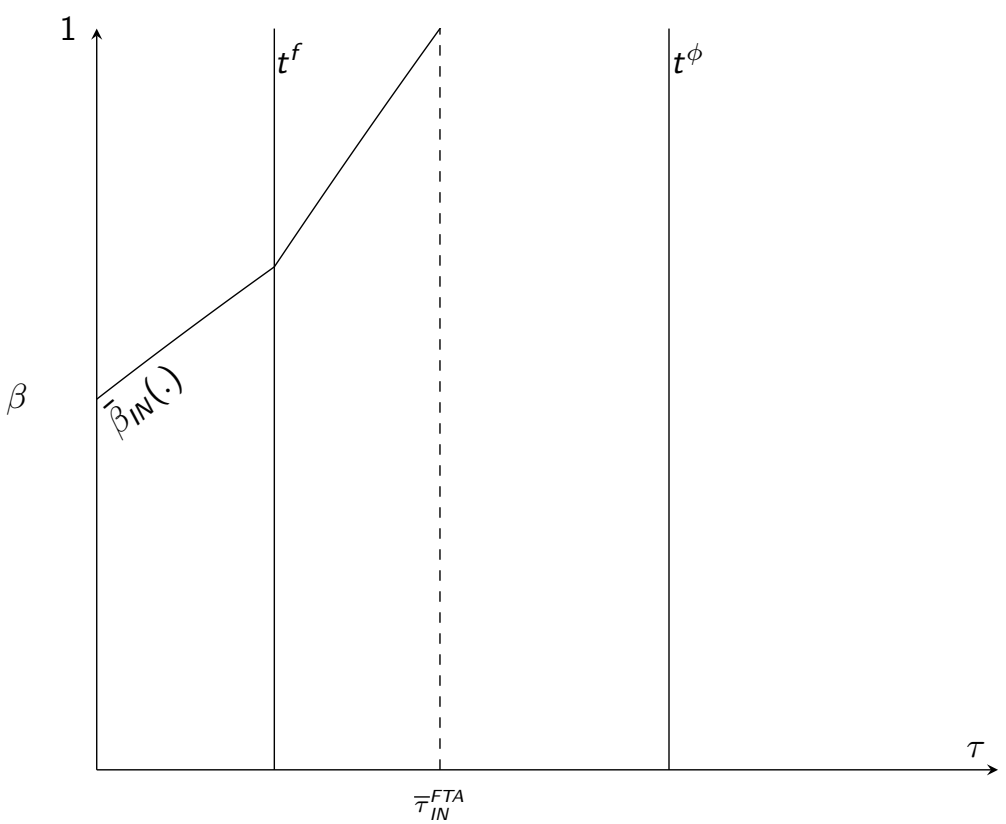

Figure 4.3: Dynamic exclusion incentive

The dynamic free riding incentive faced by the FTA outsider and the dynamic exclusion incentive faced by the FTA insiders interact in determining whether subsequent FTA formation takes place. Put simply, subsequent FTA formation takes place between an FTA insider and the FTA outsider if and only if the FTA outsider does not hold a dynamic free riding incentive and the FTA insiders do not hold a dynamic exclusion incentive. Otherwise, the FTA outsider exploits its dynamic free riding incentive and free rides on FTA formation by the FTA insiders or the FTA insiders exploit their dynamic exclusion incentive and exclude the FTA outsider from subsequent FTA formation. Lemma 4.4 summarizes these findings.

Lemma 4.4 Consider a subgame at an FTA insider-outsider network $g_{i j}^{F T A}$ where country $i$ proposes before country $j$. Then, the equilibrium outcome in the subgame is

(i) An FTA between the outsider and an insider (i.e. $\left.g_{i j}^{F T A} \rightarrow g_{i}^{H}\right)$ if $\beta \in\left(\bar{\beta}_{I N}(\tau), \bar{\beta}_{\text {OUT }}(\tau)\right)$

(ii) No FTA (i.e. $g_{i j}^{F T A} \rightarrow g_{i j}^{F T A}$ ) if $\beta \notin\left(\bar{\beta}_{I N}(\tau), \bar{\beta}_{O U T}(\tau)\right)$. 


\subsubsection{Subgame at empty network}

Rolling back to the subgame at the empty network $g_{\varnothing}$ and solving the equilibrium outcome in this subgame reveals the equilibrium path of networks. The key intuition revolves around the dynamic free riding incentive of the FTA outsider and the dynamic exclusion incentive of FTA insiders, and how these vary with the tariff binding. However, the equilibrium path of networks also relies on two additional dynamic properties summarized by Lemma 4.5.

Lemma 4.5 (i) $V_{z}\left(g_{i j}^{F T A}\right)>V_{z}\left(g_{\varnothing}\right)$ for $z=i, j$.

(ii) $V_{i}\left(g_{i j}^{F T A}\right)>V_{i}\left(g_{j k}^{F T A}\right)$ when $g_{i j}^{F T A} \rightarrow g_{i}^{H} \rightarrow g^{F T}$ and $g_{j k}^{F T A} \rightarrow g_{j}^{H} \rightarrow g^{F T}$.

Part (i) reflects a participation constraint for FTA insiders. Given Lemma 4.1(i), these participation constraints really govern situations where FTA formation expands to global free trade and say that the associated continuation payoffs for an FTA insider exceeds their continuation payoff in a world without PTAs. Given the benefit of being the hub, the tightest participation constraint is for the FTA insider-turned-spoke and says they prefer being an insider-turned-spoke on the path to global free trade over the world without any PTAs.

Given the benefits of tariff complementarity for an FTA outsider, a country may myopically prefer being an FTA insider over an FTA outsider. Nevertheless, part (ii) says that, when FTA formation expands to global free trade, a country's continuation payoff as an FTA insider-turned-hub exceeds that as an FTA outsider-turned-spoke. Intuitively, if a country participates in FTA expansion to global free trade as an FTA outsider then the myopic free riding incentive is sufficiently weak that the benefit of being the hub ensures it prefers being the FTA insider-turned-hub over the FTA outsider-turned-spoke. ${ }^{6}$

Proposition 4.1 now summarizes the equilibrium path of networks.

Proposition 4.1 The equilibrium path of networks in the FTA game is

(i) $g_{\varnothing} \rightarrow g_{a c}^{F T A} \rightarrow g_{a}^{H} \rightarrow g^{F T}$ when $\beta \in\left(\bar{\beta}_{I N}(\tau), \bar{\beta}_{\text {OUT }}(\tau)\right)$ and $\tau \geq \tilde{\tau}$

(ii) $g_{\varnothing} \rightarrow g_{a b}^{F T A} \rightarrow g_{a}^{H} \rightarrow g^{F T}$ when $\beta \in\left(\bar{\beta}_{I N}(\tau), \bar{\beta}_{O U T}(\tau)\right)$ and $\tau<\tilde{\tau}$

(iii) $g_{\varnothing} \rightarrow g_{a b}^{F T A}$ when $\beta \notin\left(\bar{\beta}_{I N}(\tau), \bar{\beta}_{O U T}(\tau)\right)$.

Proposition 4.1 says the equilibrium path of networks revolves around the dynamic free riding incentive of an FTA outsider and the dynamic exclusion incentive of an FTA insider. If neither the FTA outsider holds a dynamic exclusion incentive (i.e. $\beta>\bar{\beta}_{O U T}(\tau)$ ) nor an FTA insider holds a dynamic exclusion incentive (i.e. $\beta<\bar{\beta}_{I N}(\tau)$ ), the leader country, country $a$, becomes the hub on a path of FTAs leading to global free trade. However,

\footnotetext{
${ }^{6}$ Note that whether a country prefers being an FTA insider-turned-spoke or an FTA outsider-turnedspoke on the path to global free trade merely depends on whether a country myopically prefers being an FTA insider or an FTA outsider. That is, when $g_{i j}^{F T A} \rightarrow g_{j}^{H} \rightarrow g^{F T}$ and $g_{j k}^{F T A} \rightarrow g_{j}^{H} \rightarrow g^{F T}$ then $V_{i}\left(g_{i j}^{F T A}\right)>V_{i}\left(g_{j k}^{F T A}\right)$ if and only if $\Delta w_{i}\left(g_{i j}^{F T A}-g_{j k}^{F T A}\right)>0$.
} 
the leader country is a member of a permanent FTA if either the FTA outsider holds a dynamic free riding incentive or the FTA insiders hold a dynamic exclusion incentive (i.e. $\left.\beta \notin\left(\bar{\beta}_{I N}(\tau), \bar{\beta}_{O U T}(\tau)\right)\right)$. Thus, the dynamic free riding incentive and the dynamic exclusion incentive drive the equilibrium.

One subtlety emerges regarding the equilibrium path of networks. When $\tau \geq \tilde{\tau}$, the tariff binding is so lax that the myopic free riding incentive is sufficiently strong that countries myopically prefer being an FTA outsider than an FTA insider. Thus, when FTA formation expands to global free trade, country $b$ prefers being an FTA outsiderturned spoke over an FTA insider-turned-spoke. However, if country $b$ were to make an FTA proposal in stage 2 of the protocol, the attractiveness of being the hub implies it would propose an FTA with country $c$ and be the FTA insider-turned-hub on the path to global free trade. This threat implies country $b$ can credibly reject an FTA proposal from country $a$ (in stage 1a) knowing that such rejection will force country $a$ to propose FTA formation with country $c$ (in stage $1 b$ ) and leave country $b$ as the FTA outsiderturned-spoke. However, when FTA formation does not expand to global free trade, the non-economic benefits imply country $b$ proposes FTA formation with country $a$ if it makes an FTA proposal in stage 2. However, now country $b$ cannot credibly reject an FTA proposal from country $a$ in stage 1a because it knows it will eventually accept such a proposal.

Figure 4.4 shows how tariff binding liberalization changes the incentives that constrain FTA formation from reaching global free trade. For sufficiently high tariff bindings $\tau>\bar{\tau}_{I N}^{F T A}$, FTA insiders do not hold an exclusion incentive (i.e. $\Delta w_{i}\left(g^{F T}-g_{i j}^{F T A}\right)>0$ ) because the relatively high applied tariffs of the FTA outsider create strong incentives for FTA formation with the FTA outsider. In turn, a dynamic exclusion incentive does not exist. However, an FTA outsider holds a myopic free riding incentive whereby subsequent FTA formation is myopically unattractive. The relatively lax tariff bindings $\left(\tau>\bar{\tau}_{\text {OUT }}^{F T A}\right)$ imply the FTA outsider would give relatively large tariff concessions via FTA formation but receive relatively small concessions due to the tariff complementarity practiced by FTA insiders. In turn, a sufficiently myopic FTA outsider holds a dynamic free riding incentive and thus refuses subsequent FTA formation with an FTA insider. Ultimately, with relatively high tariff bindings, the dynamic free riding incentive constrains the attainment of global free trade.

However, as tariff bindings continually fall, the dynamic free riding incentive eventually disappears and the dynamic exclusion incentive becomes the force constraining the attainment of global free trade. Once the tariff binding falls below $\bar{\tau}_{\text {OUT }}^{F T \text {, the tariff binding }}$ constrains the FTA outsider such that the tariffs it imposes on the FTA insiders differ little from those faced by the FTA outsider. This makes the discrimination faced by the FTA outsider more prominent and eliminates any dynamic free riding incentive. However, the relatively low tariff binding means the FTA insiders have already extracted substantial tariff concessions from the FTA outsider and this generates an exclusion incentive for FTA insiders. In turn, despite the myopic incentive to become the hub, a sufficiently patient FTA insider holds a dynamic exclusion incentive and thus refuses subsequent FTA formation with the FTA outsider. Ultimately, with relatively low tariff bindings, the dynamic exclusion incentive of FTA insiders constrains the attainment of global free trade. 


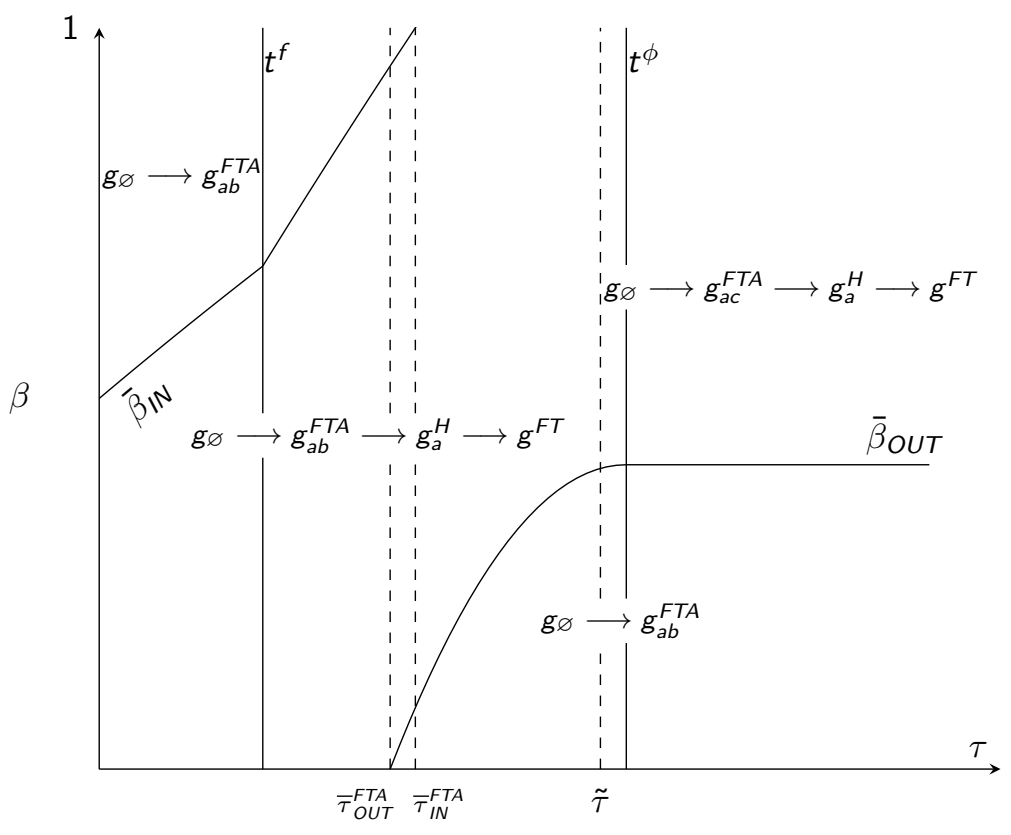

Figure 4.4: Equilibrium path of networks: FTA game

With an understanding of the forces constraining FTA expansion formation and how these forces vary with the tariff binding, we now ask how multilateral trade liberalization through lower tariff bindings impacts the extent of FTA formation. Corollary 4.1 answers this question.

Corollary 4.1 Consider sufficiently high tariff bindings $\tau>\bar{\tau}_{I N}^{F T A}$. Then:

(i) When global free trade is not attained for $\tau>\bar{\tau}_{I N}^{F T A}$, multilateral tariff binding liberalization facilitates FTA formation in achieving global free trade.

(ii) When global free trade is attained for $\tau>\bar{\tau}_{I N}^{F T A}$, multilateral tariff binding liberalization never facilitates but can impede FTA formation in achieving global free trade.

Corollary 4.1 highlights the fundamental importance of multilateral tariff binding liberalization for the prospect of FTA expansion leading to global free trade. With sufficiently high tariff bindings, the dynamic free riding incentive constrains the attainment of global free trade. In particular, when global free trade is not attained for $\tau>\bar{\tau}_{I N}^{F T A}$ then countries are sufficiently myopic, $\beta<\bar{\beta}_{\text {OUT }}\left(t^{\phi}\right)$, that the myopic free riding incentive can generate the dynamic free riding incentive. Specifically, for any tariff binding $\tau>\bar{\tau}_{I N}^{F T A}$, the FTA outsider has a dynamic free riding incentive when $\beta<\bar{\beta}_{\text {OUT }}(\tau)$ and this prevents FTA expansion to global free trade. Nevertheless, tariff binding liberalization weakens the dynamic free riding incentive by constraining the FTA outsider's ability to impose tariffs on the FTA insiders. Formally, this raises the extent that global free trade is attained by 


\begin{tabular}{c|ccc} 
& $P_{i}(g)$ & $P_{j}(g)$ & $P_{k}(g)$ \\
\hline \hline$g_{\varnothing}$ & $\left\{\phi, i j^{C U}, i k^{C U}\right\}$ & $\left\{\phi, i j^{C U}, j k^{C U}\right\}$ & $\left\{\phi, i k^{C U}, j k^{C U}\right\}$ \\
$g_{i j}^{C U}$ & $\left\{\phi, i j k^{F T A}\right\}$ & $\left\{\phi, i j k^{C U}\right\}$ & $\left\{\phi, i j k^{C U}\right\}$ \\
$g^{F T}$ & $\{\phi\}$ & $\{\phi\}$ & $\{\phi\}$ \\
\hline
\end{tabular}

Table 4.3: Proposer country's action space for each subgame in CU game

reducing $\bar{\beta}_{\text {OUT }}(\tau)$ and implies that multilateral tariff binding liberalization complements FTA formation in attaining global free trade.

Conversely, the dynamic exclusion incentive constrains global free trade with sufficiently low tariff bindings and further multilateral tariff binding liberalization further constrains the attainment of global free trade. In particular, when global free trade is attained for $\tau>\bar{\tau}_{I N}^{F T A}$ then countries are sufficiently patient $\beta>\bar{\beta}_{O U T}(\tau)$ and do not hold a dynamic exclusion incentive nor a dynamic free riding incentive. However, for any tariff binding $\tau<\bar{\tau}_{I N}^{F T A}$, the FTA insiders have a dynamic exclusion incentive when they are sufficiently patient, $\beta>\bar{\beta}_{I N}(\tau)$, and this prevents FTA expansion to global free trade. Moreover, further liberalization only increases the magnitude of tariff concessions that FTA insiders extract from the FTA outsider without having to form FTAs with the outsider. This strengthens the dynamic exclusion incentive. Formally, multilateral tariff binding liberalization reduces the extent that global free trade is attained by reducing $\bar{\beta}_{I N}(\tau)$ and implies that multilateral tariff binding liberalization impedes FTA formation in achieving global free trade. ${ }^{7}$

\subsection{Equilibrium path of networks: CU game}

In this section, we analyze the "CU game" where countries can only form CUs. Analogous to our "FTA game" proposals in Table 4.2, Table 4.3 displays the set of proposals of our "CU game".

The different tariff setting behavior of FTA insiders versus CU insiders fundamentally impacts the ability of PTA members to form subsequent PTAs. Specifically, because $\mathrm{CU}$ insiders impose a common external tariffs on non-members, they cannot individually form their own subsequent PTA. Rather, CU insiders can only engage in subsequent PTA formation jointly with, and with the consent of, its CU insider partner. When Section ?? analyzes the "PTA game" where countries can form FTAs or CUs, this has important implications on PTA formation incentives for members and non-members.

\subsubsection{CU formation incentives}

Unlike FTA formation, CU formation does not generate a tension between myopic and farsighted incentives because $\mathrm{CU}$ expansion must move directly from the CU insider-outsider

\footnotetext{
${ }^{7}$ When $\beta$ lies in the intermediate range $\beta \in\left(\bar{\beta}_{O U T}\left(\tau=t^{\phi}\right), \bar{\beta}_{I N}(\tau=0)\right)$, Figure 4.4 shows that tariff binding liberalization neither facilitates nor impedes FTA formation in achieving global free trade.
} 
network to global free trade and CU insiders have veto power over such CU expansion. Lemma 4.6 describes the myopic incentives driving the equilibrium path of networks.

Lemma 4.6 (i) $\Delta w_{i}\left(g_{i j}^{C U}-g_{\varnothing}\right)>0$ but $\Delta w_{k}\left(g_{i j}^{C U}-g_{\varnothing}\right)<0$

(ii) $\Delta w_{k}\left(g^{F T}-g_{i j}^{C U}\right)>0$ for all $\tau$ but $\Delta w_{i}\left(g^{F T}-g_{i j}^{C U}\right)>0$ if and only if $\tau>\bar{\tau}_{I N}^{C U}$ where $\bar{\tau}_{I N}^{C U} \in\left(t^{u}, t^{p h i}\right)$.

(iii) $\Delta w_{i}\left(g_{i j}^{C U}-g_{i j}^{F T A}\right)>0$ for $\tau>t^{f}$.

Part (i) governs the impact of $\mathrm{CU}$ formation on $\mathrm{CU}$ insiders and the $\mathrm{CU}$ outsider. First, CU insiders benefit which is not surprising given that FTA insiders benefit from FTA formation and the coordination of external tariffs allows CU insiders to internalize the negative intra-PTA externality of tariff complementarity. Second, unlike the outsider who could benefit from FTA formation, the CU outsider always suffers from CU formation. While CU insiders may practice tariff complementarity, they also internalize the negative intra-PTA externality of tariff complementarity. In turn, the discrimination faced by the CU outsider always dominates any tariff complementarity benefit.

Part (ii) governs the incentives of $\mathrm{CU}$ insiders and the $\mathrm{CU}$ outsider for $\mathrm{CU}$ expansion to global free trade. First, the CU outsider always benefits from such expansion. This is not surprising given that the FTA outsider always benefited from simultaneously eliminating the discrimination faced in both FTA insider markets and that the CU outsider faces a greater degree of discrimination than the FTA outsider. Thus, the CU outsider does not hold any type of free riding incentive. Second, similar to FTA insiders, CU insiders have an incentive to exclude the $\mathrm{CU}$ outsider from global free trade under sufficiently tight tariff bindings: $\Delta w_{i}\left(g^{F T}-g_{i j}^{C U}\right)<0$ when $\tau<\bar{\tau}_{I N}^{C U}$. Indeed, given CU insiders internalize the negative intra-PTA externality of tariff complementarity, this CU exclusion incentive is stronger than the FTA exclusion incentive so that $\bar{\tau}_{I N}^{F T A}<\bar{\tau}_{I N}^{C U}$.

Part (iii) captures an important incentive for the PTA game in Section ??. Unlike FTA insiders, CU insiders internalize the negative intra-PTA externality of tariff complementarity through coordinating their external tariffs. Thus, part (iii) describes the myopic coordination benefit of CU formation. Naturally, this benefit disappears in the "FTA binding region" of $\tau \leq t^{f}$ because FTA and CU insiders levy the same tariff given both are bound by the tariff binding.

Ultimately, the fact that $\mathrm{CU}$ expansion proceeds directly from the $\mathrm{CU}$ insider-outsider network to global free trade, unlike FTA formation which proceeded through the hubspoke network, implies there is no tension between myopic and farsighted CU formation incentives. Moreover, given the CU outsider always benefits from CU expansion to global free trade, the $\mathrm{CU}$ exclusion incentive of $\mathrm{CU}$ insiders is the incentive that constrains the attainment of global free trade. Thus, CU expansion takes place if and only if $\mathrm{CU}$ insiders do not hold an exclusion incentive with the leader country always proposing CU formation and being a CU insider. Proposition 4.2 summarizes this result and Figure 4.5 illustrates.

Proposition 4.2 The equilibrium path of networks in the $C U$ game is 
(i) $g_{\varnothing} \longrightarrow g_{a b}^{C U} \longrightarrow g^{F T}$ when $\tau>\bar{\tau}_{I N}^{C U}$

(ii) $g_{\varnothing} \rightarrow g_{a b}^{C U}$ when $\tau<\bar{\tau}_{I N}^{C U}$.

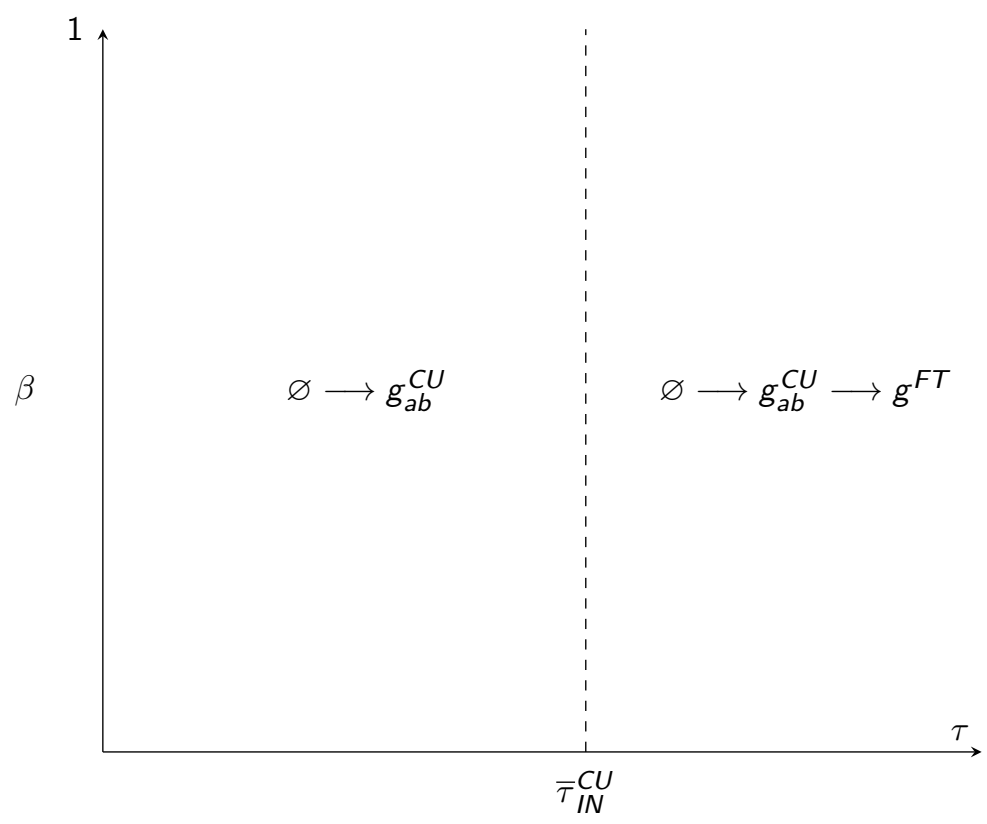

Figure 4.5: Equilibrium path of networks: CU game 


\subsection{Conclusion}

In this chapter, we investigate the impact of multilateral tariff binding liberalization on the Markov perfect equilibrium of Free Trade Agreement (FTA) and Customs Union (CU) formation in an isolated fashion. Under relatively high tariff bindings, multilateral tariff binding liberalization can facilitate or impede whether FTA expansion reaches global free trade. With relatively high tariff bindings, the intuition revolves around the FTA non-member's dynamic free riding incentive. Here, the FTA non-member weighs a myopic incentive to free ride on the tariff complementarity of FTA members against a farsighted incentive to reach global free trade which eliminates the discrimination practiced by FTA members. When the myopic free riding incentive dominates, continual tariff binding liberalization facilitates FTA expansion to global free trade by constraining the FTA nonmembers' tariffs on FTA members and, thus, eventually eliminating the myopic free riding incentive. However, when the farsighted incentive for global free trade dominates, continual tariff binding liberalization impedes FTA expansion to global free trade by effectively increasing the FTA non-members' concessions to FTA members and eventually creating an incentive for FTA members to exclude the non-member from subsequent FTA expansion. Ultimately, tariff binding liberalization crucially impacts the incentives governing whether FTA expansion reaches global free trade.

Unlike our "FTA game" which features tensions between myopic and farsighted incentives, our "CU game" is much simpler. Two observations are important: (i) CU expansion must move directly from the $\mathrm{CU}$ insider-outsider network to global free trade and (ii) $\mathrm{CU}$ insiders have veto power over such CU expansion. While the CU non-member always benefits from $\mathrm{CU}$ expansion to global free trade, $\mathrm{CU}$ insiders want to exclude the $\mathrm{CU}$ non-member from such expansion when the tariff binding is relatively low. As for FTA insiders, a relatively low tariff binding implies the CU members have extracted substantial tariff concessions from the $\mathrm{CU}$ non-member without giving concessions to the $\mathrm{CU}$ nonmember via $\mathrm{CU}$ expansion. Thus, $\mathrm{CU}$ formation proceeds to global free trade only for relatively high tariff bindings. 


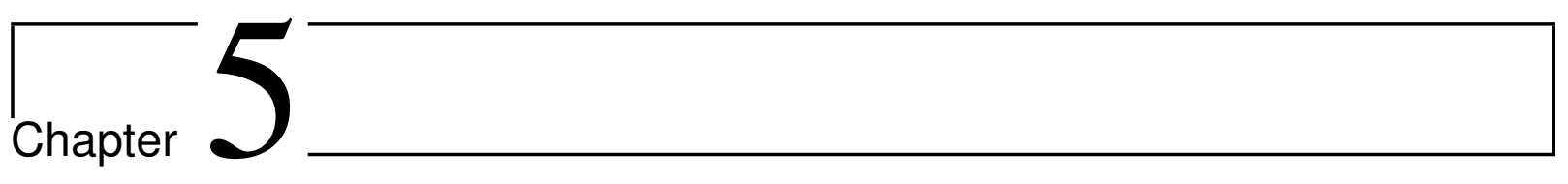

\section{Dynamic equilibrium with the endogenous choice between Free Trade Agreements and Customs Union}

In this chapter, we tackle another key question of this dissertation: whether a given type of PTA (i.e., FTAs or CUs) improves or hurts the prospects of global free trade relative to the outcome if this type of PTA was banned? To this end, we analyse our "PTA game" where countries can choose between FTA and CU formation and we introduce the terminology of a "PTA stumbling bloc" and a "PTA building bloc". We say that CUs (FTAs) are a "PTA stumbling bloc" if CU (FTA) formation emerges in equilibrium and does not lead to global free trade yet FTA (CU) formation would lead to global free trade in the absence of CUs (FTAs). Similarly, we say that CUs (FTAs) are a "PTA building bloc" if CU (FTA) formation emerges in equilibrium and leads to global free trade yet FTA (CU) formation would not lead to global free trade in the absence of CUs (FTAs).

Whether FTAs or CUs emerge in equilibrium revolves around a dynamic trade off. On one hand, $\mathrm{CU}$ formation confers coordination benefits on $\mathrm{CU}$ members. From a myopic perspective, CU members benefit from coordination of their external tariffs internalizing the negative intra-PTA externality of tariff complementarity. From a farsighted perspective, CU members benefit from the implication that coordination of their external tariffs confers veto power on each $\mathrm{CU}$ member regarding subsequent $\mathrm{CU}$ expansion to global free trade. This veto power is valuable in the presence of a $\mathrm{CU}$ exclusion incentive because, in contrast, each FTA member can form their own subsequent FTA with the FTA non-member and thus precipitate FTA expansion to global free trade. On the other hand, the ability of each FTA member to form their own subsequent FTA with the non-member confers an FTA flexibility benefit on FTA members. This FTA flexibility benefit is valuable because it allows a member of an initial FTA to then become the "hub" and have sole preferential access with the other two "spoke" countries.

Ultimately, FTAs and CUs play very different roles in helping or hurting the prospects for global free trade. On one hand, FTAs can be PTA building blocs but never PTA 
stumbling blocs. That is, when FTA formation emerges in equilibrium then (i) it can lead to global free trade when CU formation would not but (ii) if it does not lead to global free trade then neither does CU formation. On the other hand, CUs can be PTA stumbling blocs but never PTA building blocs. That is, when $\mathrm{CU}$ formation emerges in equilibrium then (i) there are conditions where CU expansion will not, but FTA expansion will, lead to global free trade and (ii) when $\mathrm{CU}$ formation leads to global free trade then so does FTA formation. In particular, this PTA building bloc role of FTAs and PTA stumbling bloc role of CUs emerges for an intermediate degree of tariff bindings. This suggests that the asymmetric impact of FTAs versus CUs may have become more prevalent with the phase in of Uruguay Round multilateral tariff binding liberalization and plurilateral tariff binding agreements like the Information Technology Agreement.

Surprisingly few papers have addressed the impact of multilateral tariff liberalization on the extent of PTA formation (Freund et al. (2010)). Ethier (1998) argues PTA formation is a benign consequence of multilateralism whereby countries left out of earlier rounds of multilateral tariff liberalization utilize PTA formation. In a repeated game setting, Freund (2000) shows how multilateral tariff liberalization can make an FTA "self-enforcing". Like our paper, in Chapter 4 we find that tariff binding liberalization weakens the free riding incentive of FTA non-members. Because of this, like Freund (2000), multilateral tariff liberalization facilitates FTA expansion. In contrast to these positive views regarding multilateral tariff liberalization, Lake et al. (2017) show how endogenous determination of multilateral tariff bindings generates an FTA exclusion that otherwise would not exist. Like our paper, relatively tight multilateral tariff bindings deliver tariff concessions from FTA non-members to FTA members without FTA members needing to form FTAs with non-members. Ultimately, multilateralism acts as a stumbling bloc to global free trade for Lake et al. (2017).

\subsection{FTA Flexibility benefit}

As stated before, the central difference between an FTA and a CU is that members of a CU impose common external tariffs on non-members whereas FTA members adopt individually optimal tariffs. This different tariff setting behaviour has an important implication for subsequent PTA formation: while an FTA member can freely form additional FTAs with non-member countries without the consent of existing FTA partners, CU members must form additional CUs together and any initial $\mathrm{CU}$ member has veto power. That is, unlike CU members who must jointly form a subsequent PTA with the CU outsider, FTA members have the flexibility to form their own individual FTAs with the FTA outsider.

The flexibility of FTAs confers an FTA flexibility benefit on FTA insiders. Unlike CU insiders who lose preferential access with each other upon $\mathrm{CU}$ expansion to global free trade, an FTA insider enjoys sole preferential access to both spoke markets upon becoming the hub via FTA expansion. Formally, Lemma 4.1(v) captured this FTA flexibility benefit as $w_{i}\left(g_{i}^{H}-g^{F T}\right)>0$. That is, the FTA flexibility benefit for an FTA insider captures the higher payoff from becoming the hub via subsequent FTA formation relative to subsequent CU formation which must proceed directly to global free trade. 


\subsection{Myopic and farsighted CU coordination benefits}

Unlike FTA members who retain sovereign discretion over their external tariffs, CU insiders coordinate their external tariffs and this coordination generates myopic and farsighted coordination benefits. Myopically, coordination of external tariffs allows internalization of the negative intra-PTA externality posed by tariff complementarity. As long as the tariff binding lies above the "FTA binding" region, i.e. $\tau>t^{f}$, the tariff binding does not completely eliminate the CU insiders' ability to internalize this externality: $w_{i}\left(g_{i j}^{C U}-g_{i j}^{F T A}\right)>0$ if $\tau>t^{f}$.

Moreover, the fact that $\mathrm{CU}$ expansion requires joint approval of $\mathrm{CU}$ insiders, due to the requirement of common external tariff, can generate a farsighted $\mathrm{CU}$ coordination benefit. Specifically, while each CU insider can veto CU expansion to global free trade, each FTA insider can precipitate global free trade by exploiting the FTA flexibility benefit to become the hub on the path to global free trade. Thus, $w_{i}\left(g_{i j}^{C U}-g^{F T}\right)>0$ not only represents the $\mathrm{CU}$ exclusion incentive but and also the farsighted coordination benefit of $\mathrm{CU}$ formation in that PTA insiders can form CUs and, due to external tariff coordination, ensure PTA expansion does not take place. As discussed above, CU insiders hold a CU exclusion incentive, and hence $\mathrm{CU}$ formation has a farsighted coordination benefit, when the tariff binding is sufficiently tight, $\tau<\bar{\tau}_{I N}^{C U}$.

\subsection{Trade-off between FTA flexibility benefit and CU coordination benefits}

The trade off between the FTA flexibility benefit and CU coordination benefits generates a dynamic trade off. Further, the exact nature of the trade-off depends on whether CU insiders hold an exclusion incentive.

In general, country $i$ prefers being an FTA insider and then the hub on the path to global free trade over being a CU insider when

$$
V_{i}\left(g_{i j}^{F T A}\right)=w_{i}\left(g_{i j}^{F T A}\right)+\beta w_{i}\left(g_{i}^{H}\right)+\frac{\beta^{2}}{1-\beta} w_{i}\left(g^{F T}\right)>V_{i}\left(g_{i j}^{C U}\right)
$$

When CU insiders do not hold a CU exclusion incentive, and hence there is no farsighted $\mathrm{CU}$ coordination benefit, $\mathrm{CU}$ formation expands to global free trade. Then, $V_{i}\left(g_{i j}^{C U}\right)=$ $w_{i}\left(g_{i j}^{C U}\right)+\frac{\beta}{1-\beta} w_{i}\left(g^{F T}\right)$ and we can rewrite (5.1) as

$$
\beta \underbrace{\left[w_{i}\left(g_{i}^{H}\right)-w_{i}\left(g^{F T}\right)\right]}_{\text {FTA flexibility benefit }}>\underbrace{\left[w_{i}\left(g_{i j}^{C U}\right)-w_{i}\left(g_{i j}^{F T A}\right)\right]}_{\text {myopic CU coordination benefit }} .
$$

That is, a country prefers being an FTA insider and then the hub on the path to global free trade over a $\mathrm{CU}$ insider on the path to global free trade if and only if the discounted 
FTA flexibility benefit dominates the myopic CU coordination benefit. In terms of the threshold discount factor, (5.4) reduces to

$$
\beta>\underline{\beta}^{\text {Flex }}(\tau) \equiv \frac{w_{i}\left(g_{i j}^{C U}-g_{i j}^{F T A}\right)}{w_{i}\left(g_{i}^{H}-g^{F T}\right)}
$$

where $\beta_{\text {Flex }}(\tau)$ measures the size of the myopic CU coordination benefit relative to the FTA flexibility benefit. As the FTA flexibility benefit grows relative to myopic CU coordination benefit then $\underline{\beta}_{\text {Flex }}(\tau)$ falls and, thus, the extent of FTA formation expands.

However, when $\mathrm{CU}$ insiders hold a CU exclusion incentive, i.e. $\tau<\bar{\tau}_{I N}^{C U}$, they hold a farsighted CU coordination benefit and this modifies the flexibility-coordination trade off. Given CU insiders exclude the CU outsider from CU expansion, $V_{i}\left(g_{i j}^{C U}\right)=\frac{1}{1-\beta} w_{i}\left(g_{i j}^{C U}\right)$ and we can rewrite (5.1) as

$$
\beta \underbrace{\left[w_{i}\left(g_{i}^{H}\right)-w_{i}\left(g^{F T}\right)\right]}_{\text {FTA flexibility benefit }}>\underbrace{\left[w_{i}\left(g_{i j}^{C U}\right)-w_{i}\left(g_{i j}^{F T}\right)\right]}_{\text {myopic CU coordination benefit }}+\frac{\beta}{1-\beta} \underbrace{\left[w_{i}\left(g_{i j}^{C U}\right)-w_{i}\left(g^{F T}\right)\right]}_{\text {farsighted CU coordination benefit }} .
$$

That is, a country prefers being an FTA insider and then the hub on the path to global free trade over a permanent CU insider if and only if the discounted FTA flexibility benefit dominates the myopic CU coordination benefit and the discounted farsighted CU coordination benefit. In terms of the threshold discount factor, (5.4) reduces to

$$
\beta \in\left(\underline{\beta}^{\text {Flex }}(\tau), \bar{\beta}^{\text {Flex }}(\tau)\right)
$$

Again, a stronger FTA flexibility relaxes the inequality in (5.4) and expands the extent of FTA formation while a stronger myopic CU coordination benefit tightens the inequality in (5.4) and constrains the extent of FTA formation. However, now the farsighted part of the CU coordination benefit, as captured by the size of the CU exclusion incentive $w_{i}\left(g_{i j}^{C U}-g^{F T}\right)>0$, also tightens the inequality in (5.4). Thus, as either the myopic or farsighted part of the CU coordination benefit become stronger then the extent of FTA formation falls.

Figure 5.1 illustrates how the trade off between the FTA flexibility benefit and CU coordination benefits change with the tariff binding. In general, the CU coordination benefits consist of a myopic component, revolving around internalization of tariff complementarity by $\mathrm{CU}$ insiders, and a farsighted component, revolving around a desire by $\mathrm{CU}$ insiders to exclude the $\mathrm{CU}$ outsider. However, $\mathrm{CU}$ insiders do not hold an exclusion incentive when the tariff binding exceeds $\bar{\tau}_{I N}^{C U}$. Thus, for $\tau>\bar{\tau}_{I N}^{C U}$, the CU coordination benefit is merely the myopic CU coordination benefit. As described by (5.3), sufficient patience, i.e. $\beta>\underline{\beta}_{\text {Flex }}(\tau)$, implies the farsighted nature of the FTA flexibility benefit dominates the myopic CU coordination benefit. Two reasons explain why $\underline{\beta}_{\text {Flex }}(\tau)$ remains constant for $\tau>\bar{\tau}_{I N}^{C U}$. First, $t^{f}<t^{u}<\bar{\tau}_{I N}^{C U}$ implies a tariff binding above $\overline{\bar{\tau}}_{I N}^{C U}$ does not bind the applied tariffs of FTA nor CU insiders. Second, while $\bar{\tau}_{I N}^{C U}<t_{\varnothing}$ implies a tariff binding above $\bar{\tau}_{I N}^{C U}$ 
could bind the FTA and CU outsider, they have the same optimal applied tariff. Thus, the myopic CU coordination benefit and the FTA flexibility benefit underlying $\underline{\beta}_{\text {Flex }}(\tau)$ in (5.3) remain constant for tariff bindings above $\bar{\tau}_{I N}^{C U}$.

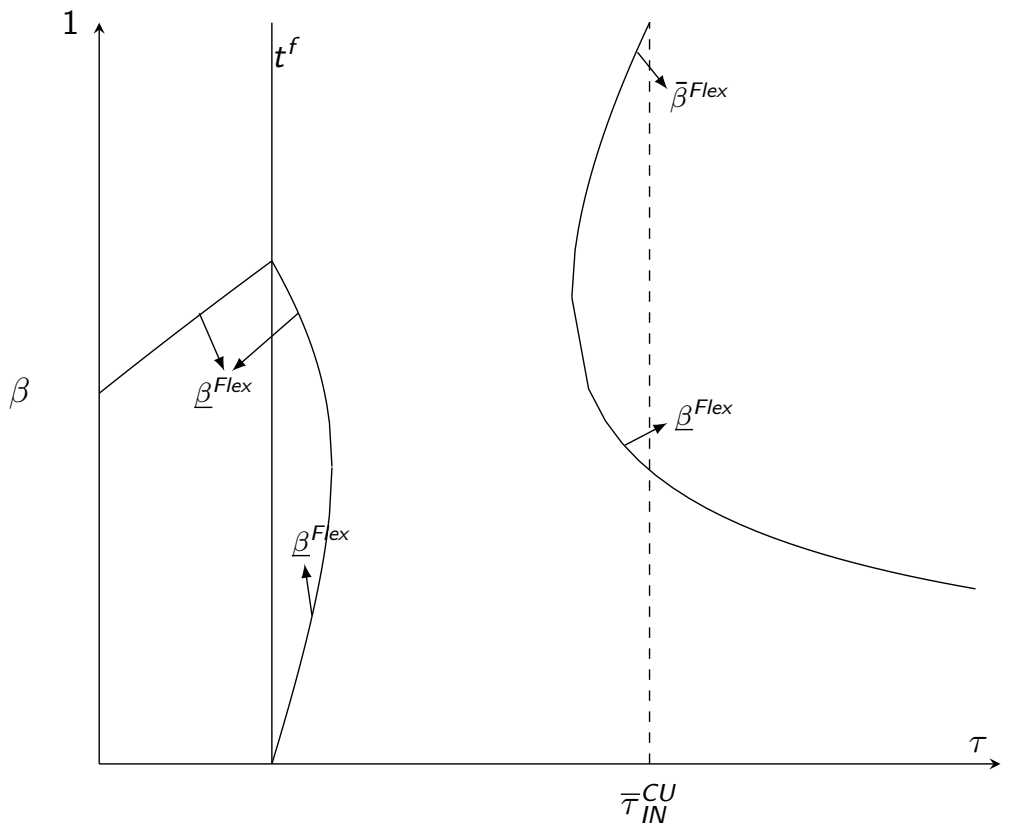

Figure 5.1: Flexibility benefit of FTAs versus coordination benefits of CUs

While only the myopic CU coordination benefit exists when $\tau>\bar{\tau}_{I N}^{C U}$, only the farsighted CU coordination benefit exists once $\tau \leq t^{f}$. Here, the tariff binding binds FTA and $\mathrm{CU}$ insiders and outsiders and, hence, eliminates the myopic $\mathrm{CU}$ coordination benefit: $\Delta w_{i}\left(g_{i j}^{C U}-g_{i j}^{F T A}\right)=0$. Moreover, $\beta \in\left(\underline{\beta}^{\text {Flex }}(\tau), \bar{\beta}^{\text {Flex }}(\tau)\right)$ reduces to $\beta<\bar{\beta}^{\text {Flex }}(\tau)=$ $\bar{\beta}_{I N}(\tau)$ (see $(4.4)$ ). Nevertheless, the relatively strict tariff binding generates the CU exclusion incentive $\Delta w_{i}\left(g_{i j}^{C U}-g^{F T}\right)>0$. In turn, the farsighted CU coordination benefit emerges whereby, unlike FTA insiders who can precipitate global free trade by exploiting the FTA flexibility benefit and becoming the hub, CU formation carries veto power over subsequent CU expansion. Now $\bar{\beta}^{\text {Flex }}(\tau)$ balances the FTA flexibility benefit and farsighted CU coordination benefit with a sufficiently patient country preferring CU formation. Moreover, further tariff binding liberalization weakens the FTA flexibility benefit by shrinking the preference margin and thus farsighted coordination benefit becomes more pronounced relative to the flexibility benefit. In turn, tariff binding liberalization makes $\mathrm{CU}$ formation more attractive by shrinking $\bar{\beta}^{\text {Flex }}(\tau)$.

In the bullet shaped regions, where bindings lie just above $t^{f}$ or just below $\bar{\tau}_{I N}^{C U}$, both the myopic and farsighted CU coordination benefits exist. Thus, sufficiently patient and sufficiently myopic countries prefer CU formation over being the FTA insider and then the hub on the path to global free trade. As $\tau$ falls just below $\bar{\tau}_{I N}^{C U}$, the myopic CU coordination and FTA flexibility benefits remain constant because the tariff binding does not yet bind 
the tariffs of PTA insiders nor spokes. However, the CU exclusion incentive strengthens because the tariff binding now binds the $\mathrm{CU}$ outsider and hence delivers concessions to $\mathrm{CU}$ insiders. This stronger farsighted $\mathrm{CU}$ coordination benefit increases the attractiveness of $\mathrm{CU}$ formation and, indeed, countries eventually prefer $\mathrm{CU}$ formation regardless of the discount factor. Once $\tau \in\left(t^{f}, t^{u}\right)$, the FTA flexibility remains constant but the myopic $\mathrm{CU}$ coordination benefit weakens because the tariff binding now binds $\mathrm{CU}$ insiders. As $\tau$ nears $t^{f}$, FTA formation again becomes attractive for an intermediate range of the discount factor and becomes more attractive as the farsighted coordination benefit starts weakening since the tariff binding binds CU insiders and myopic CU coordination benefit continues weakening and eventually disappears.

With an understanding of the trade off between the FTA flexibility benefit and CU coordination benefits in place, Proposition 5.1 characterizes the equilibrium path of networks when countries endogenously choose between FTAs and CUs. Here, we let $\underline{\beta}_{\text {Flex }}(\tau) \equiv 0$ when the myopic $\mathrm{CU}$ coordination benefit disappears (i.e. $\tau<t^{f}$ ) and, similarly, we let $\bar{\beta}^{F l e x}(\tau) \equiv 1$ when the CU exclusion incentive disappears (i.e. $\tau>\bar{\tau}_{I N}^{C U}$ ).

Proposition 5.1 In equilibrium, FTA formation emerges when $\beta>\bar{\beta}_{\text {OUT }}(\tau)$ and $\beta \in$ $\left(\underline{\beta}_{\text {Flex }}(\tau), \bar{\beta}^{\text {Flex }}(\tau)\right)$ but $C U$ formation emerges otherwise. When FTA formation emerges in equilibrium, the equilibrium path of networks is $g_{\varnothing} \rightarrow g_{a b}^{F T A} \rightarrow g_{a}^{H} \rightarrow g^{F T}$ if $\tau<\tilde{\tau}$ but $g_{\varnothing} \rightarrow g_{a c}^{F T A} \rightarrow g_{a}^{H} \rightarrow g^{F T}$ if $\tau \geq \tilde{\tau}$. When $C U$ formation emerges in equilibrium, the equilibrium path of networks is $g_{\varnothing} \rightarrow g_{a b}^{C U} \rightarrow g^{F T}$ if $\tau>\bar{\tau}_{I N}^{C U}$ but $g_{\varnothing} \rightarrow g_{a b}^{C U}$ if $\tau \leq \bar{\tau}_{I N}^{C U}$.

Figure 5.2 illustrates Proposition 5.1. From our above discussion, one may have expected that FTA formation would emerge in equilibrium if and only if $\beta \in\left(\underline{\beta}_{\text {Flex }}(\tau), \bar{\beta}^{\text {Flex }}(\tau)\right)$. However, the trade off underlying this logic presumes FTA formation leads to global free trade. In contrast, Section 4.2 showed this only happens if the FTA outsider does not hold a dynamic free riding incentive and FTA insiders do not hold a dynamic exclusion incentive. On one hand, the myopic CU coordination benefit implies an FTA insider cannot simultaneously hold a dynamic exclusion incentive and prefer FTA formation over CU formation (i.e. $\bar{\beta}^{\text {Flex }}(\tau) \leq \bar{\beta}_{I N}(\tau)$ ). On the other hand, the FTA outsider may hold a dynamic free riding incentive when an FTA insider prefers FTA formation over than CU formation; indeed, $\underline{\beta}_{\text {Flex }}(\tau)<\bar{\beta}_{O U T}(\tau)$ obtains when $\tau>\bar{\tau}_{I N}^{C U}$. Thus, the equilibrium emergence of FTA formation requires not only that the FTA flexibility dominate the CU coordination benefits but also that the FTA outsider does not hold a dynamic free riding incentive. In this case, FTA expansion reaches global free trade.

When FTA formation does not emerge in equilibrium, either because PTA insiders see the $\mathrm{CU}$ coordination benefits as dominating the FTA flexibility benefit or because the FTA outsider has a dynamic free riding incentive, PTA insiders form a $\mathrm{CU}$ to exploit the $\mathrm{CU}$ coordination benefits. If the tariff binding exceeds $\bar{\tau}_{I N}^{C U}$ then $\mathrm{CU}$ insiders do not hold a CU exclusion incentive and the $\mathrm{CU}$ coordination benefit consists entirely of the myopic $\mathrm{CU}$ coordination benefit stemming from the internalization of tariff complementarity. In this case, CU formation expands to global free trade. However, if the tariff binding falls below 


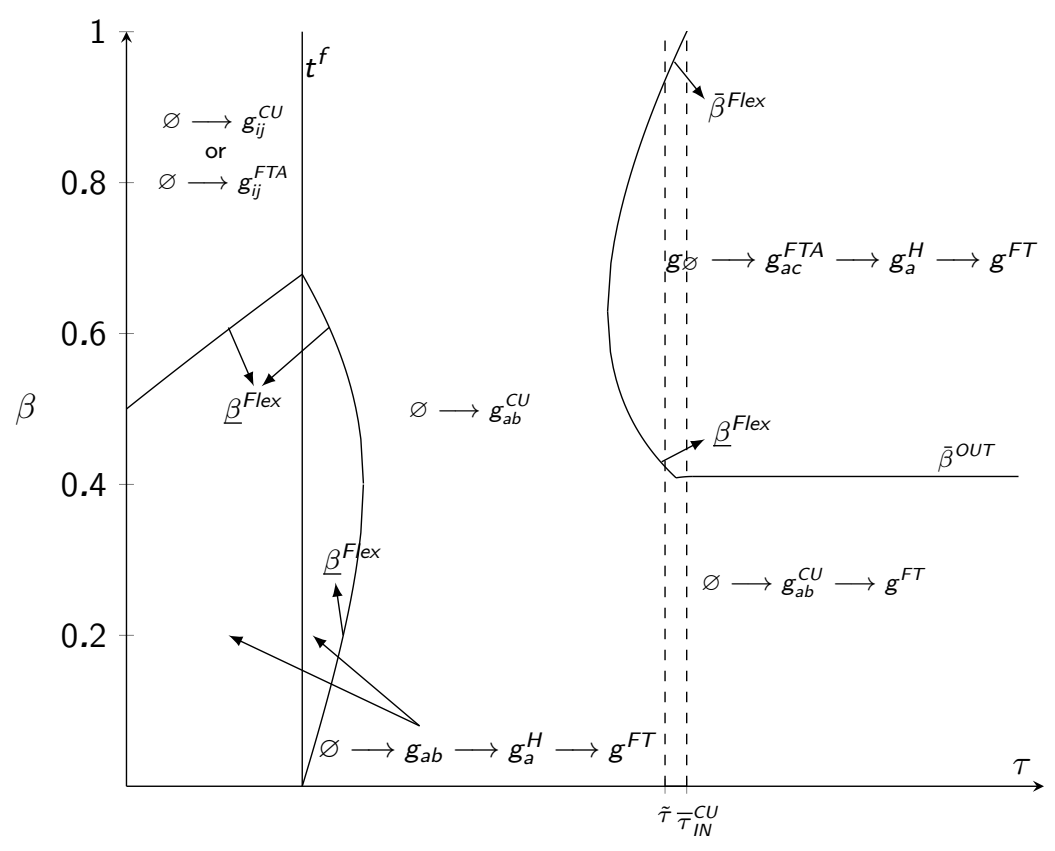

Figure 5.2: Equilibrium path of networks: PTA game

$\bar{\tau}_{I N}^{C U}$ then $\mathrm{CU}$ insiders hold a $\mathrm{CU}$ exclusion incentive and exclude the $\mathrm{CU}$ outsider from $\mathrm{CU}$ expansion to global free trade. Thus, the $\mathrm{CU}$ insiders remain permanent $\mathrm{CU}$ insiders.

Typically, the PTA literature has viewed the building bloc-stumbling bloc issue as a comparison between PTA formation and multilateral liberalization in terms of whether PTA formation improves or hurts the prospects of global free trade relative to the outcome under multilateral liberalization. However, in practice, multilateral liberalization happens in the short bursts in the background whether it be through various global rounds of negotiations or plurilateral agreements such as the Information Technology Agreement. In contrast, countries are continuously forming PTAs on the surface of the global trade policy landscape and, in doing so, choosing whether to form FTAs or CUs. Thus, an alternative view of the building bloc-stumbling bloc issue, and perhaps a more informative view, would compare the different types of PTAs in terms of whether a given type of PTA improve the prospects of global free trade relative to the outcome if this type of PTA was banned.

To this end, we introduce the terminology of a "PTA stumbling bloc" and a "PTA building bloc". We say that CUs (FTAs) are a "PTA stumbling bloc" if CU (FTA) formation emerges in equilibrium and does not lead to global free trade yet FTA (CU) formation would lead to global free trade in the absence of CUs (FTAs). Similarly, we say that FTAs (CUs) are a "PTA building bloc" if FTA (CU) formation emerges in equilibrium and leads to global free trade yet CU (FTA) formation would not lead to global free trade in the absence of FTAs (CUs). A comparison of Proposition 5.1 with Propositions 4.1-4.2 reveals the following result. 
Corollary 5.1 When the tariff binding lies in an intermediate range $\tau \in\left(t^{f}, \bar{\tau}_{I N}^{C U}\right)$ :

(i) CUs can be a PTA stumbling bloc but not a PTA building bloc

(ii) FTAs can be a PTA building bloc but not a PTA stumbling bloc.

When the tariff binding is sufficiently high, $\tau>\bar{\tau}_{I N}^{C U}$, neither type of PTA is a PTA building bloc or PTA stumbling bloc because both types of PTA lead to global free trade whether they emerge in equilibrium or not. However, CU formation does not expand to global free trade once $\tau<\bar{\tau}_{I N}^{C U}$ (and hence, CUs can never be a PTA building bloc). Nevertheless, FTA formation still expands to global free trade as long as FTA insiders do not hold a dynamic exclusion incentive (i.e. $\beta<\bar{\beta}_{I N}(\tau)$ ) and the FTA outsider does not hold a dynamic free riding incentive (i.e. $\beta>\bar{\beta}_{O U T}(\tau)$ ). In this case, $\mathrm{CU}$ formation still emerges in equilibrium when the CU coordination benefits dominate the FTA flexibility benefit and, in turn, CUs are PTA stumbling blocs. In contrast, when the FTA flexibility benefit dominates the $\mathrm{CU}$ coordination benefits, FTA formation emerges in equilibrium and leads to global free trade even though CU formation would stop short of global free trade. That is, FTAs are PTA building blocs. Finally, noting that the emergence of FTA formation in equilibrium always leads to global free trade, FTAs can never be PTA stumbling blocs. Ultimately, CUs and FTAs play very different roles in terms of the possibility that PTA liberalization reaches global free trade.

\subsection{Conclusion}

In this chapter, we inquire the impact of multilateral tariff binding liberalization on the endogenous choice of preferential trade agreement (PTA) formation. In practice, PTA formation involves countries endogenously choosing whether to form FTAs or CUs. With relatively high tariff bindings, global free trade always emerges in equilibrium whether it be through FTA or CU formation. However, outside these relatively high tariff bindings, $\mathrm{CU}$ members want to exclude the $\mathrm{CU}$ non-member from $\mathrm{CU}$ expansion to global free trade because the tariff bindings effectively force the CU non-member to grant substantial tariff concessions to $\mathrm{CU}$ members. Indeed, the equilibrium emergence of CUs can prevent (cannot facilitate) global free trade that would otherwise occur (not occur) through FTAs. In contrast, the equilibrium emergence of FTAs can facilitate (cannot prevent) global free trade that would otherwise not occur (occur) through CUs. FTAs facilitate global free trade when the FTA flexibility benefit of FTAs, i.e. the benefit each FTA member derive from being able to form their own subsequent FTA, dominates the coordination benefits $\mathrm{CU}$ members derive from coordination of their external tariffs. Ultimately, tariff binding liberalization casts a negative shadow over the impact of CUs, but a positive shadow over the impact of FTAs, on the prospect for global free trade. 


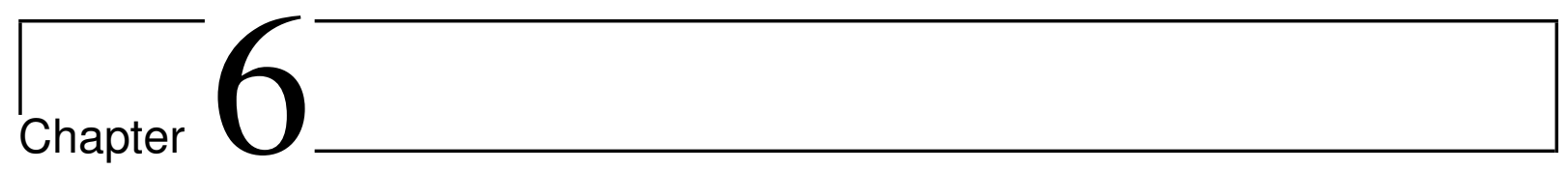

\section{Summary and Conclusions}

Following the last successful multilateral round, the last few decades have witnessed a dramatic explosion in the numbers and membership of preferential trade agreements. While the widespread concern that the formation of PTAs may undermine the prospect of global free trade led to an extensive literature, the analysis on how the continual reduction in tariff bindings affects the formation of PTAs and alters the role of Article XXIV of the GATT in achieving global free trade is relatively scarce. In an extensive survey by Freund and Ornelas (2010), they laid out the concerns regarding the lack of research on the effect of global tariff negotiations on PTA formation. While the 1994 Uruguay Round represents the last successful round of multilateral negotiations, subsequent tariff binding liberalization has taken place on IT products through large plurilateral agreement known as the Information Technology Agreement. Such an agreement has also been discussed as a template for future plurilateral agreements, including an Environmental Goods Agreement. Thus, multilateral tariff binding liberalization has taken place since the Uruguay Round and is likely to continue taking place moving forward, even in the absence of a successful turn in the currently-stalled Doha Round of negotiations. In this dissertation, we investigate the impact of multilateral tariff binding liberalization on the equilibrium extent of Preferential Trade Agreement (PTA) formation both statically and dynamically.

In both static and dynamic PTA formation settings, the ultimate objective of this dissertation is to examine how continual reduction in the tariff bindings (either via global trade negotiations or plurilateral agreements such as ITA) affects the preferences of both member and non-member countries regarding PTAs and whether PTA formation ultimately leads to global free trade or ends prematurely with a fragmented trading world with gated globalization. While the literature has long understood that PTAs can impact the extent of MFN tariff liberalization and hence the ultimate degree of global liberalization, the literature has largely ignored that the extent of MFN tariff liberalization can impact PTA formation and hence the ultimate degree of global tariff liberalization. This is despite the fact that real world MFN tariff liberalization often takes the form of tariff binding reductions which directly impact the incentives for PTA formation through changing the MFN tariffs that countries face in the absence of a PTA. While the entire literature on the role of PTAs ignores the role of tariff bindings in the tariff setting behaviour and examines 
the PTA formation assuming that countries are free in setting their optimal tariffs, we go one step further and consider more realistic cases where countries are not able to impose their optimal tariffs due to sufficiently tight tariff bindings.

In Chapter 3, using a static PTA formation game, we show that the flexible nature of FTA formation due to the independent external tariff setting plays a major role in identifying whether free riding or exclusion incentives play pivotal role in equilibrium. When countries are completely symmetric, no country has an incentive to free ride on trade liberalization by the other two countries while two countries have incentives to exclude the third one when tariff bindings are sufficiently tight. Due to the flexibility in FTA formation, such exclusion incentives go unexercised and free trade always obtains as the coalition proof Nash equilibrium (CPNE) of the FTA game. However, since hub and spoke regimes are not allowed in the $\mathrm{CU}$ game and CU members have veto power over CU expansion, countries are able to exercise the exclusion incentive and thus free trade fails to be CPNE when tariff bindings are sufficiently tight. This result suggests that, when countries are symmetric, the pursuit of CUs undermines global free trade when tariff bindings are sufficiently tight while FTA formation always acts as building blocs irrespective of the tariff bindings.

We then question when and why, if any, global free trade fails to obtain in FTA formation game. To this end, we consider a scenario where countries are asymmetric with respect to their comparative advantage. Our findings suggest that the country with a weaker comparative advantage in the exporting goods (thus larger importer country) has incentive to free ride on trade liberalization of the other two countries and this incentive is critical for whether multilateral free trade obtains as a CPNE. Since the reduction in bound tariff rates disciplines the ability of the free riding smaller exporting country in setting its external tariffs, multilateral free trade arises more likely as a CPNE (and thus acts as a building bloc). This result provides support for the idea that continual reduction in tariff bindings facilitates the FTA formation in attaining global free trade.

Then, in Chapters 4 and 5, we build a three country dynamic model of PTA formation where countries form PTAs over time. To this end, in Chapter 4, we examine FTA formation and $\mathrm{CU}$ formation games in isolation. Our main focus is on investigating the impact of multilateral tariff binding liberalization on the equilibrium extent of FTA and $\mathrm{CU}$ formation. When forming FTAs under relatively high tariff bindings, a myopic free riding incentive of FTA non-members constrains FTA formation. Thus, tariff binding liberalization can facilitate FTA expansion to global free trade. However, when forward looking countries do not value this myopic free riding incentive, tariff binding liberalization can impede FTA expansion to global free trade by effectively increasing tariff concessions given by the FTA non-member so that FTA members have incentives to exclude the FTA non-member from subsequent FTA expansion. Unlike our FTA game, the tension between myopic and farsighted incentives disappears in our CU game and CU formation proceeds to global free trade only for relatively high tariff bindings.

In practice, PTA formation involves countries endogenously choosing whether to form FTAs or CUs. To this end, in Chapter 5, we examine the PTA game under which whether FTAs or CUs emerge in equilibrium revolves around a dynamic trade off between the coordination benefits of CUs and the flexibility benefit of FTAs. With relatively high tariff 
bindings, global free trade always emerges in equilibrium whether it be through FTA or $\mathrm{CU}$ formation. However, outside these relatively high tariff bindings, CU members want to exclude the $\mathrm{CU}$ non-member from $\mathrm{CU}$ expansion to global free trade because the tariff bindings effectively force the $\mathrm{CU}$ non-member to grant substantial tariff concessions to $\mathrm{CU}$ members. Indeed, the equilibrium emergence of CUs can prevent (cannot facilitate) global free trade that would otherwise occur (not occur) through FTAs. In contrast, the equilibrium emergence of FTAs can facilitate (cannot prevent) global free trade that would otherwise not occur (occur) through CUs. FTAs facilitate global free trade when the FTA flexibility benefit of FTAs, i.e. the benefit each FTA member derives from being able to form their own subsequent FTA, dominates the coordination benefits CU members derive from coordination of their external tariffs. Ultimately, tariff binding liberalization casts a negative shadow over the impact of CUs, but a positive shadow over the impact of FTAs, on the prospect for global free trade.

To the best of our knowledge, this dissertation is one of the first studies linking multilateral tariff bindings to the endogenous PTA formation. To this end, we utilize a relatively simple trade environment where countries are competing exporters and tariff bindings are assumed to be symmetric and exogenously given. A number of extensions can be envisioned as a future research agenda. In reality, tariff bindings are product specific and highly heterogeneous. Specifically, two immediate extensions can be: (i) allowing for asymmetric bindings and (ii) endogenizing the multilateral negotiations over tariff bindings. Asymmetric tariff bindings would have direct impact on the incentives for PTA formation and thus a systematic exploration of the impact of continual reductions in asymmetric tariff bindings on the static and dynamic free riding and exclusion incentives would be an interesting area of research.

Central to our results derived in Chapter 3 and Chapters 4-5 is the notion of stability. Alternative approaches to the notion of stability can be investigated especially for the purpose of generalizing the number of countries. For instance, the pairwise stability concept used in PTA formation as in Goyal and Joshi (2006) and Furusawa and Konishi (2007) is relatively simpler concept in examining the impact of continual reductions in the tariff bindings on PTA formation in an n-country framework. Using a three country model rules out possibilities for a country to be a member of an FTA and CU at the same time. This is a substantive restriction since, in practice, the trading regime is characterized by such simultaneous preferential trade agreements relationships. It would be interesting to extend our model into $\mathrm{n}$ country to take into account such patterns.

In trade theory, the terms-of-trade hypothesis posits that countries use tariffs in part to improve their terms of trade and trade agreements cause them to internalize the costs that such terms-of-trade shifts impose on other countries. Consistent with this hypothesis, the primary motivation behind the preferential trade agreement formation in this dissertation is based on terms of trade motives and we abstract from other factors such as political economy pressures. Therefore, one immediate extension would be to integrate political economy motivation via import and export lobbies within PTA formation. To this end, one can follow the models as in Ornelas (2005, 2008) and Stoyanov and Yildiz (2015). The differences in political idiosyncrasies and protectionist preferences across countries may induce "similar" countries to negotiate PTAs rather than participate in large scale 
multilateral deals. Therefore, the political economy factors may play an important role in the analysis of endogenous formation of PTAs both statically and dynamically.

Finally, as Rodrik (2018) recently pointed out, trade agreements have evolved and gone beyond import tariffs and quotas into regulatory rules and harmonization (patent rules, health and safety regulations, labour standards, investment investor courts, etc.). Therefore, it is common to observe in modern trade agreements that there are several issues, such as trade-related intellectual property rights, rules about cross-border capital flows, investor-state dispute settlement procedures, and harmonization of regulatory standards, being negotiated beyond lowering traditional border barriers and the economic consequences are far more ambiguous. PTAs with deep integration provisions seek to strengthen the contestability of markets for firms in partner countries mainly via (i) protection of foreign firms and their interests; (ii) liberalization of behind-the-border trade barriers; and (iii) harmonization of domestic trade rules to enhance the efficiency of international production. This dissertation abstracts away from the discussion of shallow versus deep integration and we leave it for future research. 
APPENDICES 
$\prod_{\text {Appendix }}$

\section{Appendix of Chapter 2}

In this Appendix we provide the necessary supporting calculations.

\section{A.1 Welfare levels}

We begin by reporting welfare levels under different policy regimes as a function of tariffs and comparative advantage. For an arbitrary tariffs vector $\mathbf{t}=\left(t_{i j}, t_{i k}, t_{j i}, t_{j k}, t_{k i}, t_{k j}\right)$, we can write country $i$ 's welfare as

$$
w_{i}=\sum_{g} C S_{i}^{g}+\sum_{g} P S_{i}^{g}+\sum_{z \neq i} t_{i z} x_{z}^{I}
$$

where consumer surplus in country $i$ equals

$$
\sum_{g} C S_{i}^{g}=\frac{1}{2}\left[\left(\alpha-P_{i}^{I}\right)^{2}+\left(\alpha-P_{j}^{J}+t_{j i}\right)^{2}+\left(\alpha-P_{k}^{J}+t_{k i}\right)^{2}\right],
$$

its producer surplus equals

$$
\sum_{g} P S_{i}^{g}=\frac{1}{2}\left[\left(P_{i}^{I}\right)^{2}+\left(1+\lambda_{i}\right)\left(P_{j}^{J}-t_{j i}\right)^{2}+\left(1+\lambda_{i}\right)\left(P_{k}^{K}-t_{k i}\right)^{2}\right]
$$

and the tariff revenue is given by

$$
\sum_{z \neq i} t_{i z} x_{z}^{I}=t_{i j}\left[\left(2+\lambda_{j}\right) P_{j}^{I}-\alpha\right]+t_{i k}\left[\left(2+\lambda_{k}\right) P_{k}^{I}-\alpha\right]
$$


Using the above formulae and the optimal tariff levels reported in the text, we can easily calculate welfare levels under all possible trade regimes. To save space, we do not include the algebraic details underlying these straightforward calculations. 


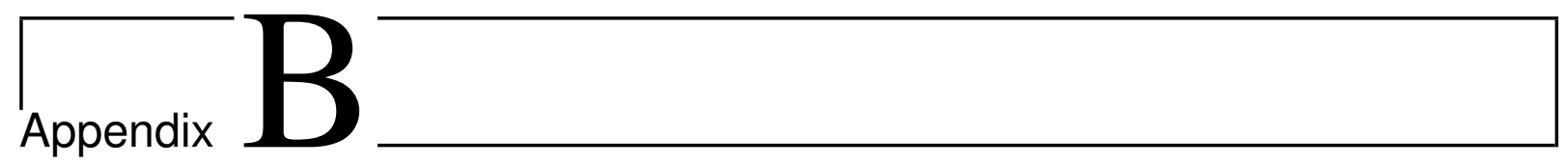

\section{Appendix of Chapter 3}

In this Appendix we provide the necessary supporting proofs.

\section{B.1 Proofs}

\section{Proof of Lemma 3.1}

Using the welfare and optimum tariff levels (when feasible) reported in the text and setting $\lambda_{z}=\lambda$, where $z=i, j, k$, we can show the following for all $\tau$ and $\lambda$ :

$$
\triangle w_{i}(i j-\varnothing)=\triangle w_{j}(i j-\varnothing)>0
$$

$$
\Delta w_{k}(F-i j)>0 ; w_{i}(i h-F)>0 ; w_{i}(i h-i j)>0 ; w_{i}(i h-\varnothing)>0 ; \text { and } \Delta w_{j}(F-i h)>0 \text {. }
$$

We also have:

$$
\begin{gathered}
\Delta w_{k}(i j-\varnothing)>0 \text { when } \tau>\bar{\tau}(\lambda) \text { where } t^{f}<\bar{\tau}(\lambda)<t^{\varnothing} \\
\Delta w_{j}(i h-i k)=\Delta w_{k}(i h-i j)>0 \text { when } \tau<\underline{\tau}(\lambda) \text { where } t^{f}<\underline{\tau}(\lambda)<t^{\varnothing}
\end{gathered}
$$

and

$$
\bar{\tau}(\lambda) \geq \underline{\tau}(\lambda) \text { for all } \lambda
$$

Proof of Proposition 3.1a 
Under symmetry, $\Delta w_{i}(F-i j)=\Delta w_{j}(F-i j)<0$ when $\tau<\widehat{\tau}(\lambda)$ where $t^{f}<\widehat{\tau}(\lambda)<t^{\varnothing}$ and $\frac{\partial \Delta w_{i}(F-i j)}{\partial \tau}>0$.

\section{Proof of Proposition 3.2}

It is immediate from the above welfare and reported optimum tariff levels (when feasible) and Lemma 3.1.

\section{Proof of Proposition 3.1b}

While $\Delta w_{i}(F-i j)=\Delta w_{j}(F-i j)<0$ and two symmetric countries have an incentive to exclude the third when $\tau<\widehat{\tau}(\lambda)$, it is immediate from part (iii) of Lemma 1 that each of the excluding countries have incentives to further deviate and thus the initial deviation is not self-enforcing, implying that the exclusion incentive goes unexercised.

\section{Proof of Proposition 3.3}

Using the Lemma 3.1 and Proposition 3.1a, there exists no self-enforcing deviation from the announcement profile leading to free trade.

\section{Proof of Lemma 3.2}

Using the welfare and optimum tariff levels (when feasible) reported above and setting $\underline{\lambda} \leq \lambda_{s}<\lambda_{l}=\lambda_{l^{\prime}}=\lambda$, we can show the following for any $\tau$ and $\lambda$ :

$$
\begin{aligned}
& \frac{\partial w_{l}(F-\varnothing)}{\partial \lambda_{s}}<0 ; \frac{\partial w_{l^{\prime}}(F-s l)}{\partial \lambda_{s}}<0 ; \frac{\partial w_{l}\left(F-l l^{\prime}\right)}{\partial \lambda_{s}}<0 ; \frac{\partial w_{l^{\prime}}(F-l h)}{\partial \lambda_{s}}<0 ; \\
& \frac{\partial w_{l}(s l-\varnothing)}{\partial \lambda_{s}}<0 ; \frac{\partial w_{l^{\prime}}(s h-s l)}{\partial \lambda_{s}}<0 \text { and } \frac{\partial w_{l}\left(l h-l l^{\prime}\right)}{\partial \lambda_{s}}<0
\end{aligned}
$$

\section{Proof of Lemma 3.3}

Using the welfare and reported optimum tariff levels (when feasible) and setting $\underline{\lambda} \leq$ $\lambda_{s}<\lambda_{l}=\lambda_{l^{\prime}}=\lambda$, we can show the following for any $\tau$ and $\lambda$ :

$\Delta w_{l}(s l-\varnothing)>0 ; \Delta w_{l}\left(l h-l l^{\prime}\right)>0 ; \Delta w_{l}(F-\phi)>0 ; \Delta w_{l}\left(F-s l^{\prime}\right)>0$ and $\Delta w_{l}\left(F-l^{\prime} h\right)>0$

and

$$
\Delta w_{l}(F-s h)>0 \text { and } \Delta w_{s}(s h-s l)>0 .
$$

\section{Proof of Proposition 3.4}

Using parts (i) and (ii) of Lemma 3.3, even when two countries have incentives to jointly exclude the third, this joint deviation from the announcement profile leading to free trade 
is not self-enforcing since each of the initially deviating country has an incentive to further deviate to become the hub country: $\Delta w_{l}\left(l h-l l^{\prime}\right)>0$ and $\Delta w_{s}(s h-s l)>0$ for all $\tau$ and $\lambda$.

\section{Proof of Proposition 3.5}

As clearly shown in the text, using Lemma 3.3 and Proposition 3.4, the binding selfenforcing deviation from the announcement profile leading to global free trade is the unilateral deviation of the smaller exporting country from $\sigma_{s}=\left\{l, l^{\prime}\right\}$ to $\sigma_{s}=\{\phi, \phi\}$ leading to deviation from $\langle F\rangle$ to $\left\langle l l^{\prime}\right\rangle: \Delta w_{s}\left(F-l l^{\prime}\right) \leq 0$ when $\lambda_{s}<\lambda_{s}\left(F-l l^{\prime}\right)$ where $\frac{\partial \lambda_{s}\left(F-l l^{\prime}\right)}{\partial \tau} \geq 0$.

\section{Proof of Proposition 3.6}

When $\lambda_{s}<\lambda_{s}\left(F-l l^{\prime}\right)$ holds, the announcement profile leading to global free trade fails to be CPNE. Announcement profile leading to no agreement $\varnothing$ is never a CPNE since $\Delta w_{l}\left(l l^{\prime}-\varnothing\right)>0$ for all $\tau, \lambda$ and $\lambda_{s}$. Similarly, the announcement profile leading to $\langle l h\rangle$ is never a CPNE as well. To see it more clearly, it is immediate from Lemma 3.3 part (i) that $\Delta w_{l}(F-s h)>0$ for all $\tau, \lambda$ and $\lambda_{s}$ and thus two larger exporters always have an incentive to coalitionally change their announcements from $\{s, \phi\}$ and $\{s, \phi\}$ to $\left\{s, l^{\prime}\right\}$ and $\{s, l\}$ respectively, taking country $s^{\prime}$ s announcement fixed at $\sigma_{s}=\left\{l, l^{\prime}\right\}$. It is a self-enforcing deviation since a larger exporting country has no incentive to unilaterally deviate from its announcement that leads to free trade as established in Lemma 3. When we consider the announcement profile that leads to a $\langle l h\rangle$, we first note that $\lambda_{s}\left(F-l l^{\prime}\right)>\lambda_{s}(F-l h)$ and thus country $s$ under $\Omega^{l h}$ always has an incentive to unilaterally deviate from from $\{l, \phi\}$ to $\{\phi, \phi\}$ converting $\langle l h\rangle$ to $\left\langle l l^{\prime}\right\rangle$ and thus the announcement profile leading to $\langle l h\rangle$ is not even a Nash equilibrium (therefore not a CPNE). Note that there exists no self enforcing coalitional deviations from the announcement profile $\Omega^{l l^{\prime}}$ and thus it is a CPNE when $\lambda_{s}<\lambda_{s}\left(F-l l^{\prime}\right)$. Finally, the critical deviation under $\Omega^{s l}$ is the joint announcement deviation of countries $s$ and $l^{\prime}$ from their respective announcements $\{l, \phi\}$ and $\{\phi, \phi\}$ to $\left\{l, l^{\prime}\right\}$ and $\{s, \phi\}$ converting $\langle s l\rangle$ into $\langle s h\rangle$. We know from part (ii) of Lemma 3.3 that country $s$ always has an incentive to participate in such a coalitional deviation while country $l^{\prime}$ does so only when $\lambda_{s}<\lambda_{l^{\prime}}(s h-s l)$. This joint announcement deviation is selfenforcing since neither $s$ nor $l^{\prime}$ has an incentive to further deviate taking the announcement of complements as given. When $\lambda_{l^{\prime}}(s h-s l)<\lambda_{s}<\lambda_{s}\left(F-l l^{\prime}\right)$ holds, there exists no other self-enforcing deviation from $\Omega^{s l}$ and thus it is a CPNE. 


\section{Proof of Lemma 3.4}

Using the welfare and optimum tariff levels (when feasible) reported in the text and setting $\underline{\lambda} \leq \lambda_{s}=\lambda_{s^{\prime}}<\lambda_{l}=\lambda$, we can show the following for all $\tau, \lambda$ and $\lambda_{s}$ :

$$
\begin{gathered}
\Delta w_{i}(i j-\varnothing)>0, i, j=s, s^{\prime}, l \\
w_{i}(i h)>\max \left\{w_{i}(F), w_{i}(i j), w_{i}(\varnothing)\right\}, i, j=s, s^{\prime}, l \text { and } \Delta w_{s}(F-l h)=\Delta w_{s^{\prime}}(F-l h)>0 \\
\Delta w_{l}(F-s h)=\Delta w_{l}\left(F-s^{\prime} h\right)>0 \\
\Delta w_{l}\left(F-s s^{\prime}\right)>0 \\
\lambda_{s}\left(F-s^{\prime} l\right)>\lambda_{s}\left(F-s^{\prime} h\right) \text { and } \frac{\partial \lambda_{s}\left(F-s^{\prime} l\right)}{\partial \tau} \geq 0
\end{gathered}
$$

and we have:

$$
\begin{gathered}
\Delta w_{s}\left(F-s^{\prime} h\right)=\Delta w_{s^{\prime}}(F-s h)>0 \text { when } \lambda_{s}>\lambda_{s}\left(F-s^{\prime} h\right) \\
\Delta w_{s}\left(F-s^{\prime} l\right)=\Delta w_{s^{\prime}}(F-s l)>0 \text { when } \lambda_{s}>\lambda_{s}\left(F-s^{\prime} l\right)
\end{gathered}
$$

\section{Proof of Proposition 3.7}

As clearly shown in the text, using Lemma 3.4, the binding self-enforcing deviation from the announcement profile leading to global free trade is the unilateral deviation of the smaller exporting country from $\sigma_{s}=\left\{s^{\prime}, l\right\}$ to $\sigma_{s}=\{\phi, \phi\}$ leading to deviation from $\langle F\rangle$ to $\left\langle s^{\prime} l\right\rangle: \Delta w_{s}\left(F-s^{\prime} l\right) \leq 0$ when $\lambda_{s}<\lambda_{s}\left(F-s^{\prime} l\right)$ where $\frac{\partial \lambda_{s}\left(F-s^{\prime} l\right)}{\partial \tau} \geq 0$.

\section{Proof of Lemma 3.5}

Using the welfare and optimum tariff levels (when feasible) reported in the text and setting $\lambda_{z}=\lambda$, where $z=i, j, k$, we can show the following:

$\Delta w_{i}\left(i j^{u}-\varnothing\right)=\Delta w_{j}\left(i j^{u}-\varnothing\right)>0 ; \Delta w_{k}\left(i j^{u}-\varnothing\right)<0$ and $\Delta w_{k}\left(F-i j^{u}\right)>0$ for all $\tau$ and $\lambda$ and

$$
\Delta w_{i}\left(F-i j^{u}\right)=\Delta w_{j}\left(F-i j^{u}\right)>0 \text { when } \tau>\widehat{\tau}^{u}(\lambda) \text { where } t^{u}<\widehat{\tau}^{u}(\lambda)<t^{\varnothing}
$$




\section{Proof of Proposition 3.8}

As clearly shown in the text, using Lemma 3.5, the binding self-enforcing deviation from the announcement profile leading to global free trade is the coalitional deviation of two symmetric countries to exclude the third one from the free trade network: $\Delta w_{i}\left(F-i j^{u}\right)=$ $\Delta w_{j}\left(F-i j^{u}\right)>0$ when $\tau>\widehat{\tau}^{u}(\lambda)$ where $t^{u}<\widehat{\tau}^{u}(\lambda)<t^{\varnothing}$. When $\tau<\widehat{\tau}^{u}(\lambda)$ holds, the announcement profile leading to global free trade fails to be CPNE. Announcement profile

leading to no agreement $\varnothing$ is never a CPNE since $\Delta w_{i}\left(i j^{u}-\varnothing\right)=\Delta w_{j}\left(i j^{u}-\varnothing\right)>0$ for all $\tau$ and $\lambda$. The announcement profile leading to a bilateral CU is a CPNE only when $\tau \leq \widehat{\tau}^{u}(\lambda)$. 


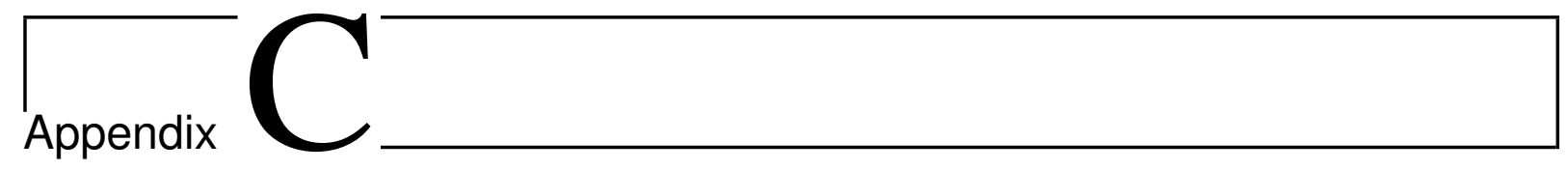

\section{Appendix of Chapter 4}

In this Appendix we provide the necessary supporting proofs.

\section{C.1 Proofs}

Before we present the proofs from the main text, we present an additional proof that will be used in Propositions 4.2-5.1.

Lemma C.1 Consider a subgame at $g_{i j}^{C U}$. The equilibrium outcome in the subgame is

(i) $g_{i j}^{C U} \rightarrow g^{F T}$ if $\tau>\bar{\tau}_{I N}^{C U}$

(ii) $g_{i j}^{C U} \rightarrow g_{i j}^{C U}$ if $\tau \leq \bar{\tau}_{I N}^{C U}$.

Proof. Lemma 4.6(ii) implies $V_{k}\left(g^{F T}\right)>V_{k}\left(g_{i j}^{C U}\right)$. Moreover, by definition, $V_{h}\left(g^{F T}\right)>$ $V_{h}\left(g_{i j}^{C U}\right)$ for $h=i, j$ if and only if $\tau>\bar{\tau}_{I N}^{C U}$. Thus, the first CU insider in the protocol, say $i$, proposes $g^{F T}$ to $j$ and $k$, who both accept, if $\tau>\bar{\tau}_{I N}^{C U}$. But, no CU insider accepts a proposal, and hence no CU insider makes a proposal, if $\tau \leq \bar{\tau}_{I N}^{C U}$. Thus, $g_{i j}^{C U} \rightarrow g^{F T}$ if $\tau>\bar{\tau}_{I N}^{C U}$ but $g_{i j}^{C U} \rightarrow g_{i j}^{C U}$ if $\tau \leq \bar{\tau}_{I N}^{C U}$.

We now present proofs of lemmas and propositions from the main text.

PROOF OF LEMMA 4.1

Using the welfare and optimum tariff levels (when feasible under the given tariff binding) reported in the text, we can show the following for all $\tau$ :

$$
\begin{aligned}
\Delta w_{i}\left(g_{i j}^{F T}-g_{\varnothing}\right) & =\Delta w_{j}\left(g_{i j}^{F T A}-g_{\varnothing}\right)>0 \\
\Delta w_{i}\left(g_{i}^{H}-g_{i j}^{F T A}\right) & =\Delta w_{i}\left(g_{i}^{H}-g_{i k}^{F A}\right)>0 \\
\Delta w_{i}\left(g_{i}^{F T}-g_{j}^{H}\right) & >0 \text { and } \Delta w_{i}\left(g^{F T}-g_{j k}^{F T A}\right)>0
\end{aligned}
$$


We also have:

$$
\begin{gathered}
\Delta w_{i}\left(g_{j}^{H}-g_{j k}\right)>0 \text { if and only if } \tau<\bar{\tau}_{\text {OUT }}^{F T A} \text { where } \bar{\tau}_{\text {OUT }}^{F T A} \in\left(t^{f}, t^{\phi}\right) \\
\Delta w_{i}\left(g_{i j}^{F T A}-g_{j k}^{F T A}\right)>0 \text { for } \tau<\tilde{\tau} \text { where } \tilde{\tau} \in\left(\bar{\tau}_{\text {OUT }}^{F T A}, t^{\phi}\right)
\end{gathered}
$$

and

$$
\Delta w_{i}\left(g_{i}^{F T}-g_{i j}^{F T A}\right)>0 \text { if and only if } \tau>\bar{\tau}_{I N}^{F T A} \text { where } \bar{\tau}_{I N}^{F T A} \in\left(t^{f}, t^{\phi}\right)
$$

\section{Proof of LemMa 4.2}

Part (i): Using the welfare and optimum tariff levels (when feasible under the given tariff binding) reported in the text, we can show the following:

If $g_{i j}^{F T A} \longrightarrow g_{i j}^{F T A}$, it is immediate from part (i) of Lemma 1 that $\Delta w_{i}\left(g_{i j}^{F T A}-g_{\varnothing}\right)=$ $\Delta w_{j}\left(g_{i j}^{F T A}-g_{\varnothing}\right)>0$.

If $g_{i j}^{F T A} \rightarrow g_{i}^{H} \rightarrow g^{F T}, w_{i}\left(g_{i j}^{F T A}\right)+\beta w_{i}\left(g_{i}^{H}\right)+\frac{\beta^{2}}{1-\beta} w_{i}\left(g^{F T}\right)>w_{j}\left(g_{i j}^{F T A}\right)+\beta w_{j}\left(g_{i}^{H}\right)+$ $\frac{\beta^{2}}{1-\beta} w_{j}\left(g^{F T}\right)$ and $w_{j}\left(g_{i j}^{F T A}\right)+\beta w_{j}\left(g_{i}^{H}\right)+\frac{\beta^{2}}{1-\beta} w_{j}\left(g^{F T}\right)>V_{i}\left(g_{\varnothing}\right)=V_{j}\left(g_{\varnothing}\right)$ hold for all $\beta$.

Part (ii): For sufficiently high $\beta$ and relevant $\tau$ values over which $g_{i j}^{F A} \rightarrow g_{i}^{H} \rightarrow g^{F T}$ and $g_{j k}^{F T A} \rightarrow g_{j}^{H} \rightarrow g^{F T}$, using the welfare and optimum tariff levels (when feasible under the given tariff binding) reported in the text, we can show that $w_{i}\left(g_{i j}^{F T A}\right)+\beta w_{i}\left(g_{i}^{H}\right)+$ $\frac{\beta^{2}}{1-\beta} w_{i}\left(g^{F T}\right)>w_{i}\left(g_{j k}^{F T A}\right)+\beta w_{i}\left(g_{j}^{H}\right)+\frac{\beta^{2}}{1-\beta} w_{i}\left(g^{F T}\right)$ always holds.

\section{ProOF OF LEMMA 4.3}

Lemma 4.1(i) implies the first spoke in the protocol, say $j$, proposes an FTA with $k$ who accepts. Thus, $g_{i}^{H} \rightarrow g^{F T}$.

\section{Proof of Lemma 4.4}

Given $i$ proposes before $j$ in the protocol, then either $i$ or $k$ proposes in stage 1a. Moreover, Lemma 4.3 implies $g_{z}^{H} \rightarrow g^{F T}$ in any subgame at $g_{z}^{H}$. Thus, by definition, $V_{i}\left(g_{i}^{H}\right)>\frac{1}{1-\delta} w_{i}\left(g_{i j}^{F T A}\right) \Leftrightarrow \beta<\bar{\beta}_{I N}(\tau)$ and $V_{k}\left(g_{i}^{H}\right)>\frac{1}{1-\delta} w_{k}\left(g_{i j}^{F A}\right) \Leftrightarrow \beta>\bar{\beta}_{O U T}(\tau)$. Moreover, parts (i) and (iv) of Lemma 4.1 imply $w_{i}\left(g_{i}^{H}\right)>w_{i}\left(g^{F T}\right)>w_{i}\left(g_{j}^{H}\right)$ so that $V_{i}\left(g_{i}^{H}\right)>V_{i}\left(g_{j}^{H}\right)$.

First, suppose $\beta \in\left(\bar{\beta}_{O U T}(\tau), \bar{\beta}_{I N}(\tau)\right)$. Then, in stage 1a, $i$ (or $k$ ) proposes an FTA with $k$ (or $i$ ) and $k$ (or $i$ ) accepts. Hence, the equilibrium outcome in the subgame is $g_{i j}^{F T A} \rightarrow g_{i}^{H}$. Second, suppose $\beta<\bar{\beta}_{O U T}(\tau)$. Then, $k$ rejects any FTA proposal received from $i$ or $j$ and chooses to make no proposal as the proposer. Hence, the equilibrium

outcome in the subgame is $g_{i j}^{F T A} \rightarrow g_{i j}^{F T A}$. Third, suppose $\beta>\bar{\beta}_{I N}(\tau)$. Then, $i$ and $j$ choose to make no FTA proposal as the proposer and reject any proposal received from $k$. Hence, the equilibrium outcome in the subgame is $g_{i j}^{F T A} \rightarrow g_{i j}^{F T A}$.

\section{Proof of Proposition 4.1}

Note throughout that country $b(c)$ receives an arbitrarily small non-economic benefit $\varepsilon>0$ from FTA formation with country $a$ rather than country $c(b)$ and country $a$ receives an arbitrarily small non-economic benefit $\varepsilon>0$ from FTA formation with country $b$ rather 
than country $c$. Moreover, Lemmas 4.3 and 4.4 describe the equilibrium transitions from subgames at the FTA insider-outsider networks and hub-spoke networks. In particular, letting $i$ be the most attractive FTA insider, $g_{i j}^{F T A} \rightarrow g_{i}^{H} \rightarrow g^{F T}$ if and only if $\beta \in$ $\left(\bar{\beta}_{\text {OUT }}(\tau), \bar{\beta}_{I N}(\tau)\right)$ but $g_{i j}^{F T A} \rightarrow g_{i j}^{F T A}$ otherwise.

Stage 2. First, suppose $\beta \notin\left(\bar{\beta}_{O U T}(\tau), \bar{\beta}_{I N}(\tau)\right)$. Then, Lemma 4.4 implies $g_{i j}^{F T A} \rightarrow$ $g_{i j}^{F T A}$ and $V_{z}\left(g_{i j}^{F T A}\right)>V_{z}\left(g_{\varnothing}\right)$ for $z=i, j$ by Lemma 4.1(i). Second, suppose $\beta \in$ $\left(\bar{\beta}_{\text {OUT }}(\tau), \bar{\beta}_{I N}(\tau)\right)$. Then, Lemmas 4.3 and 4.4 imply $g_{i j}^{F T A} \rightarrow g_{i}^{H} \rightarrow g^{F T}$ where country $i$ is the more attractive FTA insider. In turn, $V_{z}\left(g_{i j}^{F T A}\right)>V_{z}\left(g_{\varnothing}\right)$ for $z=i, j$ either by Lemma 4.1(i) or Lemma 4.2(i). Thus, country $b$ proposes FTA formation with country $a$, who accepts, when $\beta \notin\left(\bar{\beta}_{\text {OUT }}(\tau), \bar{\beta}_{I N}(\tau)\right)$ given the non-economic benefits but proposes FTA formation with country $c$, who accepts, when $\beta \in\left(\bar{\beta}_{O U T}(\tau), \bar{\beta}_{I N}(\tau)\right)$ given parts (i) and (iv) of Lemma $4.1 \mathrm{imply} w_{b}\left(g_{b}^{H}\right)>w_{b}\left(g^{F T}\right)>w_{b}\left(g_{a}^{H}\right)$ so that $V_{b}\left(g_{b c}^{F T A}\right)>V_{b}\left(g_{a b}^{F T A}\right)$.

Stage 1b. Note the equilibrium outcome in Stage 2 and that $V_{a}\left(g_{a b}^{F T A}\right)=V_{a}\left(g_{a c}^{F T A}\right)>$ $V_{a}\left(g_{\varnothing}\right)$. First, suppose $\beta \notin\left(\bar{\beta}_{\text {OUT }}(\tau), \bar{\beta}_{I N}(\tau)\right)$. Then, country $a$ proposes FTA formation with country $b$, who accepts, if country $c$ rejected country $a$ 's proposal in Stage 1a. But, given the non-economic benefits, country $a$ makes no proposal if country $b$ rejected country $a$ 's proposal in Stage 1a.

Second, suppose $\beta \in\left(\bar{\beta}_{O U T}(\tau), \bar{\beta}_{I N}(\tau)\right)$. Then, given Lemma 4.2(ii), country a proposes FTA formation with country $c$, who accepts given the non-economic benefits, if country $b$ rejected country a's proposal in Stage 1a. But, given the outcome of $g_{b c}^{F T A}$ in Stage 2 implies country $b$ will reject an FTA proposal from country $a$, country $a$ makes no proposal to country $b$ if country $c$ rejected country $a$ 's proposal in Stage 1a.

Stage 1a. First, suppose $\beta \in\left(\bar{\beta}_{O U T}(\tau), \bar{\beta}_{I N}(\tau)\right)$ noting that $V_{i}\left(g_{i j}^{F T A}\right)>V_{i}\left(g_{j k}^{F T A}\right)$ by Lemma 4.2(ii). Then, the non-economic benefits imply country $a$ proposes an FTA with country $b$ who accepts given the equilibrium outcome of $g_{a c}^{F T A}$ in Stage $1 b$ upon its rejection in Stage 1a. Second, suppose $\beta \notin\left(\bar{\beta}_{O U T}(\tau), \bar{\beta}_{I N}(\tau)\right)$. Then, the non-economic benefits imply country $a$ proposes an FTA with country $b$ who, given the equilibrium outcome of $g_{a b}^{F T A}$ in Stage $1 \mathrm{~b}$, accepts. Thus, the equilibrium path of networks is $g_{\varnothing} \rightarrow g_{a b}^{F T A} \rightarrow g_{a}^{H} \rightarrow$ $g^{F T}$ if $\beta \in\left(\bar{\beta}_{O U T}(\tau), \bar{\beta}_{I N}(\tau)\right)$ but $g_{\varnothing} \rightarrow g_{a b}^{F T A}$ if $\beta \notin\left(\bar{\beta}_{O U T}(\tau), \bar{\beta}_{I N}(\tau)\right)$.

\section{Proof of Lemma 4.6}

Using the welfare and optimum tariff levels (when feasible under the given tariff binding) reported in the text, we can show the following for all $\tau$ :

$$
\Delta w_{i}\left(g_{i j}^{C U}-g_{\varnothing}\right)>0 \Delta w_{k}\left(g_{i j}^{C U}-g_{\varnothing}\right)<0 \text { and } \Delta w_{k}\left(g^{F T}-g_{i j}^{C U}\right)>0 .
$$

We also have:

$$
\Delta w_{i}\left(g^{F T}-g_{i j}^{C U}\right)>0 \text { if and only if } \tau>\bar{\tau}_{I N}^{C U} \text { where } \bar{\tau}_{I N}^{C U} \in\left(t_{C U}, t^{\phi}\right)
$$

and

$$
\Delta w_{i}\left(g_{i j}^{C U}-g_{i j}^{F T A}\right)>0 \text { for } \tau>t^{f} .
$$

Proof of Proposition 4.2 
Note throughout that country $b(c)$ receives an arbitrarily small non-economic benefit $\varepsilon>0$ from CU formation with country a rather than country $c(b)$ and country $a$ receives an arbitrarily small non-economic benefit $\varepsilon>0$ from $\mathrm{CU}$ formation with country $b$ rather than country c. Moreover, Lemma C.1 describes the equilibrium transitions from CU insider-outsider networks with $g_{i j}^{C U} \rightarrow g^{F T}$ if $\tau>\bar{\tau}_{I N}^{C U}$ but $g_{i j}^{C U} \rightarrow g_{i j}^{C U}$ if $\tau \leq \bar{\tau}_{I N}^{C U}$.

Stage 2. Lemma 4.6(i) and, given the veto power of CU members, Lemma C.1 imply that $V_{i}\left(g_{i j}^{C U}\right)>V_{i}\left(g_{\varnothing}\right)$ regardless of the equilibrium transition in the subgame at $g_{i j}^{C U}$. Thus, given the non-economic benefits, country $b$ proposes a CU with country $a$ and country $a$ accepts.

Stage 1b. Given the equilibrium outcome in Stage 2 and the non-economic benefits, country $a$ makes no proposal to $c$ if country $b$ rejected country $a$ 's proposal in Stage 1a but country $a$ proposes a CU with country $b$, and country $b$ accepts, if country $c$ rejected country a's proposal in Stage 1a.

Stage 1a. Given $g_{a b}^{C U}$ emerges in Sage 1b or Stage 2, country a proposes a CU with country $b$ who accepts. Thus, the equilibrium path of networks is $g_{\varnothing} \rightarrow g_{a b}^{C U} \rightarrow g^{F T}$ if $\tau>\bar{\tau}_{I N}^{C U}$ but $g_{\varnothing} \rightarrow g_{a b}^{C U}$ if $\tau \leq \bar{\tau}_{I N}^{C U}$. 
Appendix

\section{Appendix of Chapter 5}

In this Appendix we provide the necessary supporting proofs.

\section{D.1 Proofs}

\section{Proof of Proposition 5.1}

Note throughout that country $b(c)$ receives an arbitrarily small non-economic benefit $\varepsilon>0$ from FTA formation with country $a$ rather than country $c(b)$ and country $a$ receives an arbitrarily small non-economic benefit $\varepsilon>0$ from FTA formation with country $b$ rather than country $c$. Moreover, Lemmas 4.3, 4.4 and C.1 describe the equilibrium transitions from, respectively, hub-spoke, FTA insider-outsider and CU insider-outsider networks.

First, suppose $\beta \notin\left(\bar{\beta}_{O U T}(\tau), \bar{\beta}_{I N}(\tau)\right)$ so that $g_{i j}^{F T A} \rightarrow g_{i j}^{F T A}$.

Stage 2. The veto power held by $\mathrm{CU}$ insiders over $\mathrm{CU}$ expansion together with parts (i) and (iii) of Lemma 4.6 and Lemma 4.1(i) implies $V_{i}\left(g_{i j}^{C U}\right) \geq V_{i}\left(g_{i j}^{F A}\right)>V_{i}\left(g_{\varnothing}\right)$. Thus, given the non-economic benefits, country $b$ proposes CU formation with $a$ who accepts.

Stage 1b. As in Stage 2, $V_{i}\left(g_{i j}^{C U}\right) \geq V_{i}\left(g_{i j}^{F T A}\right)>V_{i}\left(g_{\varnothing}\right)$. Moreover, given the equilibrium outcome in Stage 2 of $g_{a b}^{C U}$, country $b$ accepts a CU proposal from country $a$. Thus, if country $c$ rejected country $a$ 's proposal in Stage 1a so that country a can propose to country $b$, the non-economic benefits imply country $a$ proposes CU formation with country $b$ who accepts. In contrast, given the equilibrium outcome in Stage 2 of $g_{a b}^{C U}$, country $a$ makes no proposal if country $b$ rejected country $a$ 's proposal in Stage 1a.

Stage 1a. Given the equilibrium outcome in Stage 1b or Stage 2 and the logic in these stages, country $a$ proposes $\mathrm{CU}$ formation with country $b$ who accepts. Thus, the equilibrium path of networks when $\beta \notin\left(\bar{\beta}_{O U T}(\tau), \bar{\beta}_{I N}(\tau)\right)$ is $g_{\varnothing} \rightarrow g_{a b}^{C U}$ if $\tau \leq \bar{\tau}_{I N}^{C U}$ but $g_{\varnothing} \rightarrow g_{a b}^{C U} \rightarrow g^{F T}$ if $\tau>\bar{\tau}_{I N}^{C U}$.

Second, suppose $\beta \in\left(\bar{\beta}_{O U T}(\tau), \bar{\beta}_{I N}(\tau)\right)$ so that $g_{i j}^{F T A} \rightarrow g_{i}^{H} \rightarrow g^{F T}$ where country $i$ is the more attractive FTA insider in terms of non-economic benefits. 
Stage 2. Lemma 4.1(i) combined with Lemma 4.2, Lemma 4.6(iii) and the veto power of $\mathrm{CU}$ insiders over $\mathrm{CU}$ expansion implies that $V_{b}\left(g_{a b}^{C U}\right) \geq V_{b}\left(g_{a b}^{F T A}\right)>V_{b}\left(g_{\varnothing}\right)$. Moreover, $V_{b}\left(g_{b c}^{F T A}\right)>V_{b}\left(g_{b c}^{C U}\right)$ if and only if $\beta \in\left(\underline{\beta}^{\text {Flex }}(\tau), \bar{\beta}^{\text {Flex }}(\tau)\right)$ but $V_{c}\left(g_{b c}^{F T A}\right)>V_{c}\left(g_{\varnothing}\right)$ by Lemma $4.2(\mathrm{i})$. Thus, given $V_{b}\left(g_{b c}^{C U}\right)=V_{b}\left(g_{a b}^{C U}\right)$, country $b$ proposes FTA formation with country $c$, who accepts, if $\beta \in\left(\underline{\beta}^{\text {Flex }}(\tau), \bar{\beta}^{\text {Flex }}(\tau)\right)$. But, given the non-economic benefits, country $b$ proposes $\mathrm{CU}$ formation with country $a$, who accepts, if $\beta \notin\left(\underline{\beta}^{\text {Flex }}(\tau), \bar{\beta}\right.$ Flex $\left.(\tau)\right)$.

Stage 1b. Suppose country $c$ rejected country a's proposal in Stage 1a so that country $a$ can propose to country $b$. Given the equilibrium outcome in Stage 2, country $b$ will only accept country $a$ 's proposal if country $a$ proposes $\mathrm{CU}$ formation and will only accept a $\mathrm{CU}$ proposal if $\beta \notin\left(\underline{\beta}^{\text {Flex }}(\tau), \bar{\beta}^{\text {Flex }}(\tau)\right)$. Indeed, following similar logic to Stage 2, country a proposes $\mathrm{CU}$ formation with country $b$, who accepts, when $\beta \notin\left(\underline{\beta}^{\text {Flex }}(\tau), \bar{\beta}^{\text {Flex }}(\tau)\right)$. But, given the equilibrium outcome in Stage 2 of $g_{b c}^{F T A}$ when $\beta \in\left(\underline{\beta}^{F \overline{l e x}}(\tau), \bar{\beta}^{\text {Flex }}(\tau)\right)$, country a makes no proposal when $\beta \in\left(\beta^{\text {Flex }}(\tau), \bar{\beta}^{\text {Flex }}(\tau)\right)$.

Now suppose country $b$ rejected country $a$ 's proposal in Stage 1a so that country $a$ can propose to country $c$. Let $\beta \in\left(\underline{\beta}^{\text {Flex }}(\tau), \bar{\beta}^{\text {Flex }}(\tau)\right)$. Then, $V_{i}\left(g_{i j}^{F T A}\right)>V_{i}\left(g_{i j}^{C U}\right)$ where country $i$ is more attractive than country $j$ based on non-economic benefits. Thus, given the equilibrium outcome in Stage 2 of $g_{b c}^{F T A}$ and the non-economic benefits, Lemma 4.2(ii) implies country $a$ proposes FTA formation with country $c$ who accepts. Now let $\beta \notin\left(\underline{\beta}^{\text {Flex }}(\tau), \bar{\beta}^{\text {Flex }}(\tau)\right)$. Then, $V_{i}\left(g_{i j}^{C U}\right)>V_{i}\left(g_{i j}^{F T A}\right)$ where country $i$ is more attractive than country $j$ based on non-economic benefits. Thus, given the equilibrium outcome in Stage 2 of $g_{a b}^{C U}$ and the non-economic benefits, country a proposes CU formation with country $b$ who accepts.

Stage 1a. Given the equilibrium outcome in Stage $1 \mathrm{~b}$ and the non-economic benefits, country a proposes a CU with country $b$, who accepts, when $\beta \notin\left(\underline{\beta}^{\text {Flex }}(\tau), \bar{\beta}^{\text {Flex }}(\tau)\right)$ but, given Lemma $4.2(\mathrm{ii})$, country $a$ proposes an FTA with country $b$, who accepts, when $\beta \in\left(\underline{\beta}^{\text {Flex }}(\tau), \bar{\beta}^{\text {Flex }}(\tau)\right)$.

Thus, the equilibrium path of networks when $\beta \in\left(\bar{\beta}_{\text {OUT }}(\tau), \bar{\beta}_{I N}(\tau)\right)$ is (i) $g_{\varnothing} \rightarrow$ $g_{a b}^{F T A} \rightarrow g_{i}^{H} \rightarrow g^{F T}$ if $\beta \in\left(\underline{\beta}^{\text {Flex }}(\tau), \bar{\beta}^{\text {Flex }}(\tau)\right)$, (ii) $g_{\varnothing} \rightarrow g_{a b}^{C U}$ if $\beta \notin\left(\underline{\beta}^{\text {Flex }}(\tau), \bar{\beta}^{\text {Flex }}(\tau)\right)$ and $\tau \leq \bar{\tau}_{I N}^{C U}$ and (iii) $g_{\varnothing} \rightarrow g_{a b}^{C U} \rightarrow g^{F T}$ if $\beta \notin\left(\underline{\beta}^{\text {Flex }}(\tau), \bar{\beta}^{\text {Flex }}(\tau)\right)$ and $\tau>\bar{\tau}_{I N}^{C U}$. Finally, note that $\bar{\beta}_{I N}(\tau) \geq \bar{\beta}^{\text {Flex }}(\tau)$ and thus the constraint of Lemma 4.4 that $g_{i j}^{F T A} \rightarrow g_{i}^{H} \rightarrow g^{F T}$ requires $\beta<\bar{\beta}_{I N}(\tau)$ does not bind on the equilibrium path. 


\section{Bibliography}

[1] Aghion, P., Antràs, P., and Helpman, E., 2007. Negotiating Free Trade. Journal of International Economics, 73 (1), 1-30.

[2] Amador, M. and Bagwell, K., 2013. The theory of optimal delegation with an application to tariff caps. Econometrica, 81 (4), 1541-99.

[3] Bagwell, K. and Staiger, R. W., 1997a. Multilateral Tariff Cooperation during the Formation of Customs Unions. Journal of International Economics, 42 (12), 91-123.

[4] Bagwell, K. and Staiger, R. W., 1997b. Multilateral Tariff Cooperation during the Formation of Free Trade Areas. International Economic Review, 38 (2), 291-319.

[5] Bagwell, K. and Staiger, R. W., 1998. Regionalism and Multilateral Tariff Cooperation. In International Trade Policy and the Pacific Rim, edited by John Piggott and Alan Woodland, 157-185. London, MacMillan.

[6] Bagwell, K. and Staiger, R. W., 1999. An Economic Theory of GATT. American Economic Review, 89(1), 215-48.

[7] Bagwell, K. and Staiger, R. W., 2005a. Multilateral Trade Negotiations, Bilateral Opportunism and the Rules of GATT. Journal of International Economics, 67 (2), $268-94$.

[8] Bagwell, K. and Staiger, R. W., 2005b. Enforcement, Private Political Pressure and the GATT/WTO Escape Clause. Journal of Legal Studies, 34 (2), 471-513.

[9] Bagwell, K., Bown, C.P., and Staiger, R.W., 2016. "Is the WTO Passé?" Journal of Economic Literature 54(4), 1125-1231.

[10] Bernheim, D., Peleg, B. and Whinston, M., 1987. Coalition-Proof Nash Equilibria I. Concepts. Journal of Economic Theory, 42 (1), 1-12.

[11] Beshkar, M., Bond, E. W. and Rho, Y., 2015. Tariff Binding and Overhang: Theory and Evidence. Journal of International Economics, 97 (1), 1-13. 
[12] Bhagwati, J., 1991. The World Trading System at Risk. Princeton: Princeton University Press.

[13] Bond, E.W., Riezman, R.G. and Syropoulos, C., 2004. A Strategic and Welfare Theoretic Analysis of Free Trade Areas. Journal of International Economics, 64 (1), 1-27.

[14] Bown, C.P. and Crowley M.A., 2016. "The Empirical Landscape of Trade Policy," in Kyle Bagwell and Robert W. Staiger (eds.), The Handbook of Commercial Policy, 3-108.

[15] Bown, C.P. and Reynolds, K.M., 2017. "Trade Agreements and Enforcement: Evidence from WTO Dispute Settlement," American Economic Journal: Economic Policy 9(4), 64-100.

[16] Estevadeordal, A., Freund, C. and Ornelas, E., 2008. Does Regionalism Affect Trade Liberalization toward Nonmembers? Quarterly Journal of Economics, 123 (4), 153175.

[17] Ethier, W. J., 1998. Regionalism in a multilateral world. Journal of Political Economy, 106 (6), 1214-45.

[18] Freund, C. 2000. Multilateralism and the Endogenous Formation of Preferential Trade Agreements. Journal of International Economics, 52 (2), 359-76.

[19] Freund, C. and McDaniel, C., 2016. How long does it take to conclude a trade agreement with the US? Trade \& Investment Policy Watch, Peterson Institiute for International Economics.

[20] Freund, C. and McLaren, J., 2010. On the dynamics of trade diversion: Evidence from four trade blocks. Board of Governors of the Federal Reserve System, International Finance Discussion Paper No. 637.

[21] Freund, C. and Ornelas, E., 2010. Regional trade agreements. Annual Review of Economics, 2 (1), 139-66.

[22] Furusawa, T. and Konishi, H., 2007. Free Trade Networks. Journal of International Economics, 72 (2), 310-35.

[23] Gatsios, K. and Karp, L., 1991. Delegation Games in Customs Unions. Review of Economic Studies, 58 (2), 391-97.

[24] Goyal, S. and Joshi, S., 2006. Bilateralism and Free Trade. International Economic Review, 47 (3), 749-78.

[25] Grossman, G.M. and Helpman, E., 1995. The Politics of Free-Trade Agreements. American Economic Review, 85 (4), 667-90.

[26] Horn, H., Giovanni, M. and Staiger, R.W., 2010. Trade agreements as endogenously incomplete contracts. American Economic Review, 100 (1), 394-419. 
[27] Krishna, P., (1998). Regionalism and Multilateralism: A Political Economy Approach. Quarterly Journal of Economics, 113 (1), 227-51.

[28] Krugman, P.R., 1991. The Move Toward Free Trade Zones. Paper presented at the Federal Reserve Bank of Kansas City Symposium: Policy Implications of Trade and Currency Zones, Jackson Hole, August 22-24.

[29] Lake, J. and Yildiz, H.M., 2016. On the different geographic characteristics of Free Trade Agreements and Customs Unions, Journal of International Economics, 103, 213-33.

[30] Lake, J., 2017. Free Trade Agreements as dynamic farsighted networks. Economic Inquiry, 55 (1), 31-50.

[31] Lake, J., 2018. Dynamic formation of Preferential Trade Agreements: The role of flexibility. Canadian Journal of Economics (forthcoming).

[32] Lake, J. and Roy, S., 2017. Are global trade negotiations behind a fragmented world of "gated globalization"?. Journal of International Economics, 108, 117-36.

[33] Lake, J., Nken, M. and Yildiz, H.M., 2018. Tariff Bindings and the Dynamic Formation of Preferential Trade Agreements, Mimeo.

[34] Maggi, G. and Staiger, R.W., 2018. Trade Disputes and Settlement. International Economic Review, 59 (1), 19-50.

[35] McLaren, J., 2002. A theory of insidious regionalism. Quarterly Journal of Economics, $117(2), 571-608$.

[36] Melatos, M. and Woodland, A.D., 2007. Endogenous Trade Bloc Formation in an Asymmetric World. European Economic Review, 51 (4), 901-24.

[37] Missios, P., Saggi, K. and Yildiz, H.M., 2016. External trade diversion, exclusion incentives and the nature of preferential trade agreements. Journal of International Economics, 99, 105-19.

[38] Mölders, F., 2012. On the path to trade liberalization: Political regimes in international trade negotiations. Mimeo.

[39] Mölders, F., 2015. On the path to trade liberalisation: Political regimes in trade negotiations. The World Economy, 39 (7), 890-924.

[40] Nken, M. and Yildiz, H.M., 2018. Implications of multilateral tariff bindings on the extent of preferential trade agreement formation. Mimeo.

[41] Odell, J. S., 2006. Negotiating trade: Developing countries in the WTO and NAFTA. Cambridge University Press.

[42] Ornelas, E., 2005. Trade Creating Free Trade Areas and the Undermining of Multilateralism. European Economic Review, 49 (7), 1717-35. 
[43] Ornelas, E., 2007. Exchanging Market Access at the Outsiders' Expense-the Case of Customs Unions. Canadian Journal of Economics, 40 (1), 207-24.

[44] Ornelas, E., 2008. Feasible multilateralism and the effects of regionalism. Journal of International Economics, 74 (1), 202-24.

[45] Ornelas, E. and Liu, X., 2012. Free Trade Agreements and the consolidation of democracy. Mimeo.

[46] Riezman, R., 1999. Can Bilateral Trade Agreements Help to Induce Free Trade?. Canadian Journal of Economics, 32 (3), 751-66.

[47] Rodrik, D., 2018. What Do Trade Agreements Really Do? Journal of Economic Perspectives, forthcoming.

[48] Saggi, K., 2006. Preferential Trade Agreements and Multilateral Tariff Cooperation. International Economic Review, 47 (1), 29-57.

[49] Saggi, K., Stoyanov, A., and Yildiz, H.M., 2018. Do free trade agreements affect tariffs of non-member countries? A theoretical and empirical investigation. American Economic Journal: Applied Economics, forthcoming.

[50] Saggi, K., Woodland, A. and Yildiz, H.M., 2013. On the Relationship between Preferential and Multilateral Trade Liberalization: The Case of Customs Unions. American Economic Journal: Microeconomics, 5 (1), 63-99.

[51] Saggi, K. and Yildiz, H.M., 2009. Optimal Tariffs of Preferential Trade Agreements and the Tariff Complementarity Effect. Indian Growth and Development Review, 2(1), $5-17$.

[52] Saggi, K. and Yildiz, H.M., 2010. Bilateralism, Multilateralism, and the Quest for Global Free Trade. Journal of International Economics, 81 (1), 26-37.

[53] Saggi, K., and Yildiz, H.M., 2011. Bilateral Trade Agreements and the Feasibility of Multilateral Free Trade. Review of International Economics, 19 (2), 356-73.

[54] Seidmann, D., 2009. Preferential trading arrangements as strategic positioning. Journal of International Economics, 79, 143-59.

[55] Stoyanov, A., Yildiz, H.M., 2015. Preferential versus multilateral trade liberalization and the role of political economy. European Economic Review, 80, 140-64.

[56] Syropoulos, C., 2003. Rules for the Disposition of Tariff Revenues and the Determination of Common External Tariffs in Customs Unions. Journal of International Economics, 60 (2): 387-416.

[57] Yi, S.-S., 1996. Endogenous Formation of Customs Unions under Imperfect Competition: Open Regionalism Is Good. Journal of International Economics, 41 (1-2), 153-77. 
[58] Zhang, J., Xue, L., Zu, L., 2013. Farsighted free trade networks. International Journal of Game Theory 42 (2), 375-98. 